Portland State University

PDXScholar

$1-1-1981$

\title{
Coping with stress following a natural disaster: the volcanic eruption of Mt. St. Helens
}

Shirley Ann Murphy

Portland State University

Follow this and additional works at: https://pdxscholar.library.pdx.edu/open_access_etds Let us know how access to this document benefits you.

Recommended Citation

Murphy, Shirley Ann, "Coping with stress following a natural disaster: the volcanic eruption of Mt. St. Helens" (1981). Dissertations and Theses. Paper 403.

https://doi.org/10.15760/etd.403

This Dissertation is brought to you for free and open access. It has been accepted for inclusion in Dissertations and Theses by an authorized administrator of PDXScholar. Please contact us if we can make this document more accessible: pdxscholar@pdx.edu. 
COPING WITH STRESS FOLLOWING A NATURAL DISASTER:

THE VOLCANIC ERUPTION OF MT. ST. HELENS

by

SHIRLEY ANN MURPHY

A dissertation submitted in partial fulfillment

of the requirements for the degree of

\author{
DOCTOR OF PHILOSOPHY \\ in \\ URBAN STUDIES
}

Portland State University

C 1981 Shirley Ann Murphy 
AN ABSTRACT OF THE DISSERTATION OF Shirley Ann Murphy for the Doctor of Philosophy in Urban Studies presented December 4. 1981 .

Title: COPING WITH STRESS FOLLOWING A NATURAL DISASTER: THE VOLCANIC ERUPTION OF MT. ST. HELENS

APPROVED BY MEMBERS OF THE DISSERTATION COMMITTEE:

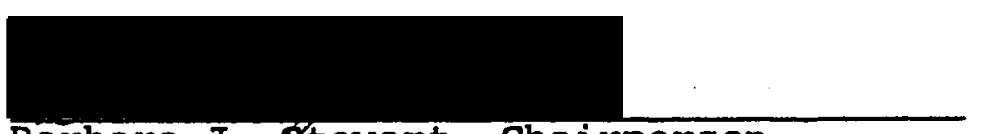

Barbara J. Btewart, Chairperson

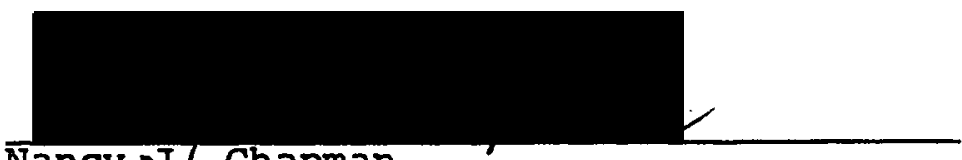
Nancy v? Chapman

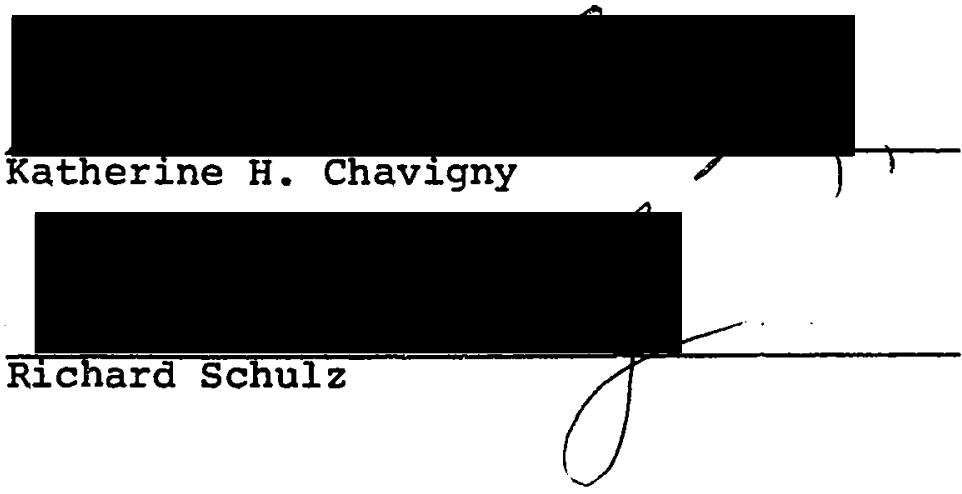

This study fucuses on the coping responses of the bereaved immediate family and close friends of persons who died as a result of the volcanic eruption of Mt. St. Helens in southwestern Washington on May 18, 1980. Three major research questions were addressed: Is there a relationship 
between illness and three life events: presumed death of a close relative or friend, confirmed death of a close relative or friend, and loss of one's permanent or recreational residence? Do self-efficacy and social supports act as intervening variables to buffer the negative effects of stress on one's health when coping with loss? What are the perceived effects of the media on coping with loss following a disaster? Subjects for this study included 155 respondents. Mailed questionnaires and interviews were used to collect data approximately 11 months post-disaster from bereaved, property loss, and control subjects.

The subjects' physical and mental health status, impact of negative life events, daily annoyances, and coping patterns were assessed by The Hopkins Symptom Checklist, The Life Experiences Survey, The Hassles Scale, The Self-Efficacy Scale, The Coppel Index of Social support, and additional items written for the present study by the investigator. Data were analyzed by multiple discriminant function analysis, one-way analysis of variance and accompanying planned and post hoc pair-wise comparisons, Pearson correlations, stepwise multiple regression analysis, and content analysis. When compared to control subjects, the major findings regarding the first study question can be summarized as follows: the bereaved of the confirmed dead were adversely affected by their loss in areas of negative life events, hassles, depression, and somatization; the adverse effects of loss for the bereaved of the presumed dead occurred in 
in the areas of negative life events and depression; the negative impact of permanent property loss occurred only on the LES measure. At the time of measurement, coping with presumed death bereavement was not found to be more difficult than coping with confirmed death bereavement.

The second study question compared the combined bereaved group ( $n=69)$ and the control group $(n=50)$ to examine the buffering roles of self-efficacy and social support. For the bereaved sample, stress accounted for 358 of the variance $(p<.001)$ in depression. After statistically controlling for stress, both self-efficacy and social support were significant predictors of depression $(p<.05)$. In contrast, stress accounted for 448 of the variance in depression for the control sample, but neither self-efficacy nor socia, support made additional significant contributions in the prediction of any of the three health outcome variables.

Findings from the third study question indicated that there were no significant differences between pairs of loss groups on the four forms of news media. However, regarding overall effects of the media (invasion of privacy, delayed recovery, etc.) the confirmed bereaved group reported significantly more ( $p<.05)$ negative effects than the other study groups.

Time of measurement, sampling, and the magnitude of the disastrous event were suggested to account for the lack of differences between the two bereaved groups on major outcome variables. Geographic location, dissatisfacticn with finan- 
cial settlement of loss, and measurement techniques may account for the high number and impact of negative life events in the property loss group. Among the suggested clinical interventions were identification of high risk individuals and early treatment, and training of helping professionals. Improved disaster planning was also recommended. 
TO THE OFFICE OF GRADUATE STUDIES AND RESEARCH:

The members of the Committee approve the dissertation

of Shirley Ann Murphy presented December 4, 1981.
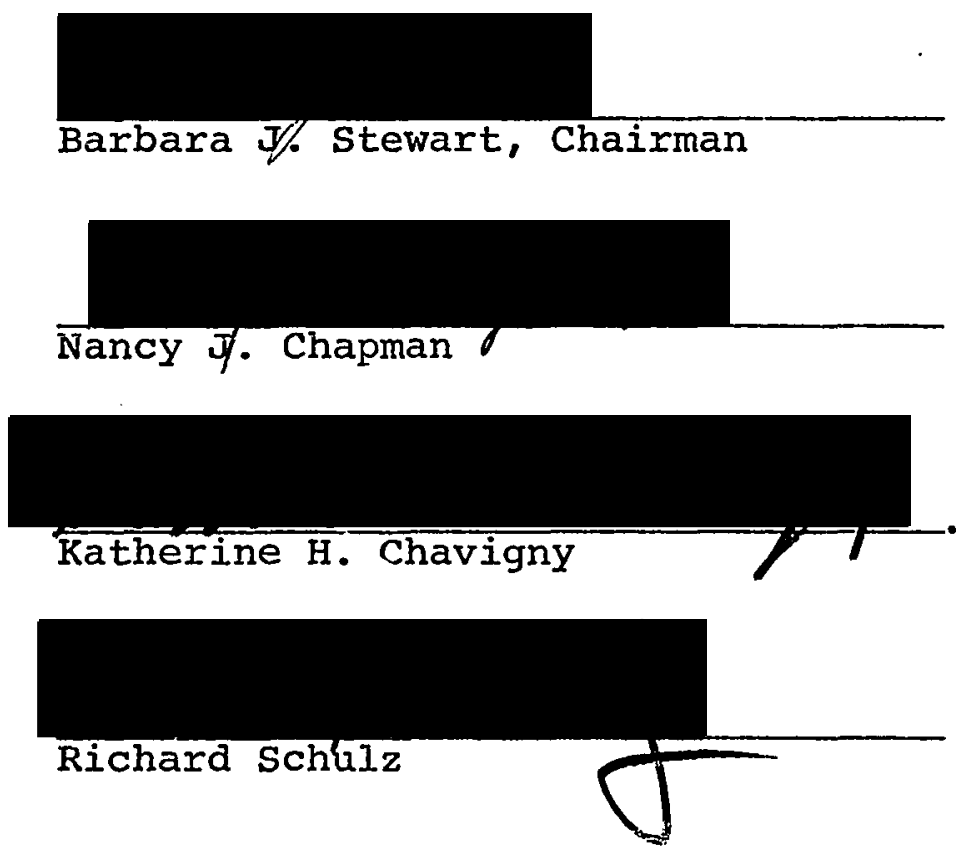

APPROVED :

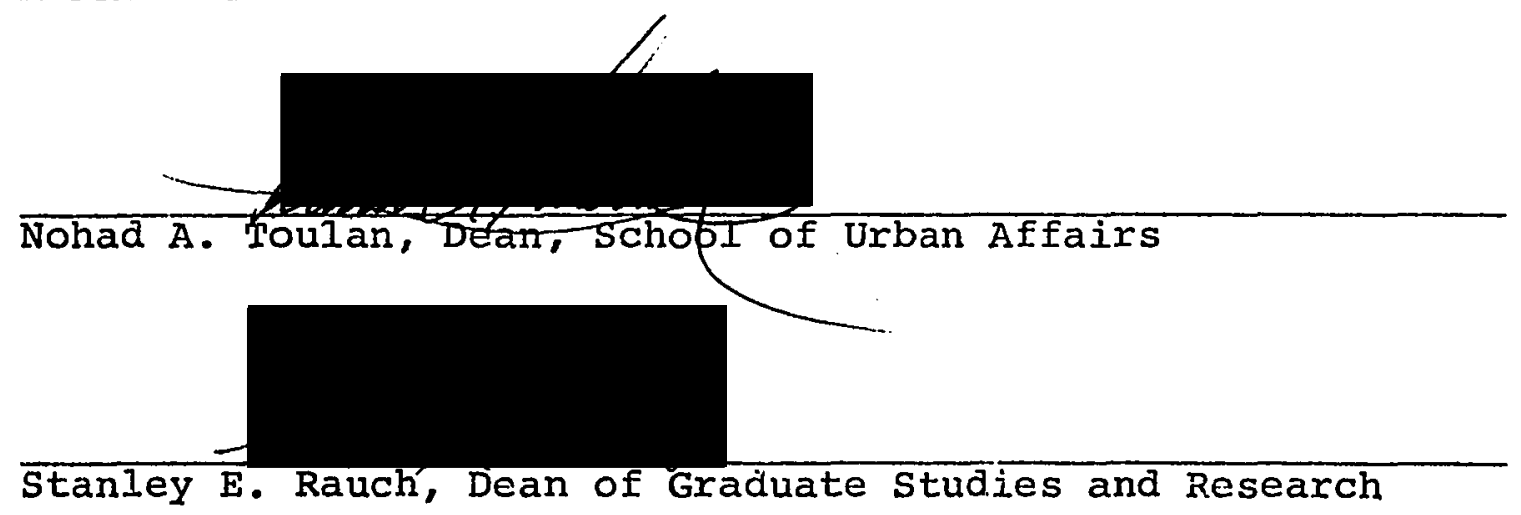




\section{MOUNT SAINT HELENS}

Throughout the ages the mountain lay

like a dormant giant at rest --

Awaiting the time to spew debris

From out of the caldron's depths,

Exploding floods of ash and mud,

Uprooting mighty trees,

Damming streams, destroying homes

With devastating ease.

Mighty pressures contained therein

With awesome heights of power,

Erupting with explosive din

Leaving man and beast to cower.

This holocaust from God's domain

Spreads death and all its sorrow,

spawning wonder in our minds

of what may come tomorrow.

Small, futile man, with vaunted brain

Shall not avoid disaster -

Convincing all just once again

That Nature is the Master.

J.D. Manley Treece

Portland

The Oregonian, 1980

The conceptualizing and planning of this research began the week following the major volcanic eruption of Mt. St. Helens on May 18, 1980. The completion of the dissertation represents a significant step in the study of an area of long standing personal interest: individuals' coping responses to negative life event.s.

I want to thank the individuals who were the subjects of this study. Both the loss and control participants gave freely of their time and energy. Most importantly, their remarks vere candid in spite of the concern some individuals had about what I would do with the information I received 
from them.

A number of people have helped me in very special ways. First, my thanks to Nancy Chapman, who has been particularly helpful as my program advisor for the past three years. She has been a member of both my course examination and dissertation committees. My thanks to Katherine Chavigny for her innovative and practical suggestions for data collection for this study. Next, thanks to Richard Schulz who has been an invaluable teacher and mentor over the past two and a half years. Barbara stewart, my dissertation committee chairperson, has given hours of her time. I want to thank her in particular for many innovative suggestions made in planning the research. Her expertise in methodology was invaluable during the data analyses. Her editorial suggestions have been extremely helpful. Moreover, my association with her over the past three years has indeed been growth-producing. Her teaching is inspiring; her research is a model of excellence; and her personal and ethical sense of self are to be admired.

I am indebted to my colleagues who encouraged my efforts and challenged my ideas. It is impossible to name them all; however, three persons have been extremely helpful. They are Patricia Archbold, Marie Driever, and Beverly Hoeffer.

Finally, the family support I have had is truly as Caplan suggests in his definition of social support: that support includes messages leading to one's worth, provides assistance with task performance, and promotes a sense of alliance. To my aging parents, thank you for teaching me how 
to persevere. I want to thank my three oldest sons who were high school students at the time I began the Ph.D. program. They tutored, typed, cooked and cleaned. To Sean, my only "latch-key" child, thank you for your patience. Finally, thanks to my husband, Ray, who appropriately disengaged himself from the sometimes chaotic process by running more and more miles. 
TABLE OF CONTENTS

PAGE

PREFACE

iii

LIST OF TABLES . . . . . . . . . . . . . . ix

LIST OF FIGURES . . . . . . . . . . . . . . xi

CHAPTER

I INTRODUCTION . . . . . . . . . . . . 1

II REVIEW OF THE LITERATURE . . . . . . . 10

Disasters . . . . . . . . . 11

Characteristics

Conceptualization as a Time Sequence

Legal Implications of

Presumptive Death

Disasters and Major Life Changes

Bereavement . . . . . . . 30

Incidence, Nature and Effects

Expected Death

Sudden Death

Coping With Major Negative Life

Events ..........

Definitions of Coping

Coping: A Highly Individualized Response

The Protective Function

of Coping

Exposure to Mass Media

The High Risk Bereaved Following

Disaster ......... . 60

Conceptual Framework . . . . . . 72 
CHAPTER

PAGE

III METHODOLOGY . . . . . . . . . . . . . 93

Research Design and Hypotheses . . . 93

Subjects . . . . . . . . . . . . 101

Study Instruments . . . . . . . . 114

Measures of Health

Measures of Stress

Measures of Supports

Procedure . . . . . . . . . . . . 127

Data Collection

Statistical Methods . . . . . . 130

Independence of Linked Pairs

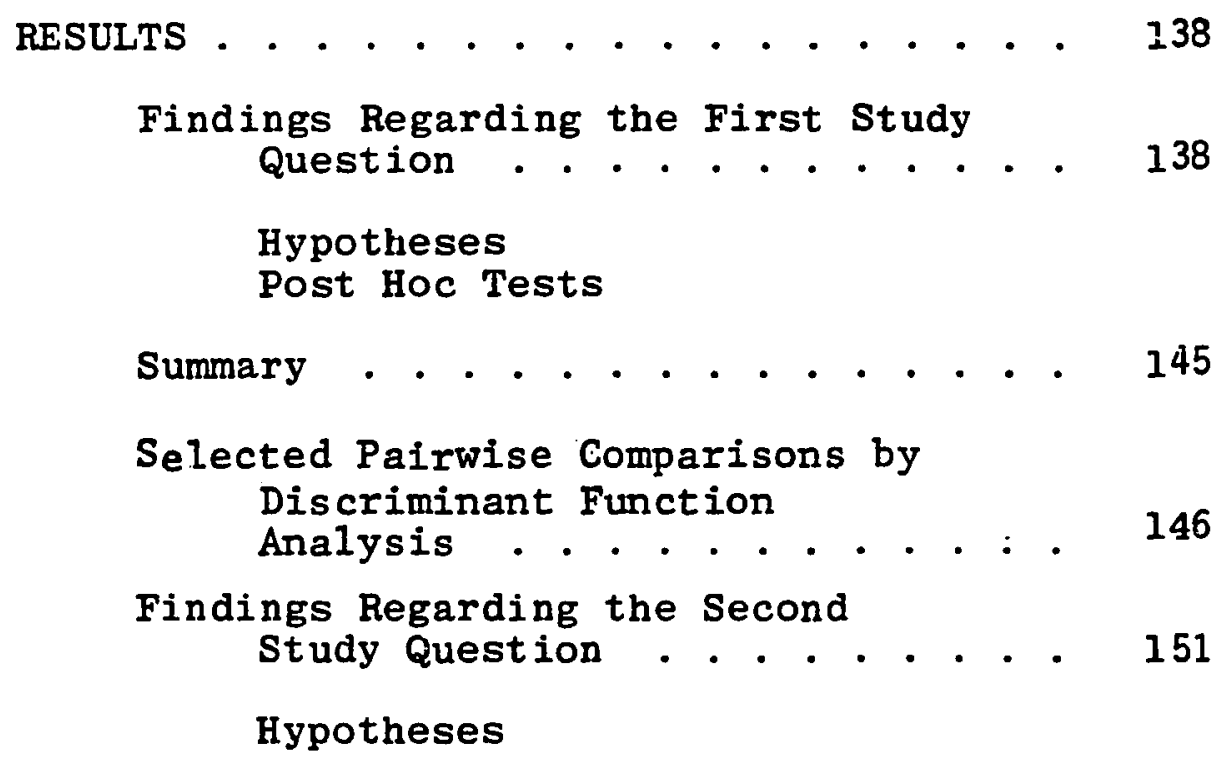

Findings Regarding the First study Question .. . . . . . . . 138

Hypotheses

post HoC Tests

Summary . . . . . . . . . . . 145

Selected Pairwise Comparisons by

Discriminant Function

Analysis . . . . . . . . . : . 146

Findings Regarding the Second

Study Question . . . . . . . 151

Hypotheses

Summary . . . . . . . . . . . . 158

Findings Regarding the Third

Study Question . . . . . . . 159

Findings Regarding Qualitative Data. . 163

Open Ended Questions

Interview Data 
V DISCUSSION OF FINDINGS . . . . . . . . . . 175

The First Study Question: The

Effects of Loss on Perceived

Stress and Health . . . . . . . . . 175

The Adverse Effects of the Death of a Significant Other on the Bereaved

The Effects of Permanent Property

Loss on Stress and Health

The Absence of Significant Differences Between Bereaved of Presumed and Confirmed Dead

Discussion of Findings Related

to the Second Study Question . . . . 185

The Relationship Between Stress and IIlness

The Buffering Effects of Social and Interpersonal Supports

The Final Question: The Effects

of the Media on Loss . . . . . . . . 191

Theoretical and Methodological

Implications . . . . . . . . . . 193

Implications for Clinical Intervention. . . . . . . . . . . . 193

Implications for Disaster Planning . . . 197

Limitations . . . . . . . . . . . 198

Directions for Future Research . . . . 201

REFERENCES. . . . . . . . . . . . . . . . . . . . 204

APPENDICES . . . . . . . . . . . . . . . . . . . . 214 


\section{LIST OF TABLES}

TABLE

PAGE

I Differential Response Rates of the Study Sample.. . . . . . . . . 102

II Demographic Data for the Five Samples . . . 108

III Summary of Major Instruments and Measures

Employed in Data Analyses. . . . . . 126

IV Results of Tests with Major Variables to

Determine Independence of Iinked Pairs . 134

$\mathrm{V}$ Results of Tests with Secondary Variables

to Determine Independence of Linked

Pairs . . . . . . . . . . 135

VI Summary of Planned Comparisons to be

Tested for the Five Outcome Measures

of the First Study Question . . . . . 141

VII Means, Standard Deviations and Significance

Tests for Differences Between Means

for the Five Outcome Groups . . . . . . 142

VIII Intercorrelation Matrix of Stress Measures,

Intervening Support Measures, and

Outcome Measures for the Bereaved,

Property Loss, and Control Groups . . . 152

IX Predicting Health Outcomes for Stress,

Support, and Self-Efficacy: Stepwise

Multiple Regression Results for the

Bereaved and Control Groups . . . . . 156 


\section{LIST OF TABLES (cont'd)}

TABLE

PAGE

X Pearson Correlations of Media Scores

with 15 other Study Variables for

the Four Loss Groups . . . . . . . . 161

XI Summary of ANOVAs for the Ioss Groups

on Media Scale and Types of Media . . . 164

XII Subjects' Response to Question 18 . . . . 166

XIII Subjects' Response to Question 20 . . . . 168 


\section{IIST OF FIGURES}

FIGURE

PAGE

1. Conceptual Model . . . . . . . . . . 75

2. Percent of Study Sample Represented by

City Size of Respondents' Residences . . 104

3. Bereaved and Control Group Comparisons

on the LES Measure . . . . . . . . 148

4. Bereaved and Control Group Comparisons

on Hassles Scale . . . . . . . . . 148

5. Bereaved and Control Group Comparisons

on HSCL Depression Measure . . . . . 149

6. Bereaved and Control Group Comparisons

on HSCL Somatization Measures . . . . 149

7. Bereaved ard Control Group Comparisons

on Physical Health Status Scores . . . 150 
Chaptex 1

INTRODUCTION

\section{Statement of Problem}

Most persons who directly experience a disaster or who are closely identified with a diaster victim suffer some form of emotional or psychosomatic after-effects in the early postdisaster period (Fritz and Williams, 1957). Many studies on natural disasters have attempted to assess economic and social impact on entire communities or assess the behavioral and health responses of persons who have survived highly traumatic disastrous events such as floods, earthquakes, and tornadoes. Lindemann (1944) studied both survivors and the bereaved relatives of non-survivors in the now famous Coconut Grove Fire in Boston in 1943. Lindemann noted that the sudden death of a significant other generates one of the most severe psychological stresses that an individual ever experiences. Lindemann's findings have been confirmed in numerous bereavement studies. Indeed, the death of one's spouse or confidant puts the bereaved in a high risk category to develop both physical and psychological disorders. However, most individuals do not develop serious disorders (Rabkin and Struening, 1976). Attention has turned to identifying those factors that enhance successful coping with major life changes and thus allow persons to remain healthy. The focus of the current study is on the coping responses of the bereaved immediate family and close friends of persons who died as a result of the recent volcanic 
eruption of Mt. St. Helens in southwestern Washington. While the disaster itself occurred in rugged mountainous terrain, the subjects for the current study are a predominantly urban population. Within this general context of coping with bereavement following a disaster, three other issues will receive special emphasis. These three issues have had little or no systematic examination in past research. The three issues concern:

- Differences in coping when the death of the significant other is presumed rather than confirmed.

- The extent to which major life events and daily annoyances are associated with differences in coping.

- The enhancement of coping as a result of one's own sense of self-efficacy, perceived support from significant others, and perceived support for, or hindrance to recovery as a result of news coverage.

Disasters are relatively rare events. There are both advantages and disadvantages associated with investigating events that occur infrequently. The major advantage is that researchers have an opportunity to gather information that is both unique and generalizable. Examination of news reports regarding the volcanic eruption of Mt. St. Helens suggests that many of the bereaved who have been contacted by the media have been willing to share their experiences. Thus, researchers have a unique opportunity to study the process of coping with sudden death and other disaster-related stresses. 
The major disadvantages of investigating an isolated event is that sample sizes can be small, and since the event has already occurred, the research approach is necessarily retrospective. A further disadvantage is related to the difficulty in replicating the study.

A review of the literature indicates that bereavement has been widely studied over the past twenty years. Particularly high mortality rates in the one-year period following the death of a spouse have been reported in a number of studies (Epstein, Weitz, Roback and McKee, 1979; Jacobs and Ostfield, 1977; Kitagawa and Hauser, 1973). Further, comparisons have been made between bereaved of those whose deaths were anticipated and those who died suddenly (Ball, 1976-77 and Sanders, 1979-80). It has been demonstrated in such studies that when preparation for a major life transition such as widowhood is possible, the individual's adjustment to the transition may be enhanced (Silverman, 1974). Conversely, unpredictability and uncontrollability is characteristic of disaster-caused deaths.

Recent studies on the impact of life events suggest that the elements of predictability and control are as important as the individual's perception of events as positive or negative (Myers, Lindenthal, Pepper, and Ostrander, 1972). While prediction of whether a disaster is likely to occur has improved demonstrably, the severity of a disaster may not be predicated as accurately. Likewise, there is often no con- 
trol over the amount of direct damage caused by the disaster, but some control can be exerted over indirect effects of disaster, such as fires and confusion. In addition, recent studies suggest that the reactions of persons to unpredictable and uncontrollable life events are influenced by individuals' expectations regarding such events, as well as social supports, coping capabilities, anc illness behavior characteristics (Rahe, 1979).

The major question of the current study regards how bereaved persons cope with the disaster death of a significant other. Is coping with a death that is presumed but not confirmed more likely to produce illness? Can individuals who must cope with both major life events and daily hassles remain healthy? What are the roles of self-efficacy, social support, and symbolic support in the coping process?

The first aspect of disaster death that has not been addressed in previous studies is the outcome experienced by the bereaved when disaster victims are presumed dead, yet their bodies have not been recovered. Cause of death is usually officially noted by physicians. If persons die unattended by a physician, as in the case of a natural disaster, a coroner is called upon to establish the fact of death. But if victims are not found, establishing the fact of death becomes a critical legal issue and has serious implications for the bereaved. Immediate loss of income, testifying at court hearings, and time delay in property settlement are 
urique added stressors to the already documented problems with. which the bereaved must cope in presumptive death following a disaster. A primary issue to be examined in this study is whether bereaved relatives and friends fof presimed dead experience higher levels of stress than do the bereaved relatives and friends of confirmed dead.

A second aspect of disaster death that has not received any systematic inquiry is whether there are minor stresses in addition to the sudden death event that increase stress to levels which may become illness-producing. Recent literature on coping with stress indicates that persistent, irritating minor stresses, termed hassles, may tax adaptive coping as severely as a major negative life event (Lazarus and Cohen, 1977).

A third aspect of disaster death not reported heretofore is the differential effects of social support from significant and symbolic others. What is the effect of national and local television and newspaper coverage on the bereaved'family and close friends of the victim? The Sunshine Mine disaster study by Harvey and Bahr (1980) suggests that some of the bereaved widows perceived nationwide media coverage as a form of social support. However, it is difficilt to separate the amount of support received by the Sunshine widows as a result of national media coverage from support received from their immediate environment. The mine study population appears to be unique in 
that the vast majority of the bereaved widows were born into mining families and married miners. A follow-up study conducted five years after the mining disaster indicated that most of the widows were still living where they had resided their entire lives. Very few had remarried. These findings suggest stable support within the community. Thus, the extent to which this bereaved population perceived symbolic support from national attention is unclear. Is the severity of the loss event related to the perception of media coverage? Is coping enhanced if the existence of news coverage is perceived as social support? The roles of self-efficacy and social support in the coping process have been examined in recent studies. This study seeks to add symbolic support to these two variables.

Finally, this study lends itself to examination of many of the multidisciplinary aspects of the urban studies Ph.D. program at Portland State University. The multidisciplinary areas include psychology, sociology, health, economics, demography, communication, law, and urban planning.

The Urban Social Patterns and Human Development major provides an opportunity for indepth exploration of the psychological concepts of stress and coping 
across the life span. Stress and coping associated with unexpected and significant loss of both persons and property is the central area of investigation of this dissertation.

The most important sociological concept to be included in this research is that of social support. The number of friends and confidants one can call upon to buffer stress in times of acute distress is currently regarded as a very significant area in behavioral research (Lin, Simeone, Ensel, and Kuo, 1979). Further, there is need for additional research regarding bereaved persons' perceptions of, and ability to benefit from, social support (Barrett, 1978).

The psychological and sociological concepts of stress, coping, and social supports are central to this study. A major objective of the current study is to determine whether stress is related to health and whether the study subjects' perceptions of social support have an intervening effect to prevent deterioration of health. Thus, concepts from more than one discipline are of primary concern in this dissertation.

of secondary concern for the current study are the multidisciplinary concepts of demography, communication, law, and urban plannins. The demographic concept of return migration is of interest in this study due to its 
relationship to disasters. Return migration refers to movement of people back to places where they formerly lived (DaVanzo and Morrison, 1977). The disaster literature indicates that families do indeed return to devastated areas to rebuild (Wright, Rossi, Wright, and Weber-Burdin, 1979; Bolin and Trainer, 1978). One of the comparison groups in this study is composed of persons whose permanent residence was either destroyed or damaged to the extent that at least temporary relocation was required.

The media, particularly radio and television, can be invaluable tools for communicating emergency plans to a community in times of crisis and disaster. It can also inhibit rapid movement of persons in and out of a dangerous area if incorrect or incomplete information is given. Urban planning for disasters is affected by the way in which plans are communicated to those needing the information. Thus, the role of the media is an integral part of disaster planning (Abe, 1979). The most significant legal issue in this study regards state statutes involving certification of death. Persons missing and presumed dead cannot be legally declared dead until bodies are found to verify identity. If no body is found, many states require a seven-year waiting period before a death certificate is issued. Such laws may impose extreme economic hardship on family 
members, particularly in the case of death due to a natural disaster. Such legal and economic issues have an impact on urban populations.

In summary, there is little information regarding coping behavior of bereaved persons following the death of a significant other as a result of a disaster. Why some people remain healthy while others become ill has not been reported. Similarly, there is nothing reported on problems associated with confirmed versus presumed death or minor versus major stress. Finally, an examination of the impact of intra-personal, social, and symbolic support in cases of sudden accidental death has not been investigated. The present study addresses these issues and is therefore consistent with the breadth of concepts offered in a multidisciplinary $\mathrm{Ph} . \mathrm{D}$. program. 
Chapter II

\section{REVIEW OF THE LITERATURE}

The following is a critical review of the literature related to the current study and includes discussion of three major areas: disasters, bereavement, and coping with bereavement. The order of these three general topics in the literature review reflects the sequence of events to be examined in this study. First the disaster itself occurs. In general, most of the reviewed disaster studies report pre-disaster preparation and warning periods and post-disaster assessment and recovery periods. Some specific disasters are cited to exemplify the sequence of events over time. Following the death of a significant other in a disaster is a period of bereavement for surviving relatives and friends. The bereavement literature cites incidence and consequences of bereavement and contrasts expected with unexpected death. The bereavement process is characterized by an initial short, intense grieving period lasting about six weeks and a longer, less intense resolution period lasting about a year. Most persons can cope successfully with uncomplicated bereavement. In the present study, however, victims' relatives and friends have been exposed to a far more complex bereavement process that has included giving legal testimony, being interviewed by members of the news media, and in some cases, accepting presumption of death without recovery of victims' bodies. Coping with these multiple stressors associated with bereavement is discussed. Finally, a profile of the high risk bereaved in- 
dividual emerges as a result of this discussion.

\section{Disasters}

The word 'disaster' connotes an unexpected catastrophic event followed by destruction of property and perhaps unavoidable injury and death to some persons. The disaster literature is characterized by a series of general themes centered on the disastrous event. These themes are: prevention, planning for potential crises, and cleanup. From this disaster literature the following topics have been identified as relevant for the current study: disaster study populations, the characteristics of a disaster, and the sequential events of a disaster. Topics that are not usually found in the disaster literature but are relevant and thus also discussed here are: disaster preparedness in the Portland, Oregon area, the unique features of the Mt. St. Helens disaster, the legal implications of presumptive death, and multiple life events.

\section{Disaster Study Populations}

The impact of both natural and man-made disasters on human beings is of continuing interest to researchers and has been a subject of study for many years. Much of the data generated by these researchers are from individual case studies and community surveys carried out following floods, hurricanes, earthquakes, nuclear holocausts, collisions of ships at sea, and air- 
plane tragedies. The proposed study seeks to add the volcanic eruption of Mt.St.Helens to this list of disasters.

The populations identified for study following disasters have usually been the surviving disaster victims. Most studies on disaster report outcomes primarily for tile victims themselves (Friedman and Linn, 1957; Fritz and Marks, 1954; Fritz and Williams, 1957; Henderson and Bostock, 1977; Lifton, 1968; Miller, 1964; Tyhurst, 1958). Cobb and Lindemann (1943) studied both survivors and the bereaved, some of whom were also survivors, of the Coconut Grove fire. Only one other study has focused exclusively on the bereaved following a disaster, where the bereaved were widows of miners who died in an industrial accident (Harvey and Bahr, 1980). In contrast is the United Nations' contribution.

The United Nations' literature on disasters has taken into account two important aspects of natural disasters that affect human settlements. First, the aims of disaster planning are person-oriented and, second, the impact of a disaster involves a complex chain of events. Each is discussed briefly.

The United Nations' role in disaster planning to date has been international in scope, while attending to the needs of people. The direct aims of disaster planning exemplify this point: 1) save lives, 2) mitigate 
the consequences of the chain of disastrous events, 3) facilitate rescue operations, 4) Iacilitate rehabilitation, 5) identify high risk areas, i.e., monitor seismic activity, 6) develop data banks that describe the population, major community services, economic impact, risk level, and infra structure for urban areas, and 7) assess educational level of the population so that warning messages can be developed to meet needs (United Nations, 1976).

The chain of events that is likely to occur following a disaster requires planning for all of the potential consequences. For example, a major earthquake or volcanic eruption will change the entire topography. Acres of land are suddenly displaced. This massive movement of earth may cause flooding. Flooding will affect additional areas. Contamination of water supplies and destruction of property may follow. Thus, it becomes important to spell out contingency plans all along the potential chain of events (United Nations, 1976).

The Characteristics of a Disaster

According to Fritz and Marks (1954), who conducted disaster studies for the National Opinion Research Center, a disastrous event is defined as follows. The disastrous event: 1) affects a community of persons, 2) confronts 
a large segment of the community with actual danger or threats of danger and loss of cherished values and material objects, 3) results in deaths, injuries, destruction of property, and other losses and deprivations to the population, such as disruption of community utilities and other community services, and 4) affects another large proportion of the population directly or indirectly. There is no question that the May 18, 1980 volcanic eruption of Mt.St.Helens in southwestern Washington meets all of these criteria identified in the NORC studies on disaster. In addition to the confirmed or presumed deaths of sixty-one people, entire families were evacuated from their homes. Businesses were closed and water supplies were threatened. It was estimated that the lumber industry would suffer multi-million dollar losses (The Oregonian, October 27, 1980). Ash damage to crops has been reported a hundred miles away (The Oregonian, October 27, 1980). President Carter, on July 21, 1980 , blamed the federal budget deficit on the vast amount of dollars required for the declared emergency status in the State of Washington (The Oregonian, July 22, 1980).

\section{Disaster Conceptualized as a Sequence of Events in Time}

Seven time stages are identified by Miller (1964) as affecting the kinds of coping responses people make to a disastrous event. The seven time stages are: 
1. Warning

2. Threat

3. Impact

4. Inventory

5. Rescue

6. Remedy

7. Recovery

This time stage conceptualization is useful for both physical and behavioral outcomes as consequences of disasters. Each of Miller's seven time stages is summarized below, emphasizing personal rather than organizational response to disaster.

Stage 1: Warning. Studies of natural disasters indicate that if too many warnings occur, people tend to ignore them and do nothing. For example, people living in an area where tornadoes occur frequently may ignore tornado watches, and warnings, if they are given too frequently. On the other hand, if there is no prior warning ait all, the recognition of danger is frequently delayed. Both extremes, then, of too few or too many warnings, appear to cause perceptual deficits in persons as they attempt to make a primary appraisal of impending danger.

Stage 2: Threat. This stage begins when perception of change indicates specific local and personal disaster. People usually leave the area to avoid danger, even though the time of the event (such as a flood) may still be unpredictable. 
One also makes decisions to leave or stay based on potential loss, available alternatives, whether counter measures to offset the event will be effective, and what the costs in money, effort, and deprivation might be.

Stage 3: Impact. Survivors respond to impact by noting feelings of isolation and separation. This period is perceived to move rapidly into the next stage.

Stage 4: Inventory. This time period is characterized by shock, disbelief, numbness, and lag in the feedback process. This period is sequentially described as an attached ideation with significant others, the drive to survive, and coping by the use of prayer and hope (Henderson and Bostock, 1977). Lifton (1968) describes the inventory experience as one of numbness or the inability to grasp the significance of what has happened.

Stage 5: Rescue. This period is marked by prominent attachment behavior. Family members will not rest or engage in helping others until their own members are found. For example, slow identification of the dead and establishment of survivor lists led to blame, anger, and low morale in the Andrea Doria disaster (Friedman and Linn, 1957).

Stage 6: Remedy. Reorganization does begin within a few days, but several researchers note that symptoms characterizing this stage begin to occur one to three weeks following the disaster. Persons are said to experience sleeplessness, inability to concentrate, blame, headaches, nightmares, 
confusion, distress as a result of separation from their significant others, and the recurring mental images of the injured and dead they, as survivors, observed at the time of the disaster (Cobb and Lindemann, 1943; Fritz and Marks, 1954).

Stage 7: Recovery. There are no consistent findings regarding the recovery stage. Perhaps this is because. there are no replicated studies of any one type of disaster; rather, what is reported are descriptive accounts of many different individual disasters. At worst, those studying the impacts of Hiroshima and the Nazi concentration camps report survivors' feelings of guilt for living, fear of additional grief, yet belief of invulnerability (Dimsdale, 1978; Lifton, 1968). Quarantelli (1978) reports an extended duration of psychosomatic and mental illness following earthquakes in both the United States and Japan. These findings are confirmed by Schaar (1980). Conversely, in a study of bereaved widows following a mine disaster, Harvey and Bahr (1980) report successful recovery in about six months. Since some disasters receive national media coverage, "shared mourning", even though symbolic, may ease the recovery process. Social supports, which may account in part for the successful recovery in the Sunshine mine disaster bereaved, may vary in subjects from study to study. These kinds of comparisons have not been reported. The level of preparedness of a community is sald to affect the human responses in the seven stages. 


\section{Disaster Preparedness in the Greater Portland Area}

The Metropolitan Service District (METRO) is composed of 12 service districts in southwestern Washington and northwestern Oregon whose purpose is urban planning and service delivery. Top priority projects for the next five years have been selected on the basis of responses to a recent survey sent to elected officials, businessmen, planners, and citizens. Disaster preparedness was not among the top five projects selected for major responsibility; however, it was among the top twelve areas for future consideration. Sixty-nine percent of those surveyed selected disaster planning as their first choice for consideration in the future. Thus, at the present time there is no regional disaster plan, no legislative authority to begin a plan, and no current steps to follow up on the results of the survey (Sims, 1980). The only disaster plans that do exist lie with county executive offices to coordinate emergency services. Furthermore, there are no planning or coordinating activities with human services agencies, specifically community mental health centers. See Appendix A for a local County plan.

This report has implications for the current study, given the uncertainty of volcanic activity of Mt.St.Helens. Current knowledge on effects of disasters would indicate need Ior primary prevention (education for coping with unpredictable events), plans for crisis intervention services in 
the event of subsequent eruptions, and plans for long-range mental health services, none of which have received priority planning at the present time.

The Sequence of Events in the Mt. St. Helens Disaster

While the Mt. St. Helens disaster shares some similarities with the disaster time sequence described earlier, there are some unique differences. The time sequence of the Mt. St. Helens volcanic eruption is discussed next.

Stage 1: Warning. The March 20 to May 17, 1980 earthquakes on the mountain can be termed early warnings. Even though there were over 600 earthquakes recorded between a magnitude of 3.2 and 4.9 on the Richter scale, and numerous eruptions of ash and steam, these events were apparently not taken seriously (Korosec, Rigby, and Stoffel, 1980).

Stage 2: Threat. On April 30, 1980, authorities declared two danger areas, the "red zone", which was declared off limits, and the "blue zone", declared dangerous but not off limits. Permits to enter the blue zone were issued to workers and property owners on a time-to-time entry basis. Roadblocks were set up and supervised by state and county law enforcement officials. Despite these precautions, some persons would not leave the area, and others somehow eluded blockades and went on to their favorite campsites. Officials attempted to evacuate some residents all during the week prior to the May 18 eruption, but met a great deal of resistance 
from some residents. (The Oregonian, October 27, 1980).

Stage 3: Impact. Three campsites were inside the red zone on May 18, 1980, the day of the eruption. At least three persons camped on the mountain witnessed the massive eruption. All began to report the unbelievable sight by radio. None were ever heard from again nor have their bodies been recovered (The Oregonian, October 27,1980 ).

Stage 4: Inventory. Over one hundred people escaped following the eruption. Some had difficulty breathing and many were severely burned. Some abandoned companions who could not run, then ran back to get them. Since there were no immediate rescues due to ash and steam, many walked out to safety without any assistance. The inventory period was recounted by one survivor as a time of excruciating pain. Four loggers working together witnessed the eruption and began running. One became confused about the source of drinking water and wandered away alone, despite pleas from the others to stay with them. This man's body was found two months later. The other three were finally rescued and transported to a burn treatment center in Portland, Oregon (The Oregonian, October 27, 1980). Two died in a matter of days. Based on a newspaper interview, the surviving logger appeared to be recovering normally (The Oregonian, July 10, 1980). He could not give a reason for his survival, except perhaps for fluid intake. He felt God was punishing him for working on Sunday and spoke of the unreality of it al1. 
Stage 5: Rescue. The landscape was altered seriously by downed timber, hot mud, raging streams, and literally movement of entire hillsides. The area was first considered too dangerous to permit immediate rescue operations. Initiaiiy, over sixty people were "missing" and presumed dead. While 27 of these have since been "officially" declared eonfirmed dead, only six of these bodies have been recovered. Thirty-one were presumed dead during the initial five-day rescue period (The Oregonian, October 27, 1980).

Federal declaration of an emergency disaster area set in motion a process whereby only federal rescue teams from an air force base some 80 miles away were allowed to conduct the search for victims. This angered many of the bereaved, who called officials demanding rescue action.

Stage 6: Remedy. In addition to attempts to rescue the dead and injured, other forms of community reorganization began. In the immediate area, dredging of riverbeds began, roads and bridges were rebuilt, and timber began to be recovered. Town meetings were held to help property owners and insurance agents discuss common problems. In eastern Washington, many thousands of people as well as their homes, crops, and nachinery, were covered by a blanket of ash that appeared to resist removal by known means, such as washing. By early July, local mental health agencies began to publish booklets on how to cope with problems of ash removal and fear of recurrence of another, or even repeated eruptions. 
Stage 7: Recovery. Specific details regarding the recovery phase of the Mt. St. Helens disaster have not been reported. Data are currently being gathered by health researchers regarding potential respiratory problems from breathing ash-filled air. While newspaper reporters interviewed many of the bereaved family members, what has been made public is primarily information about the deceased.

Recovery for the bereaved is delayed when they are deprived of participation in some "rite of passage" for the dead. Death rituals are important because they underscore the visible reality of death, provide a means of social support, and give persmission to grieve (Feifel, 1959). According to Blauner (1966),

Society has a need to push the dead away, yet needs to keep the dead alive. The social distance between the living and the dead must be increased after death, so grievers can reestablish normal activity without a paralyzing attachment to the corpses. The need to keep the dead alive directs societies to construct rituals that insure a transition to a new social status. p. 387 .

Recovery for bereaved persons whose relatives or friends are presumed dead might be especially difficult because death rituals are missing.

Perhaps the Mt. St. Helens disaster was one in which warnings were not taken seriously. Those in the area including residents, employees and visitors, took risks beyond what they apparently perceived as threatening, and there was massive destruction and death. Successful coping and complete recovery of both the bereaved and evacuated residents is con- 
tingent upon many intervening variables and is the subject of this investigation.

\section{Legal Implications of Presumptive Death}

Shneidman (1976) reports a long and fascinating history of the search for a reliable sign of death. He states, "The importance attached the certification of death by a duly qualified medical practitioner is known to all persons who are familiar with the procedure of coroners' inquests", (p.218). Doctors establish the cause of death, but in the absence of a physician this task becomes the responsibility of the coroner, who can only establish the ract of death. The impact of the death certificate is profound. It can directly affect the fate and fortune of a family, touching both its financial security and its mental health. Such is the case with families whose loved ones, particularly breadwinners, died on Mt. St. Helens. Of particular importance hereare that an official certificate of death is usually required in each case of claim for life insurance and that questions of property rights are often settled by official certification of death.

Certification of death witbout evidence could not be made for many of the victims of the St. Helens eruption, thus certificates of presumptive death were issued. Cause of death is not the issue here, but rather the issue is establishing the fact of death. Two particular problems. 
have arisen in this process and both appear to be unique to this disaster. First is a legal issue. The State of Washington does not issue presumptive death certificates unless a person has been missing for seven years. For the purpose of accommodating the bereaved following the disaster, a legal ruling by the Attorney General allowed rebuttal presented in court by those who could testify, 1) that the presumed dead person was known to be responsible, and 2) that he was thought to be in the area at the time of the disaster. If the presiding judge was satisfied with evidence as presented, he could legally declare the person dead (Attorney General, State of Washington, 1980).

Second, the lack of funds in Skamania County, Washington prevented the coroner's inquests from proceeding in a timely manner and possibly caused extreme hardship on the families of those presumed dead. Both lack of personnel and problems in scheduling the courtroom to hear a number of cases at a time forced some families to request a hearing. As a result, two months following the eruption, some families had not yet been scheduled to appear (Robert Leick, Skamania County Coroner, personal communication, August 21, 1980).

In addition to coping with sudden loss of one or more significant family members, some relatives coped with financial uncertainty, uncontrollable delay in the system, and delay in rites of passage that presumably prevent them from moving toward resolution in the bereavement process. 
A newspaper account of the June 11, 1980 coroner's inquest relates the pain inflicted on one family:

D.B., 34, the brother of missing $W . B ., 41$, related anger that authorities took nearly a week to organize a ground search for some missing loggers including W.B., despite the fact that their exact location was known. He also conveys frustration over the delay in signing death certificates.

"The whole thing disgusts me", said the testifying brother. "W.'s wife is in the hospital with terminal cancer. Without a death certificate everything's at a standstill for Social security benefits. My brother has four children under 20 . I can understand that there has to be a legal process, but there must be some way to expedite this thing." (The Oregonian, June 12, 1980.)

While "missing-in-action" is similar in accounting for war dead, the legal process is clear and financial settlement is expedited by the Tar Casualties Act of 1945. While the "missing in action" death is still painful, families do perceive the high probability of the occurence of death. Two recent studies by McCubbin (1975, 1976) investigated coping patterns of families of prisoners of war and servicemen presumed dead as a result of the Vietnam War. Increased substance abuse and perceptions of meaninglessness of life were reported by women whose husbands had been missing three to six years. These findings suggest that the longer the incertainty, the more difficult coping will become.

\section{The Disaster Event and Major Life Changes}

Some bereaved families and intimate friends of the disaster victims live and work in the immediate vicinity of Mt. St. 
Helens. Therefore, some of the bereaved study subjects may have experienced negative events such as loss of work, income, and housing thatwere direct consequences of the disaster. In addition, the bereaved may have experienced changes in interactions, living conditions, and in eating and sleeping habits, to name some of the major life changes that have been rated high on readjustment on the Holmes and Rahe Social Readjustment Rating Scale (1967) and that yield high negative change scores on the Sarason, Johnson, and Siegal Life Experiences Survey (1978).

Attempts to demonstrate a relationship between life events and physical and mental illness have been an important goal of researchers over the past decade. Life events have been linked with chronic disease (Cassel, 1973), sudden cardiac death (Rahe and Lind, 1971), psychosomatic illness (Wyler, Masuda and Holmes, 1971), depression (Brown, 1974) and attempted suicide (Paykel, 1974). Holmes and Rahe (1967) postulated that any life change, either positive or negative, which required some kind of adaptation, was a crucial determinant of life stress and its deleterious effects. Hence, their instrument to measure life change included the word "readjustment" in its title. The notion that perceived change was more important than the perception of positive or negative labeling of an event, was postulated in early work by Dohrenwend and Dohrenwend (1974). Recently, however, studies have indicated that the crucial factor is the stress evoked by some 
undesirable aspect of the event rather than by the change itself (Vinokur and Selzer, 1975). Sarason, Johnson, and Siegel (1976), in the construction of their Life Experiences Survey, found that negative life events or negative change scores were better predictors of impaired functioning and performance than positive change scores. These results suggest that life stress might best be conceptualized in terms of negative changes rather than life change per se. Therefore, after ten years of intensive research, it now appears that it is these major life changes perceived and labeled as negative that increase one's chances to suffer physical, psychosomatic, and psychological illness.

On the other hand, there is evidence that the majority of persons who experience negative life events withstand or recover from these untoward changes with few, if any, ill effects (Antonovsky, 1979; Clayton, Halikas, and Maurice, 1972; Hinkle. 1974; Hirsch, 1980; Kobasa, Hilker and lladdi, 1979). Thus, a critical question one might ask is, what is it about these individuals and their lives which protects or excludes them from the apparently strong association between negative life events as stressors and negative effects on health status? Several investigators have turned to the positive factors in the lives of individuals who experience major negative life changes. Perception of the event (Rahe, 1979; Tolsdorf, 1976), personality factors (Kobasa et al., 1979; Rabkin and struening, 1976), learned coping skills (Bandura,1977; Pearlin \& Schooler, 
1978), principal attachment figures (Weiss, i974), and social supports (Caplan, 1974, Cobb, 1976, Gore, 1973, Hirsch, 1980), all appear to be major factors. These topics will be reviewed thoroughly in the section in Coping with Negative Life Events.

Still another approach to the problem of studying negative stressful events is to examine what might be termed the "ripple effect". That is, might there be a series of negative events of less magnitude that follow the major life event that heretofore have been bypassed by researchers? For example, a widow with positive personality factors and strong social support may be able to adapt positively to the death of her spouse, however, when one considers loss of income as a direct result of widowhood; severe financial change could alter her lifestyle significantly. Thus, she may have to move to a smalier house, seek employment, and alter leisure patterns. Moreover, if the widow has children under 18 years of age, and decides to apply for Social Security, she will have to fill out numerous forms, perhaps stand in long lines, receive conflicting information as to when payments may be expected, etc., etc. These events have been termed "daily hassles" by Lazarus and Cohen (1977). They decided "hassles" as stressors were severe enough to be measured and subsequently developed The Daily Hassles Scale. Lazarus and Cohen (1977) suggest that "chronic daily hassles" are another type of stressful input investigators have overlooked. While daily hassles are far less dramatic than divorce, job loss, and death of a valued person, Lazarus and Cohen (1977) 
believe chronic hassles may produce stress that could be associated with declines in health status.

Volcanic research projects immeaiately underway indicate residents in the area of Mt.St. Helens may be subject to chronic stress, not just acute and brief duration stress (Schaar, 1980). This is because geologists report that Mt.St. Helens may be active for the next two decades, but at the present time no predictable schedule of activity can be reported. Local mental health centers have reported no increased demand for services, yet lower-level longer duration stress, specifically "chronic daily hassles", may have effects on health with passage of time.

An Emergent Role of the Community Mental Health Center The community mental health center has an increasingly important role in potential disaster communities. This initial role has been crisis intervention. However, it is becoming increasingly clear that emerging roles providing a wider range of services may be in order. First, a collaborator role is needed. Given the lack of disaster planning in many communities, the local community mental health center could collaborate with urban planning agencies in all seven disaster stages as conceptualized earlier. Second, mental health professionals are qualified to provide education on stress and coping. In disaster-prone communities, providing essential information both prior to and following disasters is a necessary service. In the case of the volcanic eruption of Mt. St. Helens, several communities were severely affected by ash fallout on four separate occasions. Individuals needed information regarding 
ways to limit breathing the ash, how to remove it, how to cope with the depressed feeling that appeared to accompany each of these unexpected "after the event" hazardous conditions. Thus, a third role emerges: treatment of chronic daily hassles that may continue indefinitely. The currert study will gather data regarding chronic daily annoyances.

In summary, disasters profoundly affect entire communities and possess clearly conceptualized stages of development and recovery. The volcanic eruption of Mt. St. Helens exemplifies the conceptualization of disaster. In addition to loss of life, loss of home, loss of income and work roles, and loss of a sense of predictability and controllability, some individuals in this disaster have also suffered the added burden of presumptive death which may add significant cumulative legal and personal stressors.

\section{Bereavement}

Bereavement is said to be the complex reaction of survivors following the experience of separation by death from a significant person (Epstein, Weitz, Roback and McKee, 1979), whereas grief is the emotional reaction to loss in bereavement (Parkes, 1972). The purpose of this section is to review the findings on the effects of the death of a spouse as well as the findings on the effects of death on parents whose children are adults, to report the incidence of bereavement, and to examine the differences between sudden and expected death. 
The Incidence, Nature, and Effects of Lèreavement

Approximateiy six percent of Âmericans are presently widowed. In 1970, this percentage accounted for 9.6 million women and 2.1 million men (Clayton and Bornstein, 1976). Many investigators have focused on the bereavement of widows because they represent a large number of persons who have difficulty adapting to the changes caused by widowhood, particularly a significant reduction of income and a significant role realignment. Widows who are mothers sometimes try to become substitute fathers and thus experience "role saturation" because they fail to realize that single parenting does not mean a fusion of both parental roles. Our "couple dominated" society makes the realization of "no longer married" difficult. Some women withdraw rather than take on the "single" label and thus experience "role inadequacy".

Death can be viewed as a crisis when it is totally unexpected because it represents an important loss requiring a major role shift, and it appears to be an insoluable problem of acute duration (Bugen, 1979). As Toynbee (1968) states, "There are two parties to the suffering that death inflicts; and in the apportionment of this suffering, the survivor takes the brunt", (p.33z), and Schulz (1978) says, "Death is a group crisis as well as an individual crisis. For the individual who dies, death is clearly an ending but for those who survive it is a beginning", (p.136). When asked to rank 43 life events on a normative scale, a large study sample ranked death 
of spouse at the top of the list and death of a close family member ranked fifth (Holmes and Rahe, 1967). Findings regarding the impact of death on survivors have been widely reported and are largely descriptive in nature. Some correlational and experimental studies are beginning to appear in the literature.

A common observation among helping professionals and researchers is that widowed individuals, in addition to experiencing. the agonies of normal grieving, are at high risk of experiencing a variety of other problems. In particular, several large scale studies suggest that the widowed experience the following reactions to death of their spouse:

1. Widowed persons exhibit excessive mortality when compared to marsied nopulations (Jacobs and Ostfeld, 1977; Kitagawa and Hauser, 1973; Mclleil, 1973; Rees and Lutkins, 1967; Ward, 1976).

2. Widowed persons exhibit a variety of emotional problems typically associated with depression such as weight loss, depressed mood, sleep difficulty, loss of interest in both tasks of daily living and social contacts, poor memory, guilt feelings, desire to die, and suicide (Clayton, 1973; Greenblatt, 1978; Kraus and Lilienfe1d, 1959; Parkes. $1969^{\circ}$ ).

3. Widowed persons exhibit an increased risk for psychiatric hospitalization (Stein and Susser, 1969).

4. Widowed persons experience illness-inducing stress that precipitates a variety of serious illnesses such 
as infections, chest pains, rheumatism and asthma (Engel, 1968; Lieberman, 1978; Maddison, 1968; Marris, 1958).

Although positive correlations between widowhood and increased risk of physical complaints, emotional problems and death have been documented in research studies, the explanation for this susceptibility has not been firmly established.

Inasmuch as there are no data beyond case studies which describe the incidence of bereavement following disaster, it is not clear to what extent bereavement as a result of disaster deaths will follow the same pattern as following other modes of death. Since adaptive bereavement may be associated with the circumstances surrounding death, two types of bereavement are contrasted: 1) bereavement resulting from predictable death such as in terminal or chronic illnesses, and 2) bereavement resulting from sudden unexpected death, such as in accidents or natural disasters.

\section{Expected Death}

Anticipatory mourning is defined as "a set of processes that are directly related to the awareness of impending loss, to its emotional impact, and to the adaptive mechanisms whereby emotional attachment to the dying person is relinquished over time", (Futterman, Hoffman, and Sabshin, 1974, p.251). Knowledge of impending death is purported to reduce the intensity of grief after death because it is a predictable event. 
allowing significant persons time to accept the impending loss, to "rehearse" new roles, and to align social support.

Because of its potential adaptive value, anticipatory grief has been studied widely both in ill people anticipating their own deaths, as well as in family members of patients with terminal illness. According to Futterman, et al. (1974), anticipatory grief is a five-stage process. The five stages are: acknowledgement, grieving, reconciliation, detachment, and memorialization. Acknowledgement is a cognitive appraisal wherein significant others put aside denial and avoidance behaviors and become progressively convinced that death is inevitable. This time provides an opportunity to do all one can for the ill person, which may lessen guilt following death. Grieving is the experiencing and expressing the emotional impact of the anticipated loss and the physical, psychological, and interpersonal turmoil associated with it. Reconciliation is the process of finding meaning in the ill person's life and impending death, the affirmation of the worth of life, and the willingness to accept the valued person's death. It is at this time that hope no longer equals cure, but rather hope for freedom. from pain and time for the ill person to complete unfinished business. Detachment is said to be characterized by the gradual withdrawal of emotional energy. It is at this time family members attempt role changes, thus rehearsing for the reality that is to come. Hospital staff members may notice shortened visits, fewer visits, and change 
in interaction between the dying patient and family members. These behaviors are sometimes misinterpreted by personnel who may presume, perhaps in error, that the family has begun to place less value on the dying person. Memorialization is the development of a relatively fixed, conscious mental representation of the dying person which will endure beyond his death. In other words, family members will internalize global attributes of the dying person which they wish to retain.

There is no empirical evidence that people move through all the five stages or even in the order specified by Futterman. What is important is that people apparently make affective and cognitive appraisals of the situation and attempt to cope with the eventual outcome. According to Nighswonger (1974), "effective anticipatory grief work does not prevent the necessity of experiencing bereavement grief, but the successful resolution of the conflict arising in anticipatory grief can do much to decrease the likelihood of morbid, unhealthy, or abnormal bereavement grief following the actual death of the loved one", (p.267). This finding suggests that anticipatory grief mitigates the post-mortem grief because the loss is "expected" and is confirmed both for widows and for parents of terminally 111 children (Averill, 1968; Friedman, Chodoff, Mason, and Hamburg, 1963; Gorer, 1965).

Glick, Weiss, and Parkes (1974) question the positive impact of anticipatory grief. In their experience with 58 Boston widows, "36 percent had been told explicitly that their 
husbands were dying, but fower than half of them made any plans at all for what they would do after death." (p.32). In spite of the fact that less than half of the women took definitive action, tae authors noted that emotional preparation for the loss was useful. "Loss without preparation seemed almost to overwhelm the adaptive capacities of the individual." (p.32). Silverman (1974) also reported reluctance of 300 women to take on anticipatory grieving. In her view, "real grieving and coming to terms with the changes death makes in a wife's life can come only after the husband has died." (p.330).

Seemingly, less anticipatory grieving occurs among widows, yet Glick et al. (1974) report that of those widows who had warning, $65 \%$ moved toward remarriage within a year; however, widows with sudden death experiences did not move toward remarriage, and even felt remarriage of fered too much danger that this event could happen to them again.

And finally, according to Schulz (1978):

Two decades of experimental, social-psychology research have taught us that stressful life events are less aversive to the extent that they are predictable. This is partly due to the fact that organisms can brace themselves for predictable stressors; they can muster the appropriate coping mechanisms and thereby diminish the impact of the stressors. The opportunity to rehearse and prepare for a death is undoubtedly very important in minimizing the effects of the loss. (p.141).

\section{Sudden Death}

If anticipatory grief can be inferred in cases where 
dying is prolonged, sudden death is an event in which anticipatory grief would have to be absent. Sudden death is said to be devastating because it is unpredictable. Missing is the time to make an acknowledgement of impending death, time to seek information on and rehearse new roles. Bereaved experiencing sudden death are likely to use denial, blame themselves, and experience a host of adaptational problems such as 11 lness and helplessness.

According to Bugen (1977), if the cause of death is believed to have been preventable, the grieving process will likely be prolonged. Preventability refers to the general belief that the factors contributing to the death may have been sufficiently controlled so that the death might have been avoided. Whether or not the factors could have actually been controlled, it is the mourner's obsession that they should have been, either by himself or others.

Unpreventability refers to the belief that nothing could have been done and is demonstrated by attributions to God, fate, or misfortune. Belief that everything possible was done to prevent death absolves the mourner of both responsibility and guilt, and thus grief is predicted to be brief.

Some examples of sudden death are homocide, suicide, accident, sudden infant death syndrome, and disaster. In each of these examples, the bereaved frequently believe death was preventable and make attributions blaming themselves or others, even if death was unpreventable. It becomes important 
in the grieving process to help the bereaved accept unpreventability if this is indeed the case.

Upon examination of the various types of sudden death, it appears there are few similarities. For example, homocide is characterized by a clear intent to do harm to another and thus implies both an aggressor and a victim. Suicide is the ultimate of self-destructive behavior and implies self-hatred and intent to harm the self. This is seldom the entire story. There are frequently multiple, important life events involved, such as marital discord, role loss, financial problems, and interpersonal strife at work. The bereaved are usually very emotionally involved, either in repeated attempts to prevent suicide or in an ambivalent relationship whereby they become "punished" when death occurs and consequently subject themselves to blame and guilt.

In a study by Demi (1978), îwo groups of high risk widows were compared--survivors of suicide and survivors of sudden death (defined as less than 48 hours warning). The widows whose husbands died by sudden death were still depressed and anxious 21 months post-death, whereas the widows of suiciae victims had, prior to death, accepted the fact that their husbands might die by their own hand, and thus "pulled away". Prior to their husbands' deaths, these women were already successfully managing the home, finances, and children. While the sample size was too small for generalizations, implied 
in the results are aspects of anticipatory grieving, role rehearsal, and detachment.

Weinstein (1978) reported parental self-blame and guilt in sudden infant death syndrome, even though it is an unpreventable condition. DeFrain and Ernst (1978) noted that clergy, police, and relatives blamed parents in cases of sudden infant death. It was reported in both studies that inability to cope with this tragedy resulted in marital discord and divorce. In the latter study, the bereaved couple reported it took eight months to regain family reorganization and sixteen months to reach personal happiness held prior to death.

Sanders (1979-80) studied bereavement reactions in the death of a spouse, child, and parent across two conditions: chronic-illness death and sudden death. Statistically significant differences were noted for greater intensity of grief in the death of a child. Fourteen parents participated in the study and the children's ages at death ranged from six to forty-nine years. According to Sanders, death oi a grown child was the most difficult and longest lasting grief to bear. Sanders reported no significant differences between chronic illness and sudden death. "Sudden death" was defined in this study as dying within seven days of onset of illness or accident. "Chronic illness death" was not defined. Perhaps seven days is too long a time to be defined as "sudden death". Thus, 
it could be argued that significant others had begun to prepare themselves in some way.

Ball (1976-77) conducted a study on 80 widows in an attempt to predict intensity of grief reaction following death of spouse. The sample was divided into three groups based on age (Young, 18-46 years; Middle, 47-59 years; old, 60-73 years), and two groups based on mode of death-sudden or prolonged. A two-factor analysis of variance was performed for each of the three measures of grief response: 1) overall grief reaction, 2) total number of grief symptoms, 3) sum severity of grief symptoms. Results indicate that in contrast to sudden death, the prolonged mode of death did mitigate post-mortem grief on the overall grief reaction. Age was also a significant predictor of overall grief reaction, with young widows being more affected than middle and old aged widows. Young, sudden death widows had a significantly higher grief response than any other group. Sudden death was defined as death occurring in less than five days from the onset of symptoms. No comparison or control groups were used. Thus, no firm conclusions can be drawn from these findings.

No studies could be found that defined sudden death as immediate, which was the case on Mt. St. Helens, and thus allowed no time for adaptation prior to learning of the death event. 
Only one study could be found in the literature wherein the problem of "confirmed versus presumed" death was similar to that which occurred as a result of the volcanic eruption. Harvey and Bahr (1980) studied widowhood resulting from a fire in the Sunshine Mines in Idaho. The rescue lasted nine days from the time the fire broke out until all men in the mine were accounted for. Thirty-five of the eighty-six missing men were found dead by the sixth day. On the seventh day, two survivors were found and hopes soared for the remaining men. The ninth day following the fire, the bodies of the rest of the missing men were found. During the waiting period a variety of behaviors of the potential widows were noted: verbalizations indicating denial, telephone calls to mine authorities, positive comparison with other "potential" widows, expression of both concern and optimism. One emergent behavioral norm was waiting at the mine site together. All lived close by, whereas in the case of the Mt. St. Helens disaster, all of the families did not live in the immediate area, so that a supportive network formed 7 waiting that was established in Kellogg, ldaho was not established near Mt. St. Helens.

In conclusion, the incidence of bereavement as a significant life stressor merits the attention it has received in recent years. The evidence indicates widowed women, in particular, experience serious negative outcomes, 
including excessive mortality rates. The extent to which widowhood bereavement can be generalized to close friend bereavement has not been discussed in the literature. Expected death, due to its predictability, causes fewer adaptive problems because people have time to "get ready". Unexpected death appears to be far more devastating for the bereaved than expected death, even when expected death was operationally defined as up to several days. No studies could be found that operationally defined sudden death as immediate. Further, no studies could be found that focused specifically on bereaved individuals who emerged unscathed by the experience. The emphasis to date is clearly on the negative aspects associated with bereavement. Thus, the coping process to be discussed next has as a major emphasis the variables that enhance coping with major life stressors.

\section{Coping With Major Negative Life Events}

A substantial bereavement and loss literature has existed for about only ten years. Most of this literature describes the symptoms of acute grief. Some studies have investigated the relationship of acute grief and excessive mortality rates. Studies that investigate coping behaviors in individuals following major loss are limited in number and scope. The purpose of this section is to identify and discuss dimensions of coping. 
Definitions of Coping

Hamburg (1974) defines coping as the ongoing adaptive processes of meeting task requirements under exceptionally difficult circumstances. Lazarus (1966) defines coping as a behavioral or psychological process activated to mitigate or eliminate threat. Similariy, Pearlin and Schooler (1978) define coping as behavior that protects people from being harmed by problematic experience.

Coping is a universal phenomenon. It has been studied in situations of everyday living, such as parenting and work, in transitions of life, such as entry into college and marriage, in situations of sudden change in body image, such as mastectomy and amputation, and in life threatening situations such as heart attack, and disaster. Coping is not considered adaptive unless the person emerges from the crisis with self-esteem intact and a sense of continuity with one's past and future. (Visotsky, Hamburg, Goss and Lebovits, 1961).

Dimsdale (1978) cautions about the misuse of the word 'coping', when he states, "Many use the concept of 'coping' like some sort of benign stimulus-response paradigm; for example, 'the subject coped with the bright light by turning it off'. This usage ignores the essentially warlike French derivation, couper, meaning to strike." (p.403). For Dimsdale, coping struggles are fought with great uncertainty and encompass individual 
flexibility, habits of information gathering, and a variety of defense mechanisms.

While Dimsdale suggests coping is not a simple stimulus-response paradigm, coping is nonetheless an action that is taken by a person to prevent harm to himself as a result of some perceived problematic transaction in his environment. Such a problematic phenomenon is the perception of stress. Stress can be defined as those environmental demands, internal demands, or both, which tax or exceed the adaptive resources of an individual at a given time (Monat and Lazarus, 1977). Other authors prefer to define the environmental demand as a stressor, the neuro-physiological change as stress, and the response as coping.

\section{Coping: A Highly Individualized Response}

Coping strategies involve affective, neurocognitive, physiologic, and behavioral responses to stress. Thus, coping is both what one is and what one does. Coping strategies depend on the significance of the event, the individual personality attributes, and the availability of interpersonal and material resources. Since management of stress is a learned response over time, one's view of the total self becomes a predictor of successful coping. Individuals who have positive self images and believe they can master stressful situations 
seem to be adaptive copers. On the other hand, persons who engage in self-denigration do not appear to cope as well (Bandura, 1977; Hamburg, 1974; Kobasa, Hilker, and Maddi, 1979; Pearlin and Schooler, 1978).

Pearlin and Schooler (1978) believe that different stressors require different coping strategies. Thus, those who have only one coping style may not be able to cope successfully. For example, Pearlin and Schooler (1978) state that in situations of interpersonal strains, an individual must remain committed and engaged to cope adaptively; whereas in impersonal strains, one must increase the distance between oneself and the problem at hand in order to cope successfully. For each new stressful event, then, one must appraise the current situation and make an initial assessment of the threat involved. In making such an appraisal, an individual is either helped or hindered by what he has learned from past experience, the number of successful coping experiences he has had, and the current helping resources he can mobilize. Thus, one would expect individuals to use coping mechanisms that have been successful in the past. How one moves through the coping process is discussed in greater detail in the sections that follow.

The Protective Function of Coping

Pearlin and Schooler (1978) believe that coping behavior is more protective than adaptive and is exercised 


\section{in three ways:}

1) Eliminating and modifying conditions giving rise to problems.

2) Perceptually controlling the meaning to neutralize the problematic character of the situation.

3) Keeping the emotional consequences of the problem within manageable bounds.

1) Eliminating and modifying conditions. It would appear that altering or eliminating sources of strain would be a highly useful coping mechanism, but Pearlin and Schooler (1978) found it not to be a frequent protective response. According to these investigators, this is because sources of a problem are not easily recognized in time to act against them. Even if recognized, people may lack the knowledge or experience to eliminate the problem source. Moreover, actions directed at modifying one situation may create another unwanted situation and inhibit coping. Finally, some of the most persistent strains originate in conditions impervious to coping. Cassel (1974) believes that when stress cannot be lessened, community supports need strengthening.

In the case of a disaster, the danger may be misperceived, but the disaster cannot be eliminated. Specifically, in the case of Mt. St. Helens, some residents refused to leave their homes even after being advised by authorities to evacuate (The Oregonian, October 27, 1980). 
Like other natural disasters, the volcanic eruption was an event totally out of human control to ejiminate or modify.

If one accepts the assumptions of Lazarus and Cohen (1977), Pearlin and Schooler (1978), Caplan (1973), and Cassel (1974) that eliminating stressors is not usually possible, then one can also accept the premise that positive coping lies with the second and third modes of protective behavior; namely controlling the meaning of the event and keeping the emotional consequences within the bounds one can handle. In order to carry out these protective behaviors, individuals experiencing negative life events must have resources. Resources can be both internal and external. Internal resources are personality variables such as self-esteem, belief about one's ability to master tasks, particularly in new situations, capacity to mobilize support, and cognitive ability to appraise and reappraise stressful situations. Conversely, external resources are social supports, such as family, friends and neighbors, community programs, and financial assets. Internal Izsources appear primarily to affect the second mode of prctective coping behavior, perceptually controlling the meining of stressful events.

2) Perceptually controllinirmeaning. In circumstances where stressful situation: cannot be eliminated or changed, the impact of the problem situation can be 
buffered by three factors: identifying the significance of the event for the individual, obtaining information, and assessing intra-personal strengths.

The way an experience is recognized and the meaning attached to it determine to a large extent the threat posed by that experience. In the case of the mine disaster reported by Harvey and Bahr (1980), when told of the fire, little threat was perceived by some of the women. One woman thought her husband stayed to help extinguish the fire. Another said "he's been in a fire before and knows what to do". If the threat is perceived to be dangerous, meaning may be controlled initially be denial of the event. Also, this protective function of coping can be accomplished by making positive comparisons with others in the same stressful situation--"we're all in the same boat", or by lessening the importance of the event. Thus, if hardship is evaluated as being an improvement over the past, its effects will be tempered. If stressful experiences have little value, they also have little threat. Thus, devaluing money in cases where there is financial loss serves to decrease the significance of using money to buy luxury items as opposed to necessities. Reorganization of values is reported in studies of widowhood by Lopata (1973) and Matthews (1979).

Obtaining information is seen as a critical variable in a number of studies. Hirsch (1980) reported that 
"cognitive guidance" was the most important support strat-. egy to two groups of young women: those returning to school after a lengthy period away from academic pursuits and those who were young widows. Giving of information was also a central factor on adaptation to widowhood reported by Barrett (1978). Tolsdorf (1976) reported that advice, or providing information on how to complete a certain task, or achieve a certain goal, assisted individuals to begin to deal with the demands of a situation. For Antonovsky (1979), meaning of events is controlled by "a crucial element in the basic personality structure of an individual and in the ambiance of a subculture" (p.124) which he calls one's sense of coherence. The sense of coherence is "a generalized long-lasting way of seeing the world and one's life in it. It is perceptual, with both cognitive and affective components" (p.124). Similarly, Kobasa et al. (1979) have identified stressresistant people as having intra-personal characteristics that keep them healiny. Kobasa et al. (1979) report that these stress-resistant people perceive their lives in general as being under their own control, rather than powerless to act, challenging rather than threatening, and committed to goals and ideals rather than feeling alienated. These findings seem to imply that specific aspects of the personality interact with specific aspects of the environment, leading to more or less resiliency. 
For others, controlling the meaning of events is based on the expectation they have of themselves and believe others have of them. Bandura's (1977) self-efficacy concept, which deals with the expectation that one can execute the behavior required to produce an outcome, seems quite related to the intra-personal characteristics described by Kobasa et al. (1979). Bandura states that "expectations of personal mastery affect both initiation and persistence of coping behavior...the stronger the perceived self-efficacy, the more active the efforts. Those who persist in subjectively threatening activities that are in fact relatively safe will gain corrective experiences that reinforce their sense of efficacy, thereby eventually eliminating their defensive behavior. Those who cease their coping efforts prematurely will retain their self-debilitating expectations..." (p.191). Thus, it seems that one's sense of self-efficacy can operate as."intra-personal support", that is, a source of support within the individual. In addition, self-efficacy may be a major factor which is involved in the mediation of subsequent impact of stressful events.

Self-efficacy can also be seen as a factor in competency-building programs. These programs attempt to enhance personal characteristics, knowledge, skills, and attitudes, which have adaptive and preventive consequences (Caplan, 1973; Cassel, 1974; Silverman, 1974). 
3) Keeping emotional consequences within manageable bounds. The third type of coping functions more for the management of stress than for its removal, since sources of stressors usualiy cannot be eliminated. Some coping strategies that moderate, mediate, or buffer stress are realization that many stressors are crises and thus, time-limited, use of intra-personal skills, and making use of external resources. Perception of the event and intra-personal characteristics were discussed in the previous section, controlling meaning of events. We turn now to availability of resources in the environment, primarily social support.

There has been a proliferation of studies on social support in the past several years. As a result, social support is defined differently from study to study. For the purposes of this study, social supports are defined as enduring ties or bonds between individuals. Social support is said to be provided in both emotional and material ways. Individuals who care deeply about valued friends and relatives comfort those in need by listening, empathizing, and providing honest feedback on progress toward crisis resolution. The spontaneity and genuineness conveyed by close personal friends and relatives is said to be as useful to those in crisis as professional helpers (Caplan, 1974). Material support provided by significant others is also very useful to persons in the 
early crisis period because they are frequently unable to make decisions and carry out tasks of daily living. Examples of material support are help with food preparation, paying bills, and providing transportation. There are numerous studies demonstrating that social supports ameliorate stress in recovery from illness, job loss, retirement, and in life-threatening conditions like chronic kidney dialysis (Cobb, 1976; Gore, 1973; MacElveen-Hoehn and Smith-DiJulio, 1978).

Cobb (1976) describes social support as information leading a person to believe that they are: 1) cared for and loved; 2) esteemed and valued; 3 ) belonging to a network of communication and mutual obligation. Dean and Lin (1977) specify similar components of social support functions: 1) mutual responsibility, caring, concern; 2) strong mutual identification; 3 ) person seen as a unique individual rather than emphasis placed upon one's performance; 4) face-to-face interaction and communication;

5) intimacy; 6) close association and bonds; 7) provision of support, affection, security and response. They state "that to the extent that the individual maintains his expressive relations in the face of instrumental changes such as work and income, he may be 'protected' from illness-inducing stress" $(p, 407)$. Marital and confidant relationships have been shown to be important buffers between experienced stress and 
individual well-being. Burke and Weir (1977) suggest that marital helping, which is a primary support relationship, serves in two capacities, a preventive one and a mediating or therapeutic one. In a prospective study cited by Pines (1980), the most important predictor of angina in males was perception of love shown by wives. Men who had loving wives reported less angina.

In support of Burke and Weir (1977) results, Brown, Bhrolchain, and Harris (1975) had found that the presence of an intimate, but not necessarily sexual, relationship between a woman and her husband or boyfriend, reduced the probability of the onset of depressive illness following a severely stressful life event. In addition, they suggest that the lack of a close reletionship with a husband or boyfriend increases the likelihood of developing a psychiatric disorder when major stress is present. Similarly, Nuckolls, Cassel and Kaplan (1972) examined birth complications in women experiencing high or low levels of social supports. Those women with low social support and high life change had a much greater percentage of birth complications than did the high life change/ high social support group. There were no differences in the low life change groups.

Also in support of Burke and Weir (1977), Weiss (1974) maintains that most people require both a principal attachment figure, e.g., a spouse, and a network of 
friends with whom to share common interests, promote self-esteem, and obtain a sense of purpose.

Two studies by Miller and Ingram (1976 $a, b)$ investigated social support as a confidant relationship. They report that having a good confidant and some acquaintances may afford partial protection against psychological symptoms when confronted with stress. Further, the absence of confidants and acquaintances appeared to be related to higher symptom levels, particularly psychological symptoms, and particularly in women.

Thus, numerous authors report the importance of a confidant relationship that acts as either an antecedent that reduces the likelihood of illness or mediates the impact following the occurrence of negative life events. In addition to the identification of a significant oneto-one relationship, the analyses of social supports are also approached in other ways.

Some researchers feel that assessments of social systems' size or density provide them with a more comparable, objective, and possibly more accurate measure; while other researchers examined the subject's perception and sense of belongingness within his social milieu. Recent authors suggest the effects of social support may be related to a person's perception of social support. These perceptions may more accurately reflect the impact of social supports and be related to adjustment, than 
are variables such as size, frequency of contact, adjacency density, and relationship density (Burke and Weir, 1977; Caplan, 1974; Lin, Simeone, Ensel and Kuo, 1979).

Rabkin and Struening (1976), in their review of stressful life events research, specify the availability of social support systems as a confounding variable in the research. They propose research which would investigate essentially the same question posed earlier in this discussion, namely, what are the conditions under which stressful life events effects occur and do not occur? They suggest that when the stressful life event is very extreme, the less significant are the social and individual characteristics determining the likelihood of any deleterious impact. However, when the stressful situation is less than extremely severe, intra-personal and social supports contribute to a greater extent and relate to differential outcome to the same stresses. Thus, perhaps individual differences in social supports and intra-personal characteristics (e.g., confidence, sense of control) play a more influential role for people in dealing with everyday hassles or daily stresses as opposed to the major stresses specified in many of the stressful life events scales. Recently, Lazarus and Cohen (1977) have suggested that chronic daily hassles" are another type of stressful input which we know very little about. They maintain that "although 
less dramatic than major and often sudden life changes such as loss of job, divorce, serious illness, bereavement, etc., chronic hassles may exact a major price in emotional distress and enervation. They feel that the specification of these daily hassles, along with the major life changes, will provide a more adequate description of stress and coping in any population.

Alternatively, in cases of both expected and unexpected death, the bereaved appeared to adjust best when they had role models who had experienced the same life event. In studies of terminally ill children, grandparents denied the seriousness of illness and attempted to persuade their own adult children that the dying grandchildren would recover (Friedman, et al., 1963). Conversely, when parents of dying chilarer used other parents of dying children as primary solurces of social support, they coped more adaptively. Whether family members impede coping with impending bereavement in situations other than with dying children is not clear.

Likewise, Barrett (1978) reported widows having more than one widowed friend adapted better than widows having only one or no widowed friends. Thus, reference others may be more helpful than immediate relatives. Therefore, the mutual withdrawal of family and married friends from widows and vice-versa may not be a negative outcome if the widow seeks reference others for support. 
The literature on coping with stress cited above raises several important issues for the current study.

1) One's coping repertoire appears to be a composite of the significance of an event, one's personality traits such as self-esteem, one's expectations to master stressful events, and one's availability and use of social supports. Thus, for some, the event may be perceived as a challenge to overcome, whereas for others, the event may be overwhelming. Perception of the event may promote health and growth or produce decline in health status. Many daily hassles may occur for some persons, whereas others may not be affected by a series of additional minor stresses that are consequent to the major negative life event. As Rabkin and Struening (1976) note, in cases of extreme stress, nothing may help; in cases of major life events, social supports appear to help most; and in crses of minor daily hassles, intrapersonal qualities are likely to enhance coping.

2) The confidant relationship takes on a particularly important significance in this study. If one assumes a confidant relationship as antecedent to an event, and if the relationship is severed by the event (sudden death), then decline in health status could be predicted. Yet recent studies suggest that most individuals do not experience declines in health. Therefore, how the confidant relationship is replaced during bereavement is a compelling question. 
Exposure to Mass Media

A related question regarding coping that is of concern here, but that has received little attention in the literature, is the relationship between the effect on coping with an uncontrollable event and national, state, and local television and newspaper coverage of the event. In general, does the visual imagery of disasters advanced by the mass media affect people's beliefs, attitudes, and behavior? Is the public likely to become more complacent about disasters? Specifically, do the bereaved friends and relatives regard mass media coverage of the disaster that affected them as a positive symbolic support or a negative invasive activity? While there is no literature on the specific question, what follows is a review of two disaster studies addressing the general question.

Abe (1978) investigated the effects of a rumored impending earthquake in Tokyo in 1973. The rumor was started by a fortune teller. Fully $85 \%$ of the 290,000 residents heard the rumor primarily spread by the mass media, friends, and acquaintances. According to the investigator, anxiety was aroused greatly and 35\% of the people who heard the rumor took some action to deal with the consequences. Another study in a nearby area prone to earthquakes reported that nearly $40 \%$ of the people believed a primary source of information and 
did not check any other source for accuracy of a report predicting an earthquake (Abe, 1978).

Clearly, the mass media may affect both the rate and meaning of messages conveyed. In view of the rapidity with which events can be reported, it becomes important to learn whether the perception of an event is altered in the minds of those whose lives have been personally affected by the event.

In summary, this section has defined coping as a set of behaviors individuals use largely to protect themselves from stressful situations. Adaptive coping either eliminates or lessens the stress before it becomes too severe, controls the meaning of an event by perception and assessment of self-efficacy, or makes the event that has occurred more manageable through the use of social supports. The literature review on coping suggests that people do cope even in the most severe life-threatening circumstances, but that coping is more adaptive in adverse situations in which people have time to make appraisals of impending threat. Some examples of uncontrollable stressful events that provide "advance warning" are iliness or injury as adults, severe illness in one's own children, and illness and subsequent death of aging parents. Numerous studies suggest that social support is the most enhancing intervening variable for coping. Implications for the present study are that coping with sudden death may be 
extremely difficult due to the uncontrollability and unpredictability involved. Further, the coping literature has not reported the combined added stressors of not having the dead person's body returned, being subjected to a court hearing during the acute grieving process to attempt to confirm the fact of death, having to cope with a time delay in estate settlement, having to meet financial obligations with sudden loss of income, differences in coping with death and other major negative life events, and effects of mass media in coping with sudden death bereavement.

\section{The High Risk Bereaved Following Disaster}

Most disaster literature reports on community response to disaster or individuals who have survived a disastrous event. Little is known about the suddenly bereaved as a result of disaster, yet a major function of community mental health is to identify "populations at risk". "Populations at risk" is a term defined as "those populations containing a sufficient number of individuals who have experienced sufficient stress to interrupt their state of emotional equilibrium" (Lancaster, 1980). A sudden unexpected event, such as the death of a significant person, is one example of a crisis that may lead to an "at risk" status. The first financial support for emo- 
tional recovery research following a disaster was awarded by the National Institute of Mental Health in 1972 (Hoff, 1978).

In the case of the volcanic eruption of Mt. St. Helens, the bereaved are primarily confidants, young widows, and parents of adult children. Previous sections have reported the unique and stressful aspects of this disaster. The findings suggest coping with all the changes required such as multiple role transitions, loss of income, and delayed closure of the death event may indeed tax the adaptive capacities of some bereaved individuals, particularly young widows. Therefore, the purpose of this section is to discuss variables that differentiate those most likely to have a painful and incomplete recovery process. Most of the literature on high risk bereavement regards widowhood.

Identification of high risk groups of individuals serves two purposes: 1) to aid in the prediction of adaptive and maladaptive coping, and 2) to develop preventive intervention strategies prior to the time they are needed. The question of why some persons can cope with the loss of a relationship while others cannot has prompted investigators to look for important variables that predict risk factors associated with bereavement. The most important variables are: demographic data, assessed preventability, relationship with the deceased prior to death, duration of bereavement, simultaneous 
Iife events, intra-personal and social supports, and intervention. Barrett and Becker (1978), using a variety of statistical analyses, noted 38 significant relationships between predictor and adjustment variables, whereas only 14 would have been expected by chance.

\section{Demographic Characteristics of High Risk Individuals}

Demographic variables appear to be the most important predictors of high risk associated with sudden death bereavement. Among the variables are age, sex, number and ages of dependent children, and income. Evidence has led many investigators to conclude that for a period of at least two years after death of a marital partuer, the surviving spouse is mortally endangered. "In general, the data among the replicated studies in both England and the United States showed that the risk of dying is at least twice as great for widows and widowers at all age levels for a great variety of diseases" (Epstein, et al., 1979, p.596).

Age. In a study by Barrett and Becker (1978) the widow's age was correlated with more adjustment criteria than any other variable. The younger the survivor is at the time of death of the spouse, the more difficult the adjustment appears to be. The study by Ball (1976-77) reported earlier on sudden death found age to be more important than mode of death. Person's "aged 45 and under" 
were specifically predicted to be vulnerable to serious illness and subsequent death (Barrett, 1978; Epstein et al., 1979; Glick et al., 1974; Parkes et al., 1969; Vachon, 1976). Kraus. and Lilienfeld (1959) studied mortality rates among the very young who were widowed. Significant differences were reported when compared with married counterparts. In another study comparing mortality rates of widowed and married persons in the United States, Kitagawa and Hauser (1973) estimated that widowed persons ranging in age from 35 to 64 have mortality rates ranging from $30 \%-89 \%$ higher than married, depending on sex and race. Hence, age appears to be a significant factor.

Sex. Studies examining sex differences in adjustment to widowhood tend to report higher rates of illness and high mortality in women, however, widows have been more widely studied since they outlive their spouses and seek professional help more frequently, and thus come to the attention of others (Barrett and Becker, 1978; Krause and Lilienfeld, 1959).

Illnesses thought to be associated with widowhood appear to be different for men than women. McNeill (1973) reviewed mortality rates of more than 9,000 persons under sixty years of age vidowed in 1965. Widowers died most frequently by silcide, accidents, and heart disease during the first six months of bereavement. Widows died 
most frequently from heart disease and cancer during the second year.

In terms of psychological adjustment, Glick, et al. (1974) report widowers experience more blame and guilt for their wives' deaths, but resolve these feelings faster than do widows. Males, according to Glick, et al., do not rehearse events that lead to the death as frequently as females. Widowers also coped with less anxiety and less fear of mental breakdown and moved more quickly into re-establishing their lives by remarrying earlier than widows.

Number and ages of dependent children. Maddison (1968) studied effects of age, sex, and number and ages of dependent children and concluded that children increase the burden of bereavement. The isolated nuclear family in our culture compared to extended family systems of other cultures, creates a situation of high vulnerability at the time of bereavement. Younger children require care if the widowed mother seeks employment outside the home. Child care is an added financial burden. Lowered income must be stretched over all needs of the household. The more children the young widow has to support financially, the greater the expense of the basic necessities of food, clothing, and shelter. For widowers, child care poses a serious problem, which is said to be one reason widowers remarry earlier than widows (Glick, et al., 1974). 
Income. While the impact of loss of income has not been reported widely, it is said to make widowhood very difficult, particularly when there are other dependents. Nuckolls (1973) studied the financial status of 1,744 prematurely widowed women. The mean average drop in income, for the surviving families was $44 \%$ from pre-death levels. Further, $71 \%$ of the sample couples had not prepared wills.

Barrett (1978) surveyed 94 widows in an attempt to identify major stresses in bereavement. In response to one question, "Is there anything you think women should know or do before they are widowed?", $50 \%$ said financial preparation. This was also the most common response. By comparison, emotional preparation was stated as useful by only $17 \%$ of the respondents. In the case of presumptive death, the financial resolution is likely to be longer, adding increased stress. In sum, evidence suggests demographic data are helpful in assessing "at risk" bereaved individuals.

Other Factors Useful in Identification of High Risk Individuals

Assessed preventability. As reported earlier, conditions surrounding death are found to alter responses. If the death is predictable and therefore not preventable, the bereaved is more likely to make external attributions, 
thus absolving himself of blame and resolving any guilt much faster. (Bugen, 1979). If the death was unpredictable and thought to be preventable, the bereaved may feel responsible in some way and is at higher risk and therefore susceptible to greater stress.

Relationship with the deceased. By and large, most studies are based on the marital relationship prior to death of the spouse. There are limited data that report responses to sibling death or death of very close friends. A woman's relationship with her spouse was relevant to her experience as a widow (Barrett \& Becker, 1978). The happiest wives viewed widowhood the most negatively. On the other hand, Maddison (1968) reported an unfavorable bereavement outcome in situations where there was unresolved marital discord at the time of death, or if the grieving person had ambivalent feelings toward the deceased.

The relationship defined and tested by Bugen (1979) is said to be either central or peripheral. A central relationship is said to be "close", whereby the deceased person made a significant difference in the life of the now bereaved. A peripheral relationship is described not having an immediate impact, or "not close". According to Bugen, if the relationship is central, grief will be intense. If peripheral, grief is predicted to be mild. Duration of bereavement. Length of time widowed was found to be significantly related to grief, loneli- 
ness, attitude toward the future and attitude toward widowhood. In all cases, the longer widowed, the more negative and pessimistic the widows became. (Barrett and Becker, 1978). Parkes (1972) reported that younger widows in his sample tended to remarry within two years. These data have implications for the current investigation because the addedi stressors of presumptive death already discussed may impede normal recovery. The stressors may be too great even for those who have coped successfully in the past.

Simultaneous life events. Holmes and Rahe (1967) and Sarason, et al. (1978) have developed scales measuring life events which can occur single or simultaneously. While death of spouse is rated as the highest stressor, when accompanied by other stressful events, it is believed to be responsible for high rates of psychosomatic, physical, and emotional illness.

Intra-personal and social supports. The personality characteristics that people have drawn upon to help them withstand threats posed by events and objects in their environment include self-efficacy, commitment, and perceiving adverse life events as challenging rather than threatening.

Perceived loss of support of friencis and relatives was reported by Jacobs and Douglas (1979), Maddison (1968), and Vachon (1976) to predict high risk bereavement. 
Raphael (1977) followed thirty-one experimental subjects and thirty-three controls into the second year of bereavement. Study subjects who perceived their pre-bereavement social networks as no longer supportive following the deaths of their spouses, benefited by a helping network formed as an intervention by a professional helper. Glick, et al.,(1974) found that widows were close to parents and siblings right after death, but as time went by they \&gain became independent of nuclear family members. Married friends' networks have also been shown to collapse for widows (Lopata, 1973). There is some suggestion that due to the search for a new identity, the widows themselves may pull away and thus be responsible for the isolation they perceive. Those at highest risk appear to be those who have no widowed friends or no one who can be consistently empathetic to them.

\section{Intervention for the High $\overline{R i s k}$ Bereaved}

Interventions are those activities that serve to reduce the aftereffects of a traumatic event. The purposes of intervention are to help survivors live longer, more productively, and less stressfully than they are likely to do without intervention.

Gorer (1965) identified three tasks associated with successful grief work: separation from the deceased, readjustment to the environment from which the deceased 
is missing., and formation of new relationships. Grief is both a subjective and an objective phenomenon that seems to fall into a time frame. The first six weeks following death seem to be a very critical period. During this time, survivors report shock, disbelief, and helplessness. The second period is said to last from six weeks to approximately one year where the bereaved searches for meaning of the death. For some, an almost obsessional review ensues, whereby scenes surrounding death are reviewed. Further, these scenes appear distorted in dreams, and are discussed with others, until the futility of this frustrating process is finally accepted. Physiological disturbances are frequent. The final period of adjustment can take up to another year. Careful analyses of these time periods and descriptive responses collected have aided in both practical interventions and theor $y^{-}$development.

Early intervention as a tool in easing the pain of grief has been studied by Epstein et al. (1979), Raphael (1977), and others. Epstein et al. noted interventions that help bereaved widows to make the separation from their spouses are more important for young survivors and more effective when instituted within two months following death of spouse. Raphael used group treatment during the first three months for 31 subjects and compared results with 33 controls. Those benefiting significantly 
more from interventions were those who perceived non-supportive social networks, aside from group intervention.

Crisis intervention following disasters is a very recent tool (Hoff, 1978). Crisis intervention teams provided immediate support primarily for survivor/victims following the Rapid City, South Dakota flood of 1975. While those not treated were predicted to experience long-term ill effects, no follow-up studies have appeared in the literature to date. Thus, actual long-term effects following disaster are not clear. Reports of crisis intervention following other disasters has also been reported (Hoff, 1978).

What can be said, then, for identifying a high risk population of bereaved is that data support the fact that the younger the bereaved person is when his or her spouse dies, the greater the risk of illness and death. Females will be of higher risk than males when they are also young, have more than one dependent child, and suffer loss of financial resources.

Similarly, the greater the perceived preventability of the death, the greater the perception of lack of support, and the greater the perception of lack of efficacy, the higher the risk. The more central or ambivalent the relationship with the deceased, the greater the inability to grieve, and the more negative past grieving experiences have been, the higher the risk. The more unexpected the 
death, the higher the risk, and finally, the more significant events occurring simultaneously, the higher the risk. These findings would appear to affect disaster bereaved in much the same way. Long-term effects are still under investigation.

\section{Summary of the Review of the Literature}

Computerized searches of both the psychological and medical literature served as a basis for an initial bibliography. References listed at the end of articles expanded the list.

The high incidence of the ill effects of bereavement in general provides rationale for further study. It appears that expected death is a negative event with which most persons can cope. Much less is known about sudden death bereavement. This is because subjects are not always willing to participate, thus making sample sizes too small for generalization. The evidence that is available suggests stressors to disaster bereavement may be uniquely severe. Identification of the high risk bereaved is essential in cases of disaster because it appears suffering may be prolonged due to a number of factors. Among them are the legal process necessary to get closure on property settlements and accompanying daily hassles. Therefore, the present study seeks to compare two conditions of disaster bereavement resulting from presumed 
and confirmed death, with a group of individuals who suffered property loss and a group of control subjects.

\section{CONCEPTUAL FRAMEWORK}

\section{Theoretical Approaches to Coping With Disaster-Related Stress}

The choice of a conceptual model for this dissertation involved examination of models used in recent disaster research and examination of models used in bereavement and coping research. Due to the complexity of the present study, no single conceptual model could be found that met the needs of the problem being examined. Therefore, the model proposed is an integration of many theoretical elements. What follows is a description of the theoretical models considered, and rationale for the development of the final model.

In Quarantelli's book, Disasters: Theory and Research (1978), two chapters (Kreps, 1978 and Bolin and Trainer, 1978) present theoretical orientations relevant to this dissertation. Kreps (1978) focuses on the community at large while Bolin and Trainer (1978) emphasize the role of the family following a disaster.

Kreps (1978) emphasizes that the major response to American disasters is an organized response of the overall community. Thus, crisis and organizational theory become 
frameworks for investigating disaster questions such as how communities mobilize during both the pre- and post-disaster periods, and how information regarding impending disasters is conveyed to and acted upon by local residents. Crisis and organizational conceptual frameworks assume potential victims reside in and/or are employed in the community, and therefore have a vested interest in the community, as well as interest in their personal and familial survival. Kreps' model focusing on organizational responses, such as those of police departments for traffic control, is inadequate for the current study due to his emphasis on physical needs at the community level and not on emotional needs at the individual level.

Bolin and Trainer (1978) developed a conceptual model of family recovery following disaster, whose major elements are: the nature of the disaster agent, social and economic characteristics of victim families, community normative and resource structures, and the extensiveness of social networks. This model was tested with data gathered following a major earthquake in 1972 in Nicaragua and following a flood in 1972 in Rapid City, South Dakota. It also assumes victims reside in the area. While the family recovery model is not entirely appropriate for the present study, some important concepts that can be applied here are the number of deaths in one family, extent of social supports, and perception of recovery level. 
Because these models involving disasters are not congruent with the problem under study, other related theoretical approaches from psychology, social psychology, and sociology have been selected. The selection of theoretical approaches from other disciplines reflects the conceptual sequence of events that occur in sudden death bereavement. This sequential order of events that occurs in coping with disaster-related stress is illustrated in Figure 1. First, bereaved friends and relatives had prior relationships with the person who died in the disaster. For some, the attachment was formed through shared recreation or work. For others, the bond was one of a parent and child or husband and wife. Second, this attachment or bond was broken by the sudden death of one member, leaving the other to accept both the event and the swiftness with which it occurred. Finally, bereaved individuals must cope with the loss that has been experienced. The bereaved must somehow find meaning in the loss of the valued person as well as in their own futures. Health may be affected by this complex process of coping.

This sequence of events serves as a basis for inclusion of six pertinent theoretical concepts in the model for the current dissertation. These six theoretical concepts are: attachment and loss, grief, coping, stressful life events, supports, and mortality. They are summarized in the following sections. 


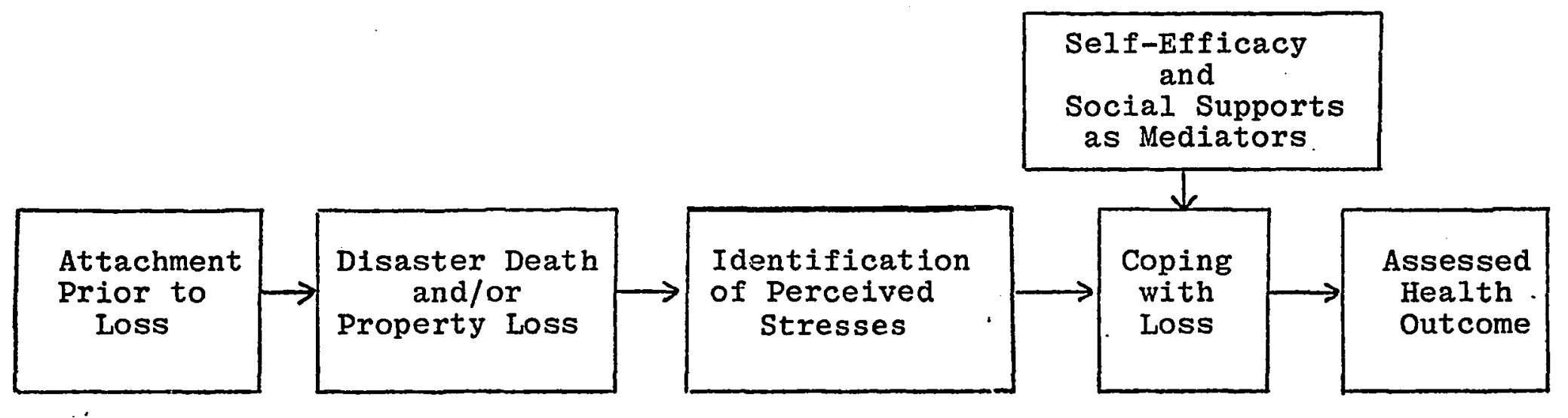

Time

Figure 1. Sequential Events in Coping With Disaster-Related Stress 


\section{The Theoretical Concepts of Attachment and Loss}

Separation is experienced early in life as the newborn leaves the security of intra-uterine life. However, a growing psychological attachment is usually formed between the newborn child and his parents. Attachment may be defined as an affectional tie that one person forms between himself and another specific person that endures over time (Ainsworth and Bell, 1970). The mutual process of attachment is fostered by the nurturing role of the caretaker, the gratification felt by the infant as physical and emotional needs are met, and the reciprical satisfaction of needs of the care-taker as provided by the infant.

As the infant grows, the process of attachment is extended to siblings and significant others, and soon extends to material objects such as a favorite toy. Through these human and non-human object relations, the individual learns about the nature of relationships. Specifically, one experiences the confort of closeness and the discomfort aroused by separation from significant others. Bowlby (1969), an attachment theorist, believes these early identifications contribute significantly to the way later choices of attachment are made, particularly intimate attachments.

Throughout life individuals experience loss of prior attachments. Sometimes these losses receive little atten- 
tion from the individuals involved. At other times, even the loss of a favorite toy may be very difficult. Both quantity and quality of attachments and losses contribute to developing adaptive techniques which one day will be challenged by the most traumatic of losses--loss of a relationship with a significant other through death.

Loss is defined as "a being without something one has had" (Peretz, 1970, p.6). According to Peretz (1970), loss is "simultaneously a real event and a perception by which the individual endows the event with personal or symbolic meaning". Because both material and human loss become a common experience, its association with physical illness, depression, and even death itself is often overlooked; yet the literature reviewed earlier exemplifies how some individuals face extreme risk following the loss of a loved or valued person. In order for an individual to accept the loss of a valued person, three behavioral changes need to occur. First, one must let go of the person who is dead. Second, one must adjust to the void in the environment that was formerly filled by the dead person. Finally, one must find meaning in both the death event and in the future of one's own life.

While theories of attachment and loss apply to the current study, mone are sufficiently developed to take into consideration age of both the deceased and bereaved, nor suddenness of loss. The impact of sudden death may 
depend both on age of deceased and age of bereaved. In the present study, the sample of bereaved is composed of both intimate friends and relatives of victims of sudden death. For some of the young adult bereaved study subjects, this may be their first experience with death of a young adult significant other. Inasmuch as establishment of intimacy is an important developmental task for young adults, sudden irreversible loss of an intimate attachment in young adulthood may be very traumatic. It can also be argued that for older parents, the death of one's adult child is likely to be overwhelming because of the expectation generally held that an older person will die before his offspring. In addition, as age increases, individuals must cope with an array of problems such as loss of work through retirement, loss of friends by death, and loss of personal health. Coping with multiple losses may decrease the bereaved older person's adaptive capacities. Thus, death, age and the precipitous nature of the loss are likely to be interrelated, yet not accounted for conceptually. Persons coping with property loss may also feel the separation from an important attachment object, although the feelings are not likely to be as intense as the loss of a valued person (Fried, 1977). Thus, in reference to the sequence of events in disaster-related loss, there is a sudden, unexpected loss of an attach- 
ment with a valued object or loved person. The grief response to loss is discussed next.

\section{The Theory of Grief}

Grief is defined as "a process of realization whereby internal awareness is brought in line with external events" (Parkes, 1972). According to Schulz (1978), modification of internal awareness occurs as a result of passage of time as well as "repeated discrepancies encountered when remembering the deceased--an environwhere the deceased no longer exists" (p.138).

Grief is differentiated from bereavement in that grief is said to be the emotional response to the death event, while bereavement includes grief but also includes the total adjustment to the death and the re-establishment of one's own life.

A number of early grief theories focused on the difficulty of separation. According to Freud, grief represents a breakdown of the denial of death. The mourner grieves because he or she can no longer deny the reality of death (Glick, Weiss, and Parkes, 1974). Bow1by (1969) believes that separation from those one prefers to remain attached to evokes behavior patterns that attempt to restore closeness. Parkes (1972) similarly states that even though the pain of separation is relentless, attempts to keep the dead person central in the bereaved 
person's life are no longer possible. Unfortunately, none of these theories are stated explicitly enough to be tested. More recently, Bugen's model of human grief (1977) has presented a set of related concepts that can be empirically tested and hence represents a major step in theory development of grieving. Bugen's model asserts that the degree of grief is best predicted by a combination of two factors: closeness of the relationship and perception of preventability. The relationship between the mourner and the deceased can be central or peripheral. Bugen emphasizes the model is dynamic. That is, if the relationship is central at the time of death, grief will be intense and the relationship must become peripheral in order for grief to be resolved. Thus, the person who feels that there is no life without the deceased is likely to sustain a sense of hopelessness. If the deceased is not a central figure in the life of the bereaved, then the initial response will be mild, or without physical symptoms.

According to Bugen, the belief by the bereaved survivor that the death was preventable, is the single most influential factor in causing the grief process to be prolonged, that is, iy Bugen's definition, beyond six months duration. The key word here is belief. If the death was believed preventable, then survivors may feel that they contributed to the death directly or indirectly. If the bereaved believes the death to be unpreventable, then the locus of control is 
external and absolves the mourner of both responsibility and guilt. Bugen's model, then, can predict the grief outcome as mild to intense and as brief to prolonged, depending on centrality of the relationship and belief about preventability. The model has significance for helping professionals because the therapist can identify four possible grieving conditions: brief and mild, brief and intense, prolonged and mild, prolonged and intense.

A note of caution is in order regarding concepts of grief, in that men, the elderly, and ethnic minorities are poorly represented in the groups that have been studied. On the other hand, there is no suggestion in the available literature that the pattern of grief is fundamentally different for these underrepresented persons (Glick, et al. 1974). Bugen's theory of grief has implications for the conceptual model of the current study. The present model needs to include consideration of whether the relationship between the victim and the bereaved prior to death was central or peripheral and whether the bereaved believed death was preventable. For example, if the relationship between the bereaved and deceased prior to death was central and there was an unresolved conflict over an important issue at the time of sudden death, resolution for the bereaved might be very difficult. Likewise, if the bereaved believe they may have had any influence in preventing 
the death from occurring, these feelings must be resolved in order to prevent guilt feelings from becoming depressive at a later time.

\section{Theoretical Concepts of Coping with Unexpected Loss}

Concepts of stress and coping have had much attention from psychologists over the past twenty years. Stress has been defined by Monat and Lazarus (1977) as "whatever taxes or exceeds personal resources" (p.3). Coping is said to be "the on-going adaptive processes of meeting task requirements under exceptionally difficult circumstances" (Hamburg, et al., 1974, p.425). While there is no one theory of stress and coping that has received consensus, there appear to be a number of underlying assumptions which are common to several theories.

The following theoretical assumptions are generally agreed upon by a number of stress and coping theorists. Among these theorists are: Monat and Lazarus (1977; Hamburg, et al. (1974); Janis (1977); and Pearlin and Schooler (1978).

- All stress does not distress.

- The individual's response to stress is contingent upon how stress is perceived, interpreted and defended against.

- One's most important values and goals are disrupted by stress, which is the reason identity may be threatened. 
- In extreme stress, people use past coping behavior, not new creative approaches.

- Coping is based on both affective and cognitive components.

- Adaptive coping helps maintain linkages with valued persons or groups.

- Adaptive coping helps maintain self-esteem and integrity.

- In order to cope successfully, individuals must be able to find meaning in their lives.

- Successful coping may be determined largely as what the individual believes he can or cannot muster.

- Direct actions are seen as protective and include lessening stress before an event occurs, controlling the meaning of the stressful event after it occurs, and controlling the stress itself after it has emerged.

- No single coping mechanism is sufficiently effective to eliminate effects of stress; rather, both internal strategy and external resources used together appear to work best.

- Inaction is identified by feelings of hopelessness and giving up and can result in depression.

What follows is a discussion of several theoretical concepts that are said to affect the coping process. They are: Stressful Life Events, Intra-Personal Support and Social Support. 
Recent Life Events as Stressors

Recent life changes can be defined as those events which appear to be stressors of sufficient magnitude to tax the coping responses of individuals. Some examples are death of a spouse or family member, divorce, financial difficulties, marriage, birth of a child, and changes in roles. Early work assessing the impact of life change emphasized change per se, but more recent work demonstrates that events perceived as negative have negative impact (Sarason et al., 1978). Recent work also suggests on-going minor stressful events may also tax adaptive capacities of the individual (Lazarus and Cohen, 1977).

The Holmes and Rahe (1967) list of life events was designed to identify key areas of life adjustment, whereas the Life Experiences Survey by Sarason et al. (1978), provides the opportunity to identify and rate the event over two time periods. As a theoretical perspective, recent life stress has relevance to the present study. One would expect that numbers of events, perception of events, and feelings of uncontrollability serve to define the magnitude of stress, all of which are related to appraisal, coping efforts, and adaptive outcome. Coping with multiple life events can be enhanced by intra-personal coping behaviors and by factors in the environment, particularly social support. These areas of intra-personal resilience to stress and social support in time of stress are elaborated in the following two sections. 


\section{Intra-Personal Resilience to Stress}

Stress researchers, the mass media, and countless physicians have warned that persons experiencing extremely high levels of stress are subject to high levels of illness. Indeed, numerous studies have demonstrated the high risk of stressful occupations and lifestyles. Despite the seemingly high risks, however, large numbers of individuals renain healthy. Some very recent stress studies focus on the positive aspects of environmental stress and pose some conceptual bases for their findings. Relevant intra-personal theories or conceptualizations are self-efficacy (Bandura, 1977); sense of coherence (Antonovsky, 1979); and hardiness (Kobasa et al., 1979).

Self-efficacy theory is based on the premise that "expectations have a profound effect on behavior. An outcome expectancy is defined as a person's estimate that a given behavior will lead to certain outcomes. An efficacy expectation is the conviction that one can successfully execute the behavior required to produce the outcomes... In this conceptual system, expectations of personal mastery affect both initiation and persistence of coping behavior" (Bandura, 1977, p.193). Thus, whether a person engages in trying to cope and how long he/she will persist in coping, depends on the belief, or expectation one has at the outset. Bandura notes that role models and past successes or failures in coping are factors that affect the development of self-efficacy. 
Antonovsky's (1979) concept "sense of coherence" is a rather global, positive view of life. If one has a sense of coherence, then one believes that life in general is worth living and difficulties can be managed. Such adaptive coping comes from a strong ego identity that has been nurtured by strong, stable social ties and positive life experiences. According to Antonovsky (1979), individuals who have strong ego identities and continuing social networks are armed with "generalized resistance resources", develop a sense of coherence, and experience health, not illness.

Kobasa et al. (1979) believe stress cannot and need not be avoided. These researchers suggest individuals who are "unaware of and involved with oneself, believe that one can control and transform tile events of one's experience, and perceive change as an opportunity and challenge...will be energized and exhilarated rather than debilitated and worried" (p.597).

Two similarities and sources of difficulty are noted. The three theories similarly postulate that a combination of intrapersonal resources and external supports are likely to promote health, and that efficacy, coherence, and hardiness become a way of life as a result of positive experiences over time. All persons are not born into strong, stable social support systems and thus may not have the kind of environment that can lead to strong ego identity. Further, these theories have not yet been tested on the most potentially stressful event: sudden death. 
Social Support in Times of Stress

A basic assumption of social support theories is that social support facilitates a person's coping in response to environmental stressors. Social support as defined by Caplan (1974) is "that continuing set of social aggregates that provide individuals with opportunities for feedback about themselves and for validations of their expectations about others, which may offset deficiencies in these communications within the larger community context" (p.4). A growing body of literature on social support reports the following specific beneficial characteristics of social supports:

- The quality of the emotional support and task-oriented assistance provided by the social network helps the individual grapple with his or her existing situation.

- Social supports act as buffers against disease processes since those who make up a social support system are interested in the individual during crisis in a very personal way.

- Social supports provide material assistance such as money and supplies and services.

- Social supports provide a feedback system that helps the individual accurately evaluate his performance in handling his difficult situation.

- Non-professional supports may be as effective as professional supports since a person-to-person influence provides a sense of authenticity and spontaneity rare among professionals. 
of particular interest in the current study is the conceptualization of positive circumstances in one's life as these positive circumstances relate to the absence of stress effects. One set of positive circumstances to be examined is one's ability to use supports found in the surrounding environment. Social supports are frequently conceptualized as mediating or moderator variables upon the impact of stressful life events (Dean and Lin, 1977). While Dohrenwend and Dohrenwend (1974) state there is a tendency to neglect the role of social supports as stress-mediating, Dean and Lin (1977) caution that social support may buffer stress "only within certain limits", that "certain events may increase or decrease the level of social supports" (p.411).

Lin et al. (1979) point out that the mediating or buffering role of social supports is becoming widely accepted, yet there is no theoretical explanation as to why the mediating effect occurs. Lin et al. (1979) discuss two explanations. 1) Social groups may exert pressure to conform to norms regarding the engaging in preventive health behaviors. This is a plausible explanation if one accepts the notion that persons maintain familial and confidant ties and interactions even in times of stress. 2) Interaction patterns provide practical information, such as where to look for work, or how to locate a counselor. This explanation is widely supported (Caplan, 1974; Rabkin and Struening, 1976).

Likewise, the withdrawal of social supports are 
said to hinder the coping process. In the case of the transition to widowhood, friends of the former couple (widow and spouse who died) are reportedly uncomfortable in the present of the widow, and may withdraw support (Parkes, 1972). Further, if drastic changes in lifestyle are required of the widowed person as a result of the death of one's spouse, the widowed person apparently gets more support and information from others who are also widowed and tends to withdraw his/her support from former friends out of need for help from a new reference group (Barrett, 1978). It is conceivable that similar findings might be reported in the present study.

In summary, the theoretical formulation of social support as a mediating variable in stressful circumstances will be formulated into hypotheses for the current study.

\section{Mortality Hypotheses}

Stroebe, et al. (1979), in a critical review of the bereavement literature, have identified five hypotheses regarding mortality rates of widowed persons. The high mortalj.ty rates of widowed persons as they move through the first year and one-half of the mourning process have been documented in the earlier literature review. Of the five hypotheses identified by stroebe, et al. (1979) and others, only three of the five-desolation, common 
unfavorable environment, and non-grief related behavior changes--were not ruled out when the relevant evidence was examined (Schulz, 1978). Of these three hypotheses, only two are relevant for this study and are discussed briefly below. They are the desolation effects hypothesis and the non-grief related behavior change hypothesis. The desolation-effects hypothesis states that hopelessness is central and is caused by the amount of change and readjustment necessary to adapt to the widowed state. This hypothesis takes into account the relationship of psychological, sociological and physiological factors operating simultaneously. It is not known how symptoms such as loss of appetite, sleep, and will to live are associated with the demands of employment, child care, and loss of income to produce physiological changes which can cause illness. This hypothesis is cited most often and probably accounts for most of the negative effects of bereavement (Schulz, 1978).

The non-grief-related behavior change hypothesis has to do with the protective and helping nature of an intimate relationship. This hypothesis asserts that in the absence of the watchful spouse or intimate person, the survivor is not as careful and hence subjects the self to accidents, unnecessary stress, and illness, and is therefore and active contributor to his or her own death. For example, car accidents are said to be examples of this 
hypothesis, since a spouse or frequent intimate companion who typically helped watch the road is no longer present.

Research to date has not been undertaken on a sufficiently large scale of broad enough scope to substantiate excessive mortality rates in the bereaved: thus confident conclusions cannot be drawn. The evidence is of such nature that continued investigation into the loss effect is urged.

In conclusion, Stroebe, et al. (1979) state:

research sliggests that attention be given to psychological processes that may unwittingly victimize the bereaved individual, cause him or her to take an active selfdestructive role, or to cease taking adequate health care. One fruitful line of future inquiry concerns the examination of outcomes among individuals who respond to the stress of bereavement with feelings of hopelessness, and who perceive the changes in important aspects of their situation (such as loss of social, emotional, and financial support, and of the specific skills contributed by the partner) as beyond their control (p.24).

Summary of Theoretical Approaches for the Current Study

In summary, the theoretical approaches that have been discussed are indeed varied but complementary, and give direction to the kinds of questions one might ask in the present study. The conceptual framework for the current study includes the following theoretical components: attachment and loss, grief, coping, stressful life 
events, supports, and mortality. Theories of attachment and loss serve to explain how relationships are formed and why a sudden loss of a valued person can be very disruptive. Theories of grief attempt to explain the variety of ways individuals respond initially to the death of a significant other. Theories of coping suggest that if past coping behaviors, such as use of intra-personal support and social supports have been successful, they are likely to be used when confronted with the current crisis. Finally, mortality hypotheses suggest that for some, the stressors associated with sudden death may be overwhelming. Some individuals may not have a coping repertoire varied enough to compensate for extreme stress and thus suffer deficits to their own well-being which may include death. 


\section{Chapter III}

\section{METHODOLOGY}

\section{Research Design and Hypotheses}

This study seeks to answer three questions. Is there a relationship between illness and three stressful life events: presumed death of a close relative or friend, confirmed death of a close relative or friend, and loss of one's permanent or recreational residence? Do self-efficacy and social supports act as intervening variables to buffer the negative effects of stress on one's health when coping with loss? What are the perceived effects of the media on coping with loss following a disaster?

At the outset of this study, it is important to establish that stressful life events do result in lowered levels of health. Does the sudden death of a person due to a natural disaster produce illness in the bereaved relatives and friends of that person? Do the bereaved of the presumed dead report greater impacts of negative life events and hassles than the bereaved of those victims of confirmed dead shortly after the disaster? Further, does stress associated with property loss produce illness? Assuming that the findings of this study confirm that stress-illness relationship found in many past studies, the second research question focuses on coping responses of those experiencing death of a significant other or property loss due to the volcanic 
eruption. Why do some persons who encounter sudden death bereavement or property loss following a natural disaster cope in ways that allow them to remain healthy while others become sick?

As a result of the volcanic eruption of Mt. St. Helens, five groups exist which are of interest in this research and comprise the five levels of the independent variable under study. The occurrence of the Mt. St. Helens disaster produced the differential conditions of presumed death bereavement, confirmed death bereavement, loss of residence, either permanent or recreational, and no adverse outcomes among members of the cohort being examined. The differential effects of these five levels of the independent variable were assessed using two sets of outcome variables: 1) the intermediate outcomes of the impact of negative life events and daily annoyances (hassles) and 2) the major personal outcomes of physical and mental health. Finally, the role of two intervening variables, self-efficacy and social supports, in mediating the effects of stress on health were examined.

The first research question examining the relationship of sudden death bereavement or property loss with illness was addressed using a five-group post-test only design. This post-test design was selected since the eventleading to sudden death or property loss (the volcanic eruption) had already occurred. Five groups of subjects were compared: 
bereaved as a result of presumed disaster death, bereaved as a result of confirmed disaster death, disaster subjects experiencing the loss of a permanent residence, disaster subjects experiencing the loss of recreational property, and a group of non-bereaved, non-property-loss subjects. Underlying the use of this design is the assumption that prior to the stressful life event there were no significant differences among the five groups being examined. Following the disastrous event, then the five groups of subjects are expected to differ on two sets of outcome variables: 1) the perceived negative impacts of major life events and daily annoyances or irritations, and 2) physical and mental health. Henceforth, the perceived negative impact of major life events will be referred to as negative life events and daily annoyances will be referred to as hassles. For this study, directional predictions were made only for four groups: the two bereaved groups, the permanent property loss group, and the control group. No directional predictions were made for the recreational property loss group since they were added to the design after the onset of the study. Therefore, as a consequence of the volcanic eruption, it is expected that the four groups differ in the following ways:

The bereaved of the presumed dead are expected to report the greatest impact of negative life events and the lowest levels of physical and mental health compared to each of the 
other three groups. In addition to experiencing the sudden death of one or more family members or friends, many individuals in this presumed bereaved group were required to present court testimony that the victims had been in the designated area at the time of the disaster, did not return, and thus are now presumed dead. Such court testimony, filing for claims and benefits, and filling out forms are hassles that are expected to contribute to the stress experienced by this group of bereaved persons. Thus, this presumed bereaved group is predicted to report more hassles than the confirmed bereaved and control groups, but not more than the permanent property loss group since this latter group is known to have experienced similar legal hassles.

The bereaved of confirmed dead are expected to report a greater impact of negative life events and lower levels of physical and mental health than the property loss and control groups. The confirmed bereaved group are also expected to report more hassles than the control group. No directional differences were made between the confirmed bereaved and permanent property loss groups on hassles. It is not thought that the confirmed bereaved group will be as adversely affected in coping with their bereavement as those experiencing the presumptive death of a significant other for two reasons. First, even though the sudden death of a significant other is reported to be extremely stressful, early 
confirmation of the death allows family members and close friends to gain a sense of closure. Second, closure or verification of death allows immediate legal processing of the death certificate, and insurance and property claims. Consequently, minor stress should be lower.

Persons in the permanent-resident property loss group are predicted to report a lower impact of negative life events and higher levels of physical and mental health than either of the bereaved groups, but not to differ from these bereaved groups on the hassles measure. It is also expected that the permanent property loss group will report a greater impact of negative life events and lower levels of health than the non-bereaved, non-property loss control group. The permanent-residence property loss group are expected to report persistence and irritation with such minor hassles as concerns about obtaining money or credit for repairs, not enough money for other necessities, being exploited, making decisions, filling out forms, etc.

Finally, the non-bereaved, non-property loss control group are expected to report fewer negative life events and lower impact ratings of these events, fewer hassles, and higher levels of physical and mental health when scores on these measures are compared to the other three groups. Since the control group is thought not to have experienced any direct adverse effects of the volcanic eruption, they 
are expected to score lower on measures of the two sets of outcome variables when compared to the other three groups. These predictions were used in formulating six specific hypotheses to be tested for the first research question. Hypothesis 1:

The bereaved of presumed dead will report a greater impact of negative life events and hassles and lower levels of health than the bereaved of confirmed dead.

Hypothesis 2:

The bereaved of presumed dead will report a greater impact of negative life events and hassles and lower levels of health than the permanent property loss group. (No differences were hypothesized for hassles).

Hypothesis 3

The bereaved of presumed dead will report a greater impact of negative life events and hassles and lower levels of health than the control group.

Hypothesis 4

The bereaved of confirmed dead will report a greater impact of negative life events and lower levels of health than the permanent property loss group. (No differences were hypothesized for hassles). 
Hypothesis 5:

The bereaved of confirmed dead will report a greater impact of negative life events and hassles and lower levels of health than the control group. Hypothesis 6:

The permanent-property loss group will report a greater impact of negative life events and hassles and lower levels of health than the control group.

The second research question focuses on the coping responses of those experiencing death of a significant other or property loss due to the volcanic eruption. Specifically, the roles of two intervening variables, selfefficacy and social supports, in buffering the negative effects of stress on health will be assessed.

Two hypotheses were formulated regarding this second research question.

Hypothesis 1:

It is hypothesized that among those who experience a loss due to the volcanic eruption, higher levels of perceived negative stress and hassles will be related to lower levels of health. While numerous past recent studies have reported a causal relationship between high levels of stress and low levels of health, care has not always been taken to conceptualize perceived negative stress as being different from total perceived change. Further, instruments used in 
past studies have not been designed so that subjects could rate the extent of the positive or negative impact of an event. Thus, in this study, it seems important to assess the extent to which various life events are perceived as having a negative impact.

\section{Hypothesis 2:}

It is hypothesized that self-efficacy and social supports serve to mediate the negative effects of high levels of stress on health. It is predicted that this mediating function will be reflected in a positive relationship between the criterion of health and the predictors of selfefficacy and social supports after the effects of stress have been statistically controlled.

The third research question is an exploratory one and regards the perceived effects of the news media on coping with negative life events. It is not yet known whether the reporting of the disaster, particularly on national television, was perceived as a form of symbolic support or an invation of privacy. No directional hypotheses were proposed for the third research question.

In summary, the existing evidence presented in the literature review suggests that a significant number of bereaved individuals, experience one or more physiological, psychological, or behavioral deficit during the first two years of bereavement. While the bereaved are also reported to experience higher mortality rates than their non-bereaved 
cohorts, these findings have recently been questioned (Stroebe et al., 1979). In cases of sudden death, both morbidity and mortality rates could be higher because the bereaved in such cases do not experience an advance warning of the death, which has been shown to facilitate coping in some cases. Thus, evidence suggests that persons bereaved as a result of sudden death could be a high risk health population. Community authorities in potential disaster areas attempt to predict storms and earthquakes in order to prepare for evacuation prior to the event and promote restoration of services following the event. Likewise, community mental health professions could better serve the needs of their communities if they could offer specific information prior to disaster, identify high risk populations in their communities, and provide treatment following disasters. Thus, the hypotheses tested provide findings pertinent to health policies and procedures in the event of a community disaster.

\section{Subjects}

Subjects for this study included 155 respondents. Data were collected from five groups of subjects: 1) bereaved of presumed dead, $n=39 ; 2)$ bereaved of confirmed dead, $n=30$; 3) persons experiencing disaster-caused property loss of permanent residence, $n=21$; 4), persons experiencing disastercaused property loss of vacation or leisure residence $n=15$; 
and 5) persons experiencing no disaster-related loss, $n=50$. This latter group is considered the control group for the current study. The potential numbers of subjects, the numbers of persons invited to participate, and actual participation rates by group are presented in Table 1.

TABLE I

DIFFERENTIAL RESPONSE RATES OF THE STUDY SAMPLE

\begin{tabular}{lccccc} 
Group & $\begin{array}{c}\text { Potential } \\
\text { Number } \\
\text { Participants }\end{array}$ & $\begin{array}{c}\text { Persons } \\
\text { Contacted }\end{array}$ & $\begin{array}{c}\text { Actual } \\
\text { Participa- } \\
\text { tion }\end{array}$ & $\begin{array}{c}\% \\
\text { of } \\
\text { Poten- } \\
\text { tial }\end{array}$ & $\begin{array}{c}\% \\
\text { of } \\
\text { those } \\
\text { Contacted }\end{array}$ \\
\hline $\begin{array}{l}\text { Presumed Dead } \\
\text { Bereaved }\end{array}$ & 62 & 45 & 39 & $63 \%$ & $87 \%$ \\
$\begin{array}{l}\text { Confirmed Dead } \\
\text { Bereaved }\end{array}$ & 40 & 36 & 30 & $75 \%$ & $83 \%$ \\
$\begin{array}{l}\text { Property Loss } \\
\text { (Permanent Resi- } \\
\text { dence) }\end{array}$ & a & 39 & 21 & -- & $54 \%$ \\
$\begin{array}{l}\text { Property Loss } \\
\text { (Leisure Residence) }\end{array}$ & a & 26 & 15 & -- & $58 \%$ \\
$\begin{array}{l}\text { Control Subjects } \\
\text { Total }\end{array}$ & a & $\underline{73}$ & $\underline{50}$ & $\underline{--}$ & $\underline{68 \%}$ \\
\hline
\end{tabular}

a Data Unavallable 
Results from this study are expected to be generalized to other disasters occurring with little or no forewarning and having similar consequences (death, property loss). While disasters are said to affect entire local communities, they can also have widespread effects. These broad effects are due, in part, to the geographical spread of the residences of family members and friends of disaster victims. Even though the volcano erupted in a remote mountainous area, 65.6\% of the study respondents reside in urban areas with populations 10,000 or over. An additional 68 live in suburban areas adjacent to U.S. cities of 100,000 or over. . . Figure 2 is a description of city size based on 1980 census data for the locations of the residences of the study subjects. These cities are located in 10 states. Census data on two Canadian cities where two respondents reside were not available.

\section{The Bereaved Samples}

The disaster bereaved subjects comprise two of the groups examined: 1) bereaved of the presumed dead, and 2) bereaved of the confirmed dead. For the purposes of this study, presumptive death was operationally defined as after seven days following the volcanic eruption. Some presumed dead persons were confirmed dead in the months that followed the disaster, but for study purposes of conceptualizing the effects of sudden known death, the bereaved study subjects in the presumed 


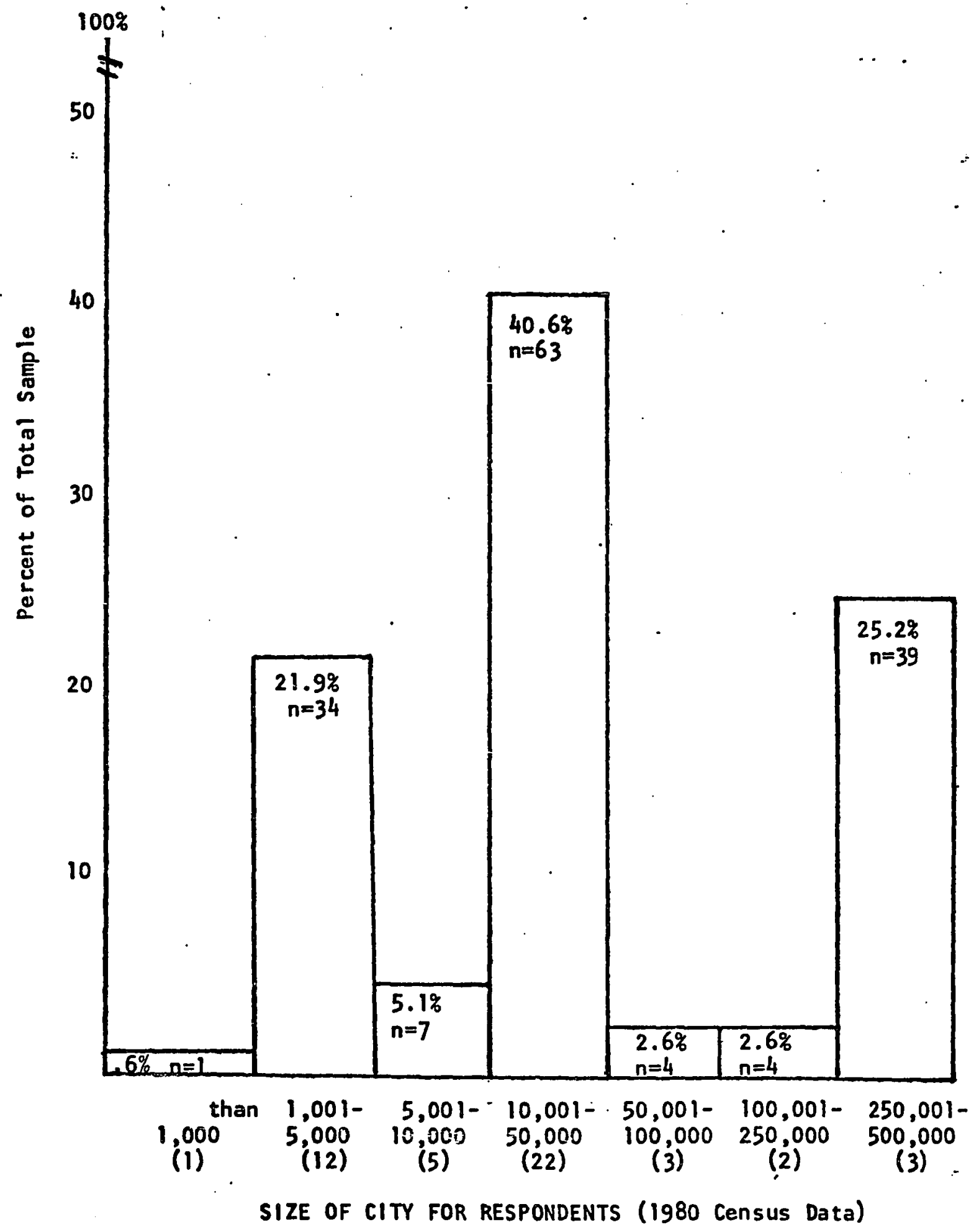

(Number of cities per population category in parentheses)

Figure 2. Percent of Study Sampic Represented

by City Size of Respondents' Residences 
group were not transferred to the confirmed group as bodies were found and the actual number of dead changed. Thus, the figures given here are not the same as the presumed and confirmed dead reported by authorities and the media. Further, there were additional missing persons not declared presumed dead. No attempt was made to contact bereaved family and friends of these missing persons. Confirmed death was defined as identification of victim's bodies up to seven days following the volcanic eruption.

In order to obtain the names of potential study subjects for the bereaved samples, several approaches were used. First, a list of persons who testified at court hearings to validate presumptive death of the volcano victims was obtained from the Skamania County (Washington) coroner's office. This list provided names, addresses, telephone numbers, and in some cases, the relationship of the testifying person to the deceased victim. This list was difficult to work from because some persons testifying were from other states and in some cases the telephone number on the list was a temporary, local one. Reaching these persons at their permanent residence to which they had returned was not always possible. In three additional cases, persons on this list were no longer at local permanent addresses. In other cases, repeated attempts to reach persons by telephone were unsuccessful. Letters addressed to these potential subjects were sometimes opened by attorneys and other family members who were acting as 
executors of estates and were neither forwarded to potential subjects nor answered by those who intercepted these letters. Thus, the sample of bereaved of presumed dead persons was small because sometimes it was impossible to find anyone associated with the deceased volcano victim.

The second approach used to find potential subjects was to obtain death certificates for the confirmed dead victims. Due to the disaster, this was a complex process. Some death certificates could not be obtained. Others were unavailable until eight months following the disaster. Names, addresses, and telephone numbers of the nearest relatives and employers of the victims were obtained from available death certificates. These persons were then contacted. The third approach used to put together a potential sample list was to go through social networks. Since some of the victims lived in the local area, it was sometimes possible to learn of an organization to which the deceased belonged. A member of the organization was contacted who then provided another contact person. In other cases, names of initimate friends were obtained from family members and colleagues of deceased victims.

The final approach was to contact a local newspaper reporter who wrote a special story on the disaster that was published in October of 1980 . This reporter had interviewed some of the bereaved family and friends for the story and was willing to share a few names the investigator had been 
unable to obtain.

The two bereaved samples contacted included spouses, parents, adult children, brothers, sisters, intimate friends, and colleagues of all except three of the 51 adult disaster victims (31 presumed dead and 20 confirmed dead). Demographic data for these two samples are presented in Table II. Of the 51 adult disaster victims, 41 (80\%) are represented in this study by at least one bereaved family member or friend.

Bereaved sample subjects included two bereaved persons per deceased person whenever possible and were selected as follows: 1) First, the bereaved spouse was asked to participate if the victim was married at the time of death. If the victim was not married at the time of death, either a parent or adult child was selected. If neither were available, or willing to participate, a brother or sister was selected. If none of the three participated, this was considered missing data. 2) The second bereaved subject for each victim was the closest friend or colleague willing to participate. For ethical reasons, no bereaved relatives or friends under 18 years of age were contacted. A further restriction was that no two bereaved individuals from the same household were sampled.

The presumed dead, most of whom have still not been accounted for, number 31. Thus, there were 62 potential subjects for the bereaved presumed group. Of these 62 
taber $\|$

DenocerpHIC aATA fOR THE FIVE SAYPLES

\begin{tabular}{|c|c|c|c|c|c|c|}
\hline vertable & $\begin{array}{l}\text { Croup I } \\
\text { Presumed deas } \\
\text { (ereaved } \\
\text { (om-39) }\end{array}$ & $\begin{array}{l}\text { Growp } 2 \\
\text { conflirmed deed } \\
\text { oereoved } \\
(n-30)\end{array}$ & $\begin{array}{l}\text { Group } 3 \\
\text { Permonent Residence } \\
\text { (n-21) }\end{array}$ & $\begin{array}{c}\text { Croup } \\
\text { Leisure testo } \\
(n-15)\end{array}$ & dence & $\begin{array}{l}\text { Group } 5 \\
\text { Control } \\
\text { sebjeess } \\
(n-50)\end{array}$ \\
\hline \multicolumn{7}{|l|}{$\sec x$} \\
\hline Fenile & $\begin{array}{l}27(69.2) \\
12(30.8)\end{array}$ & $\begin{array}{l}21(70) \\
9(30)\end{array}$ & $\begin{array}{ll}10 & (47.3) \\
11 & (52.4)\end{array}$ & $\begin{array}{l}(40) \\
g(60)\end{array}$ & & $34(68)$ \\
\hline $\begin{array}{l}\text { Pean age in Years } \\
\text { lge Ranges by Age }\end{array}$ & $\begin{array}{l}38.4 \\
18.67\end{array}$ & 37.7 & 40.5 & $\begin{array}{l}54.1 \\
33-68\end{array}$ & & $\begin{array}{l}38.9 \\
19-69\end{array}$ \\
\hline \multicolumn{7}{|l|}{ Cecupation } \\
\hline $\begin{array}{l}\text { Retired } \\
\text { tot Employed } \\
\text { Self-Employed } \\
\text { Skllifed } \\
\text { Professional } \\
\text { Student }\end{array}$ & 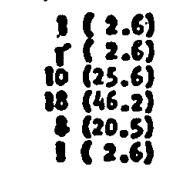 & $\begin{array}{l}3(10) \\
(3.3) \\
6(20) \\
11(36.7) \\
8(26.7) \\
1(3.3)\end{array}$ & $\begin{array}{c}\infty \\
5(23.8) \\
5(57.1) \\
12(19.0) \\
-\infty\end{array}$ & $\begin{array}{l}3(20) \\
1(6.7) \\
(26.7) \\
5(46.7)\end{array}$ & $\cdot$ & $\begin{array}{l}2(40) \\
2(8.0) \\
18(36) \\
24(48) \\
2(4.0)\end{array}$ \\
\hline
\end{tabular}

cducation

Completed Grade School
Atrended High School
Completed High School
Attended College
Completed College
Adronced Degree

$\begin{array}{ll}3(7.7) & 3(10) \\ 3(43.6) & 7(23.3) \\ 7(17.9) & 9(30) \\ 8(15.4) & 6(20) \\ 6(15.4) & 4(13.3)\end{array}$
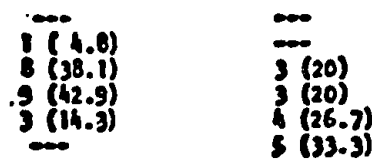

Coletionship to Decesed

- Non

wother

con

Bughter

Intimote frien.

Cól league

Brother or sister

Oever

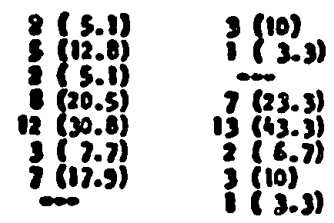

8

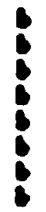

8

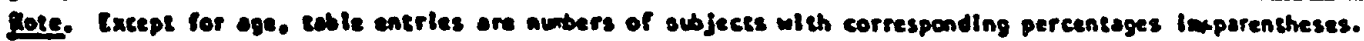

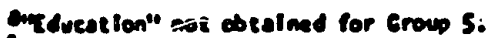

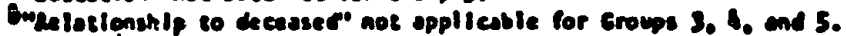


persons, 45 were contacted and 39 participated in the study. The confirmed adult dead whose bodies were found within 7 days after the disaster number 20. Thus, there were 40 potential subjects for this group. Of these 40 persons, 36 were contacted and 30 participated in the study.

For both the presumed and confirmed groups, one family member and one friend per victim were selected for two reasons. First, no studies could be found that assessed both friend and relative bereavement coping responses. Second, Sanders (1979-80) discusses the difficulty of obtaining adequate sample sizes of bereavement studies. Refusal rates among bereaved individuals may run as high as 50 percent.

Since the number of potential subjects for the current study can be regarded as small, sample size was a critical concern. The choice of two bereaved subjects per deceased victim improved the possibility of obtaining an adequate sample size for statistical analyses. Further, due to the fact that 12 husband/wife or intimate friend pairs died together, it was expected that it would be difficult to obtain both a relative and friend for each deceased person. The potential problem of the lack of statistical independence between the two bereaved subjects for a given victim is addressed later in this chapter. 


\section{Initial Sampling of the Bereaved Groups}

Master lists were compiled regarding potential study subjects by using information that was obtained from death certificates, social networks, and other sources described above. Since not all of the names on the master list were the closest relative and friend, these persons were contacted to obtain the name of the closest relative. For example, if a father-in-law testified at the presumptive death hearing, he was contacted to obtain the widow's name and address. Finally, the closest known bereaved relative and friend were invited to participate in the study. The data collection procedure is described later in this chapter.

Replacement Sampling of the Bereaved

Subjects in the two bereaved groups who did not respond to the initial invitation to participate in the study received one follow-up request. In cases where telephone numbers were available, subjects were called either by a community health nurse in their respective community or by the investigator. Subjects who could not be contacted by telephone were sent a follow-up letter. Due to the sensitive nature of the bereavement, no further attempts were made to encourage subjects to participate. In cases of refusal, subjects were replaced by contacting the next closest relative or intimate friend in order to maximize sample size. These were sometimes given by the referring pexson. In other 
cases, a friend or work associate provided the name of the next closest relative. Since the replacement subjects may not have occupied as central a relationship with the deceased as the initial subject sampled, every effort was made to contact the most significant person possible. Replacement of subjects in cases of refusal of those initially sampled occurred in only seven cases.

\section{The Property Loss Samples}

The third group of subjects consists of 21 persons who experienced the loss of a permanent residence due to the volcano disaster. These residences were located in the Cowlitz and Toutle River flood areas in southeastern Washington. Many of these subjects have relocated on or near their former property. Potential subjects' names were obtained by random selection from local telephone listings. These 21 persons represent 548 of the 39 persons contacted who had permanent property loss. Replacement sampling for the permanent-property loss groups followed the initial sampling procedure of randomly selecting additional subjects. However, obtaining this sample was more difficult than anticipated. The data collection deadine arrived before 50 subjects had returned their questionnaires.

The fourth group of subjects included 15 persons and represents 588 of 26 persons who were randomiy selected from a recreational homeowners association list and contacted 
regarding this study. These subjects had recreational homes on the north side of Mt. St. Helens. This area was totally devastated by the volcanic eruption.

Demographic data for the property loss groups are reported in Table II.

\section{The Control Sample}

The fifth group of study subjects were 50 persons who served as comparison subjects with the four groups of loss subjects. They were matched proportionately by geographic location, age, sex, and occupation with the combined four loss group subjects. Names of potential control subjects were obtained by asking subjects in the four loss groups to identify persons who might serve as their controls. A letter sent to the loss subjects suggested that participants choose a neighbor who did not suffer a volcanic loss. A master list was compiled for all potential control subjects.

During the data collection process, it became apparent that not all of the study subjects would submit names of potential control subjects. Further, of these potential controls who met study criteria, some did not wish to participate in the study. Additional control subjects were obtained by the investigator by finding comparison subjects in the population who met study criteria and who could be matched on the demographic variables selected. For example, if a subject in one of the bereaved groups was a photographer for a 
newspaper and did not submit the name of a potential control, the investigator noted the age and sex and contacted a newspaper whose daily circulation was approximately the same size as the loss subjects' newspaper. Similarity in circulation presumably would account for similar conditions of work.

Refusal to participate by control group subjects was compensated for by contacting additional persons who met study criteria as discussed earlier. Thus, a quota sample of 50 subjects was attained. Demographic data for the control group subjects are presented in Table II.

\section{Protection of Human Subjects}

Protection of human subjects for the current study involved the following considerations: providing sufficient information to potential subjects so they could make informed decisions regarding their participation, assuring confidentiality of information shared by subjects, and attending to subjects' rights to privacy.

A letter to each potential subject explained the nature and purpose of the study and assured subjects that their responses to mailed quesionnaires would be confidential. Written informed consent (Appendix B-9) was obtained from subjects prior to participation. Thus, special care was taken to keep participation risks at minimal levels. 


\section{Study Instruments}

The subjects' physical and mental health status, report of major and minor life stresses, and coping patterns were assessed through the following instruments: The Hopkins Symptom Checklist (HSCL-90), the Life Experience Survey (LES), the Hassles Scale (HS), the Self-Efficacy Scale, the Coppel Index of Social support (CISS), and additional items written for the present study by the author to measure physical health, perception of the media, and other items not included in the battery of questionnaires.

\section{Measures of Mental and Physical Health}

The Hopkins Symptom Checklist

The Hopkins Symptom Checklist-90 (HSCL-90) was used in this study to assess the mental health of the subjects. The HSCL-90 is a self-report symptom rating scale which has undergone several major revisions and numerous minor alterations. At the present time, four. forms of the HSCl are available for clinical use. They are the HSCL-58, the HSCL-35, the HSCL-72, and the HSCL-90. The numerical values denote the number of items on each form. The major psychometric development of the HSCL has focused on the 58-item version and has been reviewed extensively by its senior author in two publications (see Derogatis et al. 1974 a, b, for a detailed description). The HSCL-90 was selected for 
use in the current study because of its wide range of $s$ dimensions.

The HSCL-90 is comprised of 90 items, each measured on a five-point scale of distress from "not at all" to "extremely." (See Appendix B-1). Current psychopathology is reflected in terms of eight primary symptom dimensions and three global indices of distress. The eight symptom dimensions are: Somatization (SCM), Obsessive-Compulsive (O-C), Interpersonal Sensitivity (INT), Retarded Depression (RET DEP), Hostility (HOS), Phobic Anxiety (PHOB), Agitated Depression (AGIT DEP), and Psychoticism (PSY).

While the HSCL-90 has not had as much research as the HSCL-58, it is viewed by the investigators as a "significant developmental milestone" (Lipman, 1979, p. 23). The normative samples for the data reported here are based on 1500 subjects from three samples. Two of the samples were psy-. chiatric outpatients experiencing symptoms of depression and anxiety. The other sample was part of a general health survey in a large Western city. The symptom constructs underlying the HSCL have been determined through two distinct but coincident methods: clinical-rationale clustering and empirical-analytic factor analysis.

The clinical-rationale clustering procedure has been demonstrated to be sensitive to change in emotional status among both psychiatric and non-psychiatric samples. Results of two studies reported by Rickels, Lipman, Garcia, and 
Fisher (1972) indicate the HSCL primary symptom dimensions can rank-order patient groups in the same manner as expert clinicians. Thus, evidence of construct validity has been consistently demonstrated by both Derogatis et al. (1974) and other investigators.

A factor analysis of the 90 item version revealed that the eight dimensions were uncorrelated and each contained at least five items with loadings above .40 and explained 50.28 of the total variance. Further, the eight factors were found to have coefficients alpha ranging from .77 to .86, thus indicating that the HSCL scales possess high levels of internal consistency (Lipman, Covi, Shapiro, 1979).

The HSCL-90 scales that have primary importance for this study are the Somatization and Depression Scales. Psychosomatic symptoms and varying levels of depression have been reported in the literature as health and behavioral changes that frequently follow major stressful life evenis. While the entire checklist was self-administered, two scales were scored for the purpose of the current study. They are: 1) the Depression Scale (13 items plus seven non-scaled measures of depression recommended for inclusion in this scale in the HSCL manual), 2) the Somatization Scale (12 items). (See Appendix B-1 for scoring information). According to Derogatis (1974), somatization is defined as "the tendency to react to stress or tension of psychological origins through physical bodily symptoms" (p. 60). 
Complaints tend to be focused on cardiovascular, gastrointestinal, respiratory, skin, and other systems with strong autonomic mediation and a lack of clear organic basis for the complaint. Depression is defined here as "a primary disturbance of mood characterized by sad and dysphoric affect, loss of interest and motivation, negative ideations of pessimism, guilt, and self-deprecation, problems with concentration, and somatic symptoms such as loss of appetite" (p. 60)

\section{Items of Physical Health}

Nine items specific to perceived physical health status were written and pretested by the author for inclusion in the study. (See Appendix B-2 for a list of these items). These items include: 1) change in perceived health status over two recent time periods, the past six months, and seven months to one year ago, 2) items assessing acute illness that require persons to visit a doctor or be admitted to a hospital, and 3) items indicating presence of and worsening of a chronic health condition. Using traditional item analysis procedures, a composite index measuring physical health was constructed. Five of the nine items were found to be adequately intercorrelated and were converted to $\mathrm{Z}$ scores and then averaged to form an index of health. Coefficient alpha for this measure was .69 .

This new health index was constructed due to difficulties 
with existing measures. The current stress literature now documents that physical illnesses do indeed follow stressful events (Dean \& Iin, 1977; Rahe \& Lind, 1971), but measuring illness has been a problem.

\section{Measures of Stress}

\section{Iife Experiences Survey (IES)}

The Life Experiences Survey (LES) used in this study provides three measures of stress (positive change, negative change, and total change) experienced by the subjects. Only the negative change scores were used in the analyses. This is because undesirable events may have a more detrimental effect on individuals (Brown et al., 1975; Sarason et al., 1978). The LES (Sarason et al., 1978) is a 47-item selfreport measure which asks respondents to indicate events they have experienced in the past year and to rate the impact of each event on their lives (no effect, some effect, moderate effect, or great effect). Respondents were instructed to designate LES events they experienced as either "good", which yielded a positive change score, or "bad", which produced a negative change score. The total change score is the sum of positive and negative change scores. Both negative and total change scores were calculated. The IES provided respondents with three blank spaces to indicate and rate additional events they may have experiences that were not listed among the 47 items that make up the LES. The LES 
items represent life changes frequently experienced by individuals in the general population $(e=g=$, death of a spouse, divorce, personal injury). Many of these items were based on the Schedule of Recent Experiences (Holmes:\&. Rahe,'1967). For further detailes concerning the LES and its development, see Sarason et al, (1978). For the purposes of this study, the LES.items were conceptualized as negative life stress, in contrast to daily annoying or irritating events which occur in a person's life (e.g., "death of a spouse" versus "having to wait in line"). The LES can be found in Appendix B-3.

Normative data for the LES were gathered by Sarason and his colleagues on a sample of 345 undergraduate students. No significant differences between males and females were found on any of the three change scores. The authors also report that positive and negative change scores are uncorrelated and reliable using test-retest procedures over a sixweek interval on two additional samples.

The Hassles Scale (HS)

Measurement of subjects' level of daily annoyances was obtained through the use of the Hassles Scale (Lazarus \& Cohen, 1977l. The HS consists of 117 items which describe ways in which a person may feel hassled (e.g., misplacing or losing things, troublesome neighbors, shopping, filling out forms, or worrying about health or one's employment). Respondents indicate which of the 117 hassles are important in 
their lives currently and over the past year. Each of these selected hassles was rated for persistence (1-somewhat, 2moderate, 3-extreme) for each. (See Appendix B-4 for a copy of the HS). Respondents' levels of .. annoyances. were evaluated based on a single total score which was obtained by a summed total of all individual item persistence $\mathrm{x}$ irritability ratings. This suggestion for scoring was one obtained from Coppel (1980), who is currently conducting research with the HS. the Hassles project report by Lazarus and Cohen (1977) does not provide specific scoring instructions . or have figures on reliability and validity been reported.

\section{Measures of Intra-Personal and Social Supports}

\section{Self-Efficacy Scale}

The Self-Efficacy Scale was developed by Coppel (1980) based on the conceptualization of self-efficacy put forth by Bandura (1977). Self-efficacy is seen as the expectation that one can execute the beiravior required to produce an outcome. Respondents in Coppel's study (1980) were asked to rate each of the 22 self-descriptive statements on a 5-point scale ranging from "Not at all like me" to "Very much like me" (See Appendix B-5i . Validity and reliability measures for the Coppel study were obtained by testing a group of undergraduate students $(n=166)$. The Self-Efficacy Scale demonstrated excellent internal consistency (coefficient alpha 0.91). In addition, a test-retest reliability coefficient 
of $r=0.86$ was obtained over a two-week interval $(n=90)$. It was conceived that self-efficacy and self-esteeem woula be strongly related and data coliected revealed these two scales to have correlation coefficients ranging from $r=0.68$ to $r=0.73$. A principal components factor analysis of the Self-Efficacy Scale yielded four factors accounting for $56 \%$ of the total variance. Factor 1 consisted of statements dealing with positive coping, pride, and positive learning expectations. Factor II was made up of four statements reflecting one's expectations in interpersonal situations. Factor III was made up of five statements which deal with one's feelings of influence, or contribution, to one's life. Factor IV had four statements which reflect negative selfthoughts and lack of self-assuredness (Coppel, 1980). For this study, self-efficacy was thought to operate as an "interpersonal support", and that these expectations of personal mastery affect both initiation and persistence of coping. behavior (Bandura, 1977).

\section{Coppel Index of Social support (CISS)}

Social support was measured using Coppel's Index of Social support which results in three measures: size of network, contact with network, and quality of social supports. The size of network measure is based on how many confidants, friends, family, and social groups respondents are currently involved with. The contact with network measure indicates 
how many times, in an average week, respondents have contact with these people: As suggested by Coppel, one score was computed to determine the size of network (number of friends, family, etc.) and another score to represent the average weekly contact with these four network components. For subjects in his study, coefficient alpha was 0.54 for the size of network scale and 0.41 for the contact with network scale. Coppel's scale measuring quality of social support was based on conceptualizations of social support reported by Caplan (1974) and Cobb (1976). In the Coppel study (1980), study participants rated each of 15 self-descriptive statements related to their social supports $(\mathrm{e} . \mathrm{g}$. , "I feel people have been there when I've needed them; There are peopid in my life who have the same or similar problems as $I$ do and with whom I can discuss things; I have a group (or groups) in which I feel I belong") on a five-point scale ranging from "Not at all like me" to "Very much like me" (See Appendix $B-6)$. An original pool of 40 statements was developed and, based on a pilot study with 170 undergraduate students, Coppel constructed the 15-item scale. This social support scale demonstrated excellent internal consistency (coefficient alpha $=0.89$ ) and a test-retest reliability coefficient of $x=0.82$ over a two-week interval $n=90$ ). A principal components factor analysis of the scale revealed four factors, accounting for $63.17 \%$ of the total variance. Factor I contained six statements relating to support being 
reliable, personal, communicative, and helpful in handling stress. Factor II was made up of four statements and reflected the existence of role models and advisors. Factor III consisted of three statements dealing with having feelings of safety, confidence and belongingness. Factor IV contained two statements relating to others having similar problems and family and friends being a positive influence on one's moods. In a study with University of Washington undergraduates $(n=170)$ this perceived social support scale was found to be uncorrelated with self-esteem ( $r=0.14$, ns) and only minimally correlated to the perviously described self-efficacy scale $(r=0.22, p<0.01)$ (Coppel, 1980). Several recent articles have discussed the methodological shortcomings in studies examining life stress and social support and their purported causal relationship to decline in health (Henderson, 1980, Lin et al., 1979, Rabkin \& Struening, 1976). A major problem cited is the lack of established reliability and validity measures on instruments. The Coppel measure is new and has not been cited as problematic. Hence, care has been taken in the present study to incorporate instruments that have been carefully developed and tested for stress-related research.

Media

Subjects' perceptions of whether the news media was supportive or invasive regarding their loss due to the 
volcanic eruption was assessed using 12 items which are listed in Appendix B-7. Eleven of the 12 items were adequately intercorrelated to form a scale. Items were converted to $z$ scores and averaged to form one measure. Coefficient alpha for the media scale was 0.87 .

\section{Other Items}

Change in financial status, particularly loss of income, has been shown to contribute to the major stress associated with bereavement (Barrett, 1978). Yet, current available instruments do not ask respondents to rate adequacy of new financial status and how satisfied respondents are with their progress in settling financial matters. Three items address this issue.

Several items refer to recovery from material or personal loss. Such items could not be found in any standardized instruments. Closely associated with these items are nine demographic and interpersonal items which include identification and quality of the relationship with the deceased victim prior to death, as well as subjects' perception of preventability.

\section{Measurement by Self-Report}

The self-administered, self-report mode of psychological measurement possesses several unique characteristics to recommend it. Self-report scales possess the singular 
advantage of reflecting information via the person directly experiencing the phenomena, i.e., the subject inimseif or herself. All other observers are limited to reporting apparent versions of the patient's experience, based on his behavior and verbal response.

Self-report was relied upon here because many subjects live far away, making personal contact with the investigator impossible. Instruments selected for the current study can be self-administered and are measures of self-report (personal perceptions). An exception was the structured, openended interview instrument parallel to areas assessed with closed-ended instruments (See Appendix B-8).

A summary of measures employed in the analysis can be found in Table III. As can be noted, measures used for this study were a combination of standardized, multi-item questionnaires and scales designed for the unique aspects of this study.

Questionnaire, scores and individual items scores provided a total of 59 variables. Since the total number of subjects is 155, some items were combined to form scales. The major objective of building scales from study items was to reduce the number of variables for the statistical analyses. For the purpose of this study, five scales were constructed: Media, 11 items; Current Health Status, 5 items; Number of Social Contacts, 4 items; and Size of Social Network, 4 items. Items used to form scales are so indicated in their 
TABLE III

SUMARY OF MAJOR INSTRUMENTS \& MEASURES EMPLOYED IN DATA ANALYSES

\begin{tabular}{|c|c|c|}
\hline$\frac{\text { Intermedlate Outcome }}{\text { Variables }}$ & Measures & Possible Range \\
\hline $\begin{array}{l}\text { - Negative Life Events } \\
\text { - Daily annoyances }\end{array}$ & $\begin{array}{l}\text { Hegative LES score } \\
\text { Hassle Scale Score }\end{array}$ & $\begin{array}{l}0 \text { to } 50 \\
0 \text { to } 1053\end{array}$ \\
\hline \multicolumn{3}{|l|}{ Later Outcome Variables } \\
\hline - Physical Health & $\begin{array}{c}\text { Five-Item Heal th Seale } \\
\text { constructed for this } \\
\text { study }\end{array}$ & $\begin{array}{c}-3.00 \text { to }+3.00 \text { (approx.) } \\
\text { (average of standardized } \\
\text { I tems) }\end{array}$ \\
\hline - Mental Heal th & $\begin{array}{l}\text { Depression E Somatiza- } \\
\text { tlon Scales from HSCL-90 }\end{array}$ & 0 to $\$ .00$ \\
\hline \multicolumn{3}{|l|}{ Intervening Variables } \\
\hline - Self-Efficacy & Self-Efficacy Scale & 22 to 110 \\
\hline - Soclal Support & $\begin{array}{l}\text { Scores from Coppel Index: } \\
\text { SIze of Network } \\
\text { Contact with Network } \\
\text { SS Total (Quallty of } \\
\text { Support) }\end{array}$ & $\begin{array}{l}0 \text { to } 38 \\
0 \text { to } 10 \\
15 \text { to } 75\end{array}$ \\
\hline - Symbolic Support & $\begin{array}{c}\text { II-l tem hedia seale } \\
\text { constructed for this } \\
\text { study }\end{array}$ & $\begin{array}{c}-3.00 \text { to }+3.00 \text { (approx.) } \\
\text { (average of } 5 \text { tandardized } \\
\text { (tems) }\end{array}$ \\
\hline
\end{tabular}


respective appendices.

In order to construct scales, items were subjected to Pearson product moment correlations and factor analysis using the principal components method and Varimax rotation, computation of coefficient alpha as indices of internal consistency. Examination of factor analyses, inter-item correlations, and measures of internal consistency demonstrate that the scales were adequate for the purposes of this research.

\section{Procedure}

The procedure for data collection involved four major steps.

1. A letter was sent to the prospective subjects in each of the loss groups. The original identification of the potential subjects is described in the earlier subjects section. The letter described the study, summarized confidentiality and privacy to be provided, and requested the prospective subjects to sign and return the informed consent to the investigator.

2. When consent was obtained, the battery of tests was mailed to the loss group subjects.

3. Control subjects were selected as described earlier in the subjects section. These individuals were mailed a letter describing the study and inviting their participation. Control subjects confirmed the fact that they had not 
sustained a loss due to the volcanic eruption. As informed consents were received by the investigator, the battery of questionnaires were mailed.

4. Interviews were conducted with 34 loss subjects. Widows, adult children, parents, sibling and friends of the deceased and persons sustaining property loss were included to represent a cross-section of the loss subjects. Both personal and telephone interviews focused on what could be learned for coping with bereavement and property loss in future disasters.

The interviews were conducted with 17 subjects either in their homes, offices, or over lunch and lasted about one and one-half hours. Telephone interviews were conducted with an additional 17 subjects and lasted approximately forty-five minutes (See Appendix B-8).

\section{Data Collection}

Data were collected primarily during April and May of 1981, approximately the eleventh and twelfth months following the volcanic eruption. The rationale for this decision was based on two factors. Consideration for the subjects is of utmost importance. During the earlier bereavement period, some subjects had to give court testimony for presumptive death certification for family victims. Also, during the first few months following the disaster, many subjects were requested to provide information about the deceased. 
The second factor determining data collection time is related to findings by Kobasa et al. (1373) that illness symptoms track total stress with about a six-month lag. Since a six-month lag coincided with the Thanksgiving, Hanukkah, and Christmas holidays, data collection was postponed until April, 1981. Data collection from bereaved subjects was completed prior to the anniversary date (May 18) with a few exceptions. Data collection for the control group lagged somewhat beyond the four loss groups.

\section{Randomization of Test Battery}

The battery of instruments were mailed to the five sample groups described earlier. The study instruments discussed above fall into three general groups: stress, support, and health. That is, the Life Experience survey and the Hassles Scale are measures of stress, self-efficacy and social supports are measures of support, eic. Thus, it was possible to randomize the order of instruments received by the subjects. The order of instruments placed in the envelope was rotated systematically so that equal proportions of each group received one of three orders of instruments. This randomization procedure was carried out across all of the sample groups. While direct control over the order in which the questionnaires are completed was impossible, this different ordering in the envelope should have decreased any effects due to responding to the instruments 
in a particular order. Data were not collected comparing randomization order with rate of return.

\section{Statistical Methods}

The statistical analysis of the data was done at the Portland State University Computer Center, using the program Statistical Trial Dackage for the Social Sciences (Nie, N., Hull, C., Jenkins, J., Steinbrenner, K. \& Bent, 1975).

\section{Independence of Linked Pairs}

Frequency distributions. Analysis of data for the dissertation began with frequency distributions on all of the study variables for the entire study sample as well as on the five study groups. Further, frequency distributions were obtained by combining the bereaved and property loss samples. Absolute and relative frequencies provided a description of the study sample in raw numbers and percentages. Measures of central tendency and dispersion of the variables were examined to determine the usefulness of a variable for higher level statistical analyses.

Pearson correlations. The Pearson product-moment correlation procedure was conducted among all of the major variables in the study. These correlations were obtained for the total sample, for each of the five groups separately and for the combined bereaved groups. Correlations were 
also computed among various sets of variables for scale construction purposes.

The independence of linked pairs of subjects for the bereaved groups. The choice of two bereaved subjects per deceased victim presented a potential complication in that observations may not be viewed as truly independent. In traditional matched observation designs (e.g., randomization block, paired t-tests), subjects are matched with the expectation that their scores will be correlated. Such correlations can be taken into account in statistical analyses and will actually increase the power of the statistical tests. However, the pairs of bereaved subjects in this study were not chosen for the traditional purposes of matching. Consequently, each pair of bereaved subjects is referred to as a "linked pair" rather than a "matched pair", based on the following rationale.

While the bereavement for a pair of subjects is clearly linked to the same deceased victim, the two bereaved subjects are assumed to have had different relationships with the deceased prior to death. Clearly, a wife-husband relationship is different from a mother-son relationship. Similarly, it was assumed that the coping responses and other measures obtained would usually not be similar with a given pair. Three factors thought to affect the bereavement process are age of both the deceased and bereaved, whether the relationship between the deceased and bereaved was 
central or peripheral, and whether the bereaved believe the death may have been preventable. It is expected that the paired subjects differ on these important factors. Finally, the relationship between the two members of the pair is not constant across pairs for this study. For example, one bereaved pair may include a 30 -year-old female spouse and a 35-year-old colleague, while another bereaved pair may include a 45-year-old intimate friend and a 30-year-old brother. Thus, the bereaved pairs cannot be considered matched observations in the traditional sense, but rather, they are linked pairs. For the current study, 28 linked pairs were obtained. In addition, 13 non-paired individuals participated.

Unless the assumption is correct that scores of linked persons on various intervening and outcome variables are unrelated, there still exists a potential statistical problem in analyses of these 28 linked pairs.

To check on this assumption of independence of observations, two statistical tests were carried out for all obtained measures using data from the linked pairs of bereaved subjects. First, a Pearson $r$ was computed to determine if there was a linear relationship between corresponding scores of linked pairs of bereaved subjects. Second, a random effects, one-way analysis of variance (ANOVA) was utilized to determine if there were sigrificant differences among the means of the 28 linked pairs on 26 study variables. 
(The one-way ANOVA had 28 levels of the linked-pairs variables with $n=2$ subjects per Ievel). Iarge aipha levels $(\alpha=0.10$ to 0.20$)$ were employed so that if some statistical dependence of observations existed due to the linked pairs, it could be detected.

The results of these correlationai and Aivova checks on the independence of the linked pairs generally resulted in Pearson $r$ and $F$ values with relatively large $p$ levels. Tables IV and V present a summary of these statistical tests for both the major and secondary variables used in this study. For the ten major variables, none of the ten Pearson $r$ values and none of the ten $F$ values were significant at $p \leq 0.05$; only two of the ten Pearson $r$ values and three of the ten $F$ values had $p$ levels $\leq 0.20$. For the 16 secondar, variables, only two Pearson $r$ values and one $F$ value were significant at $\mathrm{p} \leq 0.05$; only two of the 12 Pearson $r$ values and three of the $16 \mathrm{~F}$ values had $\mathrm{p}$ levels $\leq 0.20$. Thus, the linked pairs appeared to be unrelated. Data from both members of any pair were then used in further statistical analyses employed in this research.

Analysis of variance. One-way analysis of variance was conducted with all five groups of the study sample on all study variables and scales that were developed prior to data analysis. Planned comparisons between the means were used to test hypotheses related to the first research question. 


\section{TABLE IV}

RESULTS OF TESTS WITH MAJOR VARIABLES TO

DETERMINE INDEPENCENCE OF LINKED PAIRS

\begin{tabular}{|c|c|c|c|c|}
\hline \multirow[t]{2}{*}{ Lajor Variables } & \multicolumn{2}{|c|}{$\begin{array}{l}\text { Pearson Correlation } \\
\text { and } p \text { level } \\
\end{array}$} & \multicolumn{2}{|c|}{$\begin{array}{l}\text { F statistic } \\
\text { and p level }\end{array}$} \\
\hline & $\mathbf{r}$ & $\mathbf{p}$ & $\mathbf{F}$ & $\mathbf{p}$ \\
\hline LES negative change score & .11 & .29 & 1.20 & .32 \\
\hline Hassles & .03 & .44 & 2.03 & .46 \\
\hline ESCL-90 Depression & .06 & .38 & .82 & .70 \\
\hline HSCL-90 Somatization & .03 & .43 & .98 & .52 \\
\hline Health Scale (5 items) & .13 & .25 & 1.48 & .15 \\
\hline Social Support & -.19 & .66 & .63 & .89 \\
\hline Size of Social Network (4 items) & -.23 & .62 &. .66 & .86 \\
\hline Contact w/Social Network (4 it.) & .23 & .12 & 1.66 & .09 \\
\hline Self-Efficacy & .30 & .06 & 1.50 & .15 \\
\hline $\begin{array}{l}\text { Hedia Scale (1l Items) } \\
\text { Summary of Results for } 10 \text { Major }\end{array}$ & $\begin{array}{c}.27 \\
\text { Variables } \\
\end{array}$ & .08 & 1.13 & .37 \\
\hline $\begin{array}{l}\text { Ledian of } r, F, p \text { values } \\
\text { Range of } r, F, p \text { values } \\
\text { ip values (out of } 10 \text { ) } \leq .10 \\
\text { ip values (out of } 10) \leq .20\end{array}$ & $\begin{array}{c}.08 \\
-.23-.30\end{array}$ & $\begin{array}{c}.33 \\
.06-.66 \\
.8 \\
3\end{array}$ & $\begin{array}{c}1.08 \\
.63-1.66\end{array}$ & $\begin{array}{l}.41 \\
.09-.89 \\
1 \\
3\end{array}$ \\
\hline
\end{tabular}

$n=28$ for all Pearson $r$ values

b $d f=(27,28)$ for all $f$ tests 


\section{TABLE V}

RESULTS OF TESTS WITH SECONDARY YARIABLES TO

DETERMINE INDEPENDENCE OF LINKED PAIRS

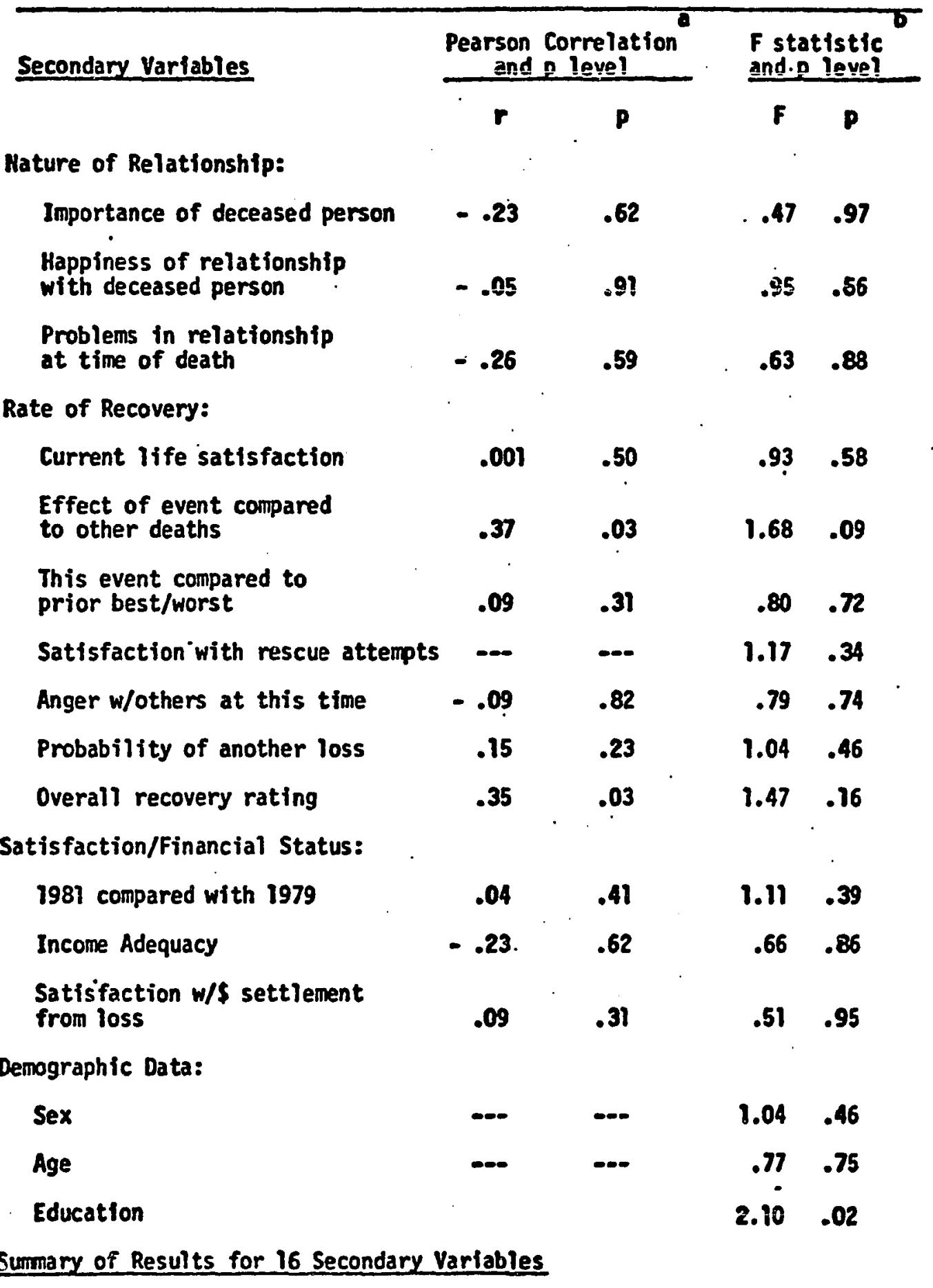

Median of $r, F, p$ values

Range of $r, F, p$ values

10 values (out of 16$) \leqslant .10$

(p values (out_of 16) $\leq 20$

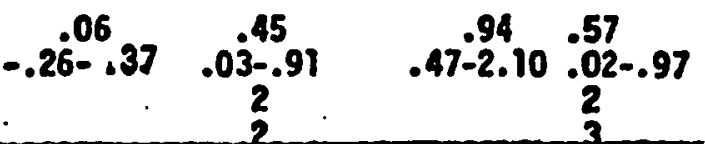

- $n=28$ for ali Pearsoñ $r$ values

b $d f=(27,28)$ for all $F$ tests 
Discriminant function analysis. Discriminant function analysis was used in three ways. First, it was used as an omnibus test of the hypotheses for the first research question. In this case, it was used to discriminate among the five groups of the study sample on five measures of the two outcome variables, health and stress. Second, it was used to compare the confirmed and presumed bereaved groups on measures of dependent variables. Similarly, it was employed to discriminate between the two property loss groups.

Multiple regression analysis. The hierarchical stepwise regression procedure was conducted to test the second hypotheses assuciated with the second research question. LES negative and Hassles scores were entered first, followed by the intervening variables of self-efficacy and social support, with the media scale variable entered last.

Analysis of open-ended questions and interview data. Four open-ended questions were among the questionnaire items. The health status questionnaire asked all study subjects to list any chronic health problems they had prior to the disastrous event and then rate on a nine-point scale whether the chronic condition was worse/same/better.

The other open-ended questions (control subjects excluded) were: "What kinds of things have happened to you before that helped you get through, or prepared you for, this event?" "Fise you angry with anyone at the present time for your loss" If yes, please explain." "Can you imagine 
that such a devastating loss might happen to you again? If yes, please explain." "Is there anytining eise you would like to tell us that will help us understand what you have been through?" Content analysis was the method used to detect major themes reported. Personal contact and telephone interview data were also analyzed in this way. 


\section{Chapter IV}

\section{RESULTS}

The results of this study are presented in four sections. The first section presents findings related to the first study question which asks whether a relationship exists between three specific types of loss events and the outcomes of perceived stress and illness. The second section presents findings related to the second research question which asks what roles the two intervening variables of selfefficacy and social support play in mediating stress that may interfere with coping with significant loss. The third section presents findings related to the third study question which asks how the study subjects perceived the role of the media in relation to the recovery process. The fourth section presents findings regarding the major study questions based on subjects' responses to open-ended questions and in personal interviews.

\section{Findings Regarding the First Study Question}

The first study question was: Is there a relationship between three stressful life events, presumed death of a close relative or friend, confirmed death of a close relative or friend, loss of one's permanent or recreational residence, and the outcomes of perceived stress and iliness? Six hypotheses were derived from this research question. 
It will be recalled that these six hypotheses were designed to test the differential effects of stressful life events on illness. These hypotheses generally specify the hierarchical order of efrects due to the three types of 1oss. Generally, the loss hypothesized as having the most serious effects is the presumed death of a significant other, with confirmed death of a significant other and permanent pro-. perty loss ranked second and third in this hierarchy of adverse effects. A summary of the hypotheses and corresponding planned comparisons is presented in Table VI. Hypotheses were tested using multiple discriminant function analysis and analysis of variance.

Discriminant function analysis was used first to test for overall differences among the five study groups on the set of five major outcome variables. The outcome measures used to differentiate the five groups included the two stress measures, LES Negative and Hassles, and the three health measures, HSCI Depression, HSCL Somatization, and the Physical Health Scale. This set of five measures significantly differentiated among the five groups (approximate $F(20,482)=$ 3.81, $\mathrm{p}<0.001)$. The Wilks' Lambda statistic indicated that 38.58 of the variance in the set of five outcome measures was accounted for by the five groups.

In order to test the six hypotheses derived from the first research question and to probe the overall significance found in the discriminant function analysis, one-way 
analysis of variance (ANOVA) was employed. ANOVAs were computed for each of the five major outcome variables. Means, standard deviations, and overall $\mathrm{F}$ values from the five ANOVAs are presented in Table VII. Following the ANOVAs, a procedure similar to that suggested by Dunn (Kirk, 1968) was employed to carry out the six planned comparisons per dependent variable. An alpha level of 0.05 or 0.01 was divided by six to split the level of significance among the six comparisons. (For the Hassles Scale, only four planned comparisons were made and, consequently, the alpha level of 0.05 or 0.01 was divided by four). This procedure was used since the number of planned comparisons exceeded the four degrees of freedom between the groups: and since the planned comparisons were not orthogonal. The t-tests employed for the planned comparisons used a separate variance estimate rather than a pooled variance estimate in order to offset any distortion in results due to heterogeneity of variance and unequal n's across groups. Scheffe's $S$ method was selected for the post hoc pairwise comparisons because this procedure is recommended when groups are composed of unequal n's (Kirk, 1968). Results of the planned t-tests are reported in Table VI and are summarized below.

\section{Hypothesis 1:}

Hypothesis 1 states, the bereaved of presumed dead will report greater impacts of negative life events and hassles, 
TABLE VI. SUMMARY OF PLANHED COMPARISONS TO BE TESTED

FOR THE FIVE OUTCONE MEASURES FOR THE FIRST STUDY QUESTION

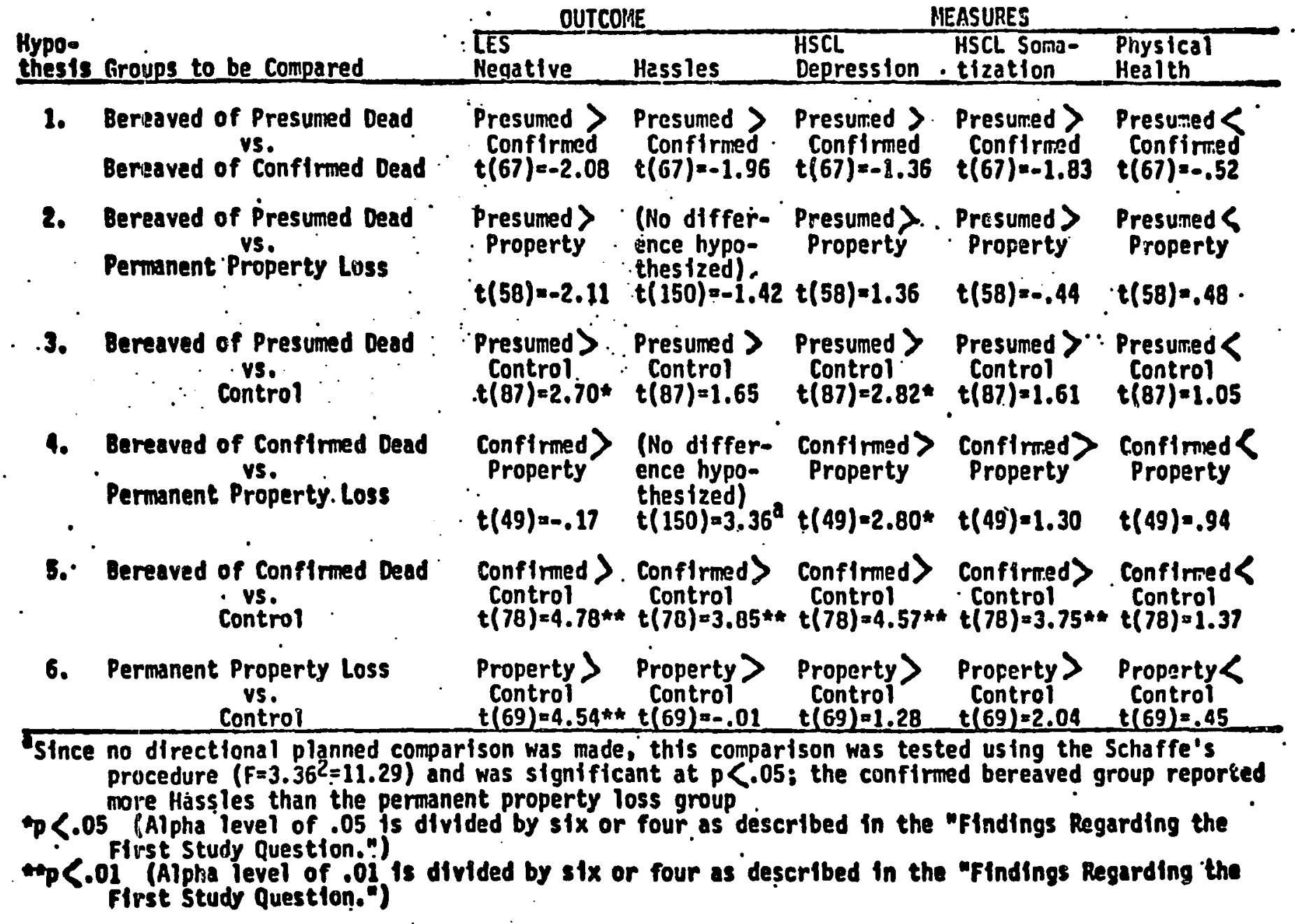


TABLE VII

MEANS, STANDARD DEVIATIONS AND OVERALL SIGNIFICANCE TESTS FOR DIFFERENCE.S BETWEEN MEANS FOR THE FIVE OUTCOME GROLPS

Group Mears and Standard Deviations for Each Outcome

\begin{tabular}{|c|c|c|c|c|c|c|}
\hline $\begin{array}{l}\text { OUTCOME } \\
\text { MEASURES }\end{array}$ & $\begin{array}{l}\text { Group } 1 \\
(B P)(n=39)\end{array}$ & $\begin{array}{l}\text { Group } 2 \\
(B C)(n=30)\end{array}$ & $\begin{array}{l}\text { Group } 3 \\
(P P)(n=21)\end{array}$ & $\begin{array}{l}\text { Group } 4 \\
(P R)(n=15)\end{array}$ & $\begin{array}{l}\text { Group } 5 \\
\text { (C) }(n=50)\end{array}$ & $\begin{array}{l}\text { From ANOVA } \\
(\mathrm{df}=4,150)\end{array}$ \\
\hline $\begin{array}{l}\text { Intermediate } \\
\text { Stress Outcomes } \\
\text { LES Negative } \\
\text { HASSLES }\end{array}$ & $\begin{array}{c}10.67 \\
(9.54) \\
101.95 \\
(97.25)\end{array}$ & $\begin{array}{l}15.63 \\
(10.06) \\
147.37 \\
(93.73)\end{array}$ & $\begin{array}{c}16.10 \\
(9.46) \\
71.57 \\
(51.44)\end{array}$ & $\begin{array}{c}7.47 \\
(5.07) \\
57.80 \\
(57.34)\end{array}$ & $\begin{array}{c}5.94 \\
(6.07) \\
71.66 \\
(68.40)\end{array}$ & $\begin{array}{l}9.52 * \star * \\
5.68 * \star *\end{array}$ \\
\hline $\begin{array}{l}\text { Health Outcomes } \\
\text { HSCL Depression } \\
\text { HSCL Somatization } \\
\text { Health }\end{array}$ & $\begin{array}{c}1.16 \\
(.78) \\
.63 \\
(.63) \\
-0.03 \\
(.62) \\
\end{array}$ & $\begin{array}{l}1.39 \\
(.64) \\
.88 \\
(.51) \\
-0.13 \\
(.86)\end{array}$ & $\begin{array}{l}.93 \\
(.54) \\
.69 \\
(.49) \\
0.05 \\
(.51)\end{array}$ & $\begin{array}{c}.65 \\
(.54) \\
.38 \\
(.40) \\
-0.08 \\
(.62)\end{array}$ & $\begin{array}{l}.74 \\
(.58) \\
.42 \\
(.55) \\
0.11 \\
(.55)\end{array}$ & $\begin{array}{l}6.70 * \star \star \\
4.05 * \star \\
.77 \\
.\end{array}$ \\
\hline
\end{tabular}

Note. $\quad B P=$ Bereaved Presumed, $B C=$ Bereaved Confirmed, PP (Property Loss, Permanent Res.) PR (Property Loss, Recreation Res.), C (Control).

Each mean and standard deviation pair are presented such that the top number is the mean. The bottom numbers of each pair enclosed in parentheses, is the standard deviation.

$\star p<.05 * * p<.01 \quad * * * p<.001$ 
and lower levels of health than the bereaved of confirmed dead. Contrary to expectations, the bereaved of presumed dead did not exhibit significantly more adverse reactions to their loss than did the bereaved of confirmed dead on any of the five outcome measures.

\section{Hypothesis 2:}

Hypothesis 2 states, the bereaved of presumed dead will report greater impacts of negative life events and lower levels of health than the permanent property loss group. Contrary to predictions, there were no significant differences between these two groups on any of the study measures.

Hypothesis 3:

Hypothesis 3 states, the bereaved of presumed dead will report greater impacts of negative life events and hassles, and lower levels of health than the control group. This hypothesis is partially supported by the data. The bereaved of presumed dead reported significantly $(p<0.05)$ greater impacts of negative events and depression than the controls. However, contrary to predictions, there were no significant differences between these two groups on hassles, somatization or physical health. 


\section{Hypothesis 4:}

Hypothesis 4 states, the bereaved of confirmed dead will report a greater impact of regative life events and lower levels of health than the pelinanent property loss group. The confirmed group reported significantly $(p<0.05)$ higher levels of depression than this property loss group as hypothesized. However, contrary to the hypothesis, there were no group differences on LES scores, somatization, and physical health measures. It will be recalled that no difference was hypothesized regarding hassles. Consequently, the significance of the difference between the two groups on Hassles was tested by the Scheffe procedure. Contrary to prediction, the bereaved of confirmed dead reported significantly higher levels of hassles than the permanent-property loss group $(F=11.29, p<0.05)$.

Hypothesis 5:

Hypothesis 5 states, the bereaved of confirmed dead will report greater impacts of negative life events and hassles and lower levels of health than the control group. This hypothesis is supported by the findings except for the physical health measure. The bereaved of confinned dead reported significantly $(p<0.01)$ higher LES and Hassles scores, as well as more depression and somatization than the control group. 
Hypothesis 6:

Hypothesis 6 states, the permanent-property loss group will report greater impacts of negative life events and hassles and lower levels of health than the control group. The only component of this hypothesis supported by the findings is on the LES measure. The property group reported significantly $(p<0.01)$ higher scores on the LES negative measure than the controls. There were no significant differences on the other four outcome measures.

\section{Post Hoc Tests}

Post hoc tests were employed to determine if any other non-predicted pairwise comparisons were significant. Besides the earlier-reported Scheffe comparison between the confirmed and permanent-property loss groups on hassles, only two other post hoc comparisons were significant. When compared to the bereaved confirmed group, the recreational-property loss group reported significantly less hassles $(F(1,150)=$ 12.71, $\mathrm{p}<0.05)$ and significantly lower levels of depression $(F(1,150)=13.69, \mathrm{p}<0.05)$.

Compared to control subjects, the major findings regarding the first study question can be summarized as follows: the bereaved confirmed dead were adversely affected by their loss in areas of negative life events, hassles, depression, and somatization; the adverse effects of loss for the bereaved of the presumed dead occurred in the areas of 
negative stressful events and high levels of depression; and the negative impact of property loss occurred only on the LES measure. Finally, at least at the time of measurement, coping with presumed death bereavement was not found to be more difficult than coping with confirmed death bereavement.

\section{Selected Pairwise Comparisons by}

Discriminant Function Analysis

The planned comparisons carried out to test the six hypotheses formulated for the first study question indicated that there were no significant differences between the two bereaved groups on any of the five outcome measures. Similarly, post hoc comparisons revealed no differences between the property samples. Thus, it seemed advisable to determine whether the two bereaved groups and the two property groups could be combined prior to addressing the second study question. Combining the groups would result in an $\mathrm{n}=69$ sample size for the bereaved group and an $\mathrm{n}=36$ sample size for the property loss groups.

Inasmuch as the post hoc procedure used here is a conservative test, one aditional powerful statistical test was undertaken to determine whether the two bereaved groups could be combined and the two property loss groups could be combined. The groups were compared by discriminant function analysis on all outcome measures. For the bereaved group 
comparisons, the overall approximate $F(5,62)=0.99,(p=$ 0.43). For the property loss group comparisons, the overall approximate $F(5,30)=4.85(p<0.002)$. Based on these findings, along with the results from the first study question, the two bereaved groups were judged sufficiently similar to combine prior to further analysis. The two property loss groups were judged not similar enough to combine. Moreover, since the samples of the two property loss groups were small, the major focus for the second study question was on the combined bereaved group and the control group.

Since the combined bereaved group and control group were to be emphasized in later analyses, a prior graphical comparison of these two groups on selected variables was completed. Differences between the bereaved and control groups on the five outcome measures are illustrated by frequency polygons in Figures 3-7. For example, thirty-six percent of the control sample reported LES negative scores between 0 and 9 , whereas only $17 \%$ of the bereaved subjects scored in this low range. Further, the bereaved subjects reported scores as high as 45 , compared to 27 for the control group. Similar patterns emerge on the Hassles, Depression, and Somatization measures but not on physical health. Visual examination of the frequency polygons in Figures 3 through 6 indicate positively skewed frequency distributions for the control group. In contrast, the distributions for 


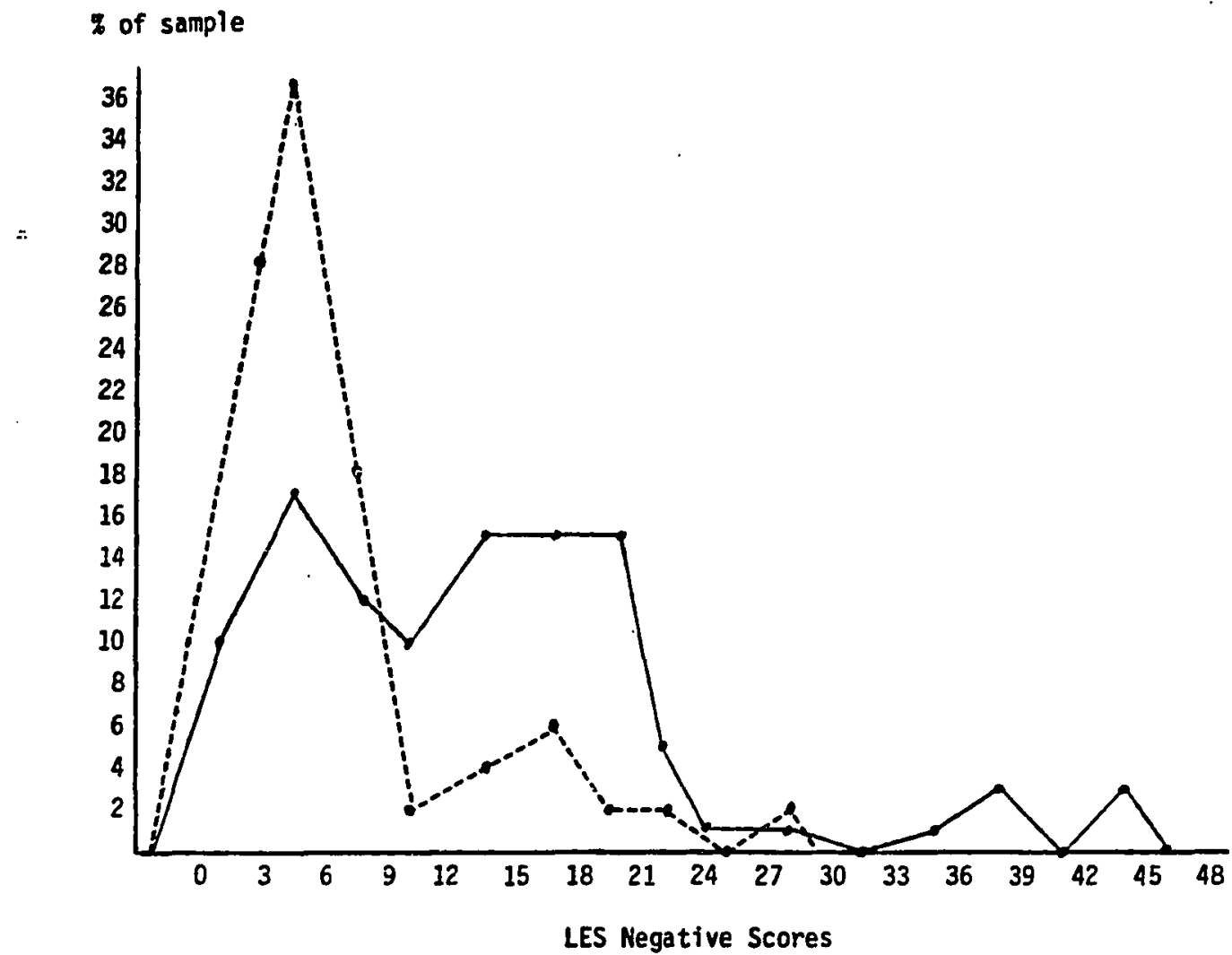

Figure 3. Percents of Combined Bereaved Group $(n=69),(-)$ and the Control Group $(n=50)$, (....) samples compared on the LES Measure.

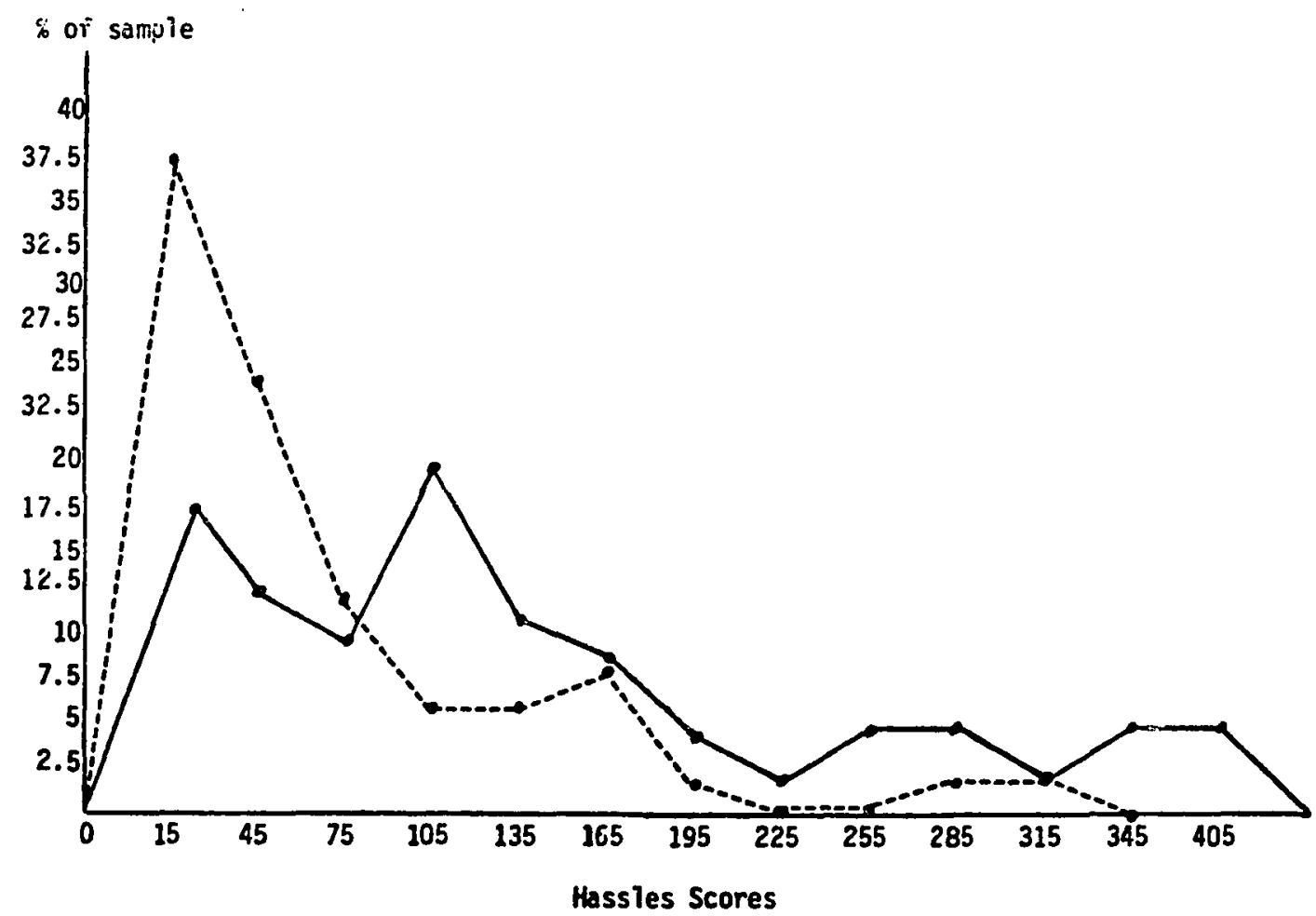

Figure 4. Percents of Combined Bereaved Group $(n=69),(-)$ and the Control Group $(n=50)$, (....) samples compared on the Hassles Measure. 


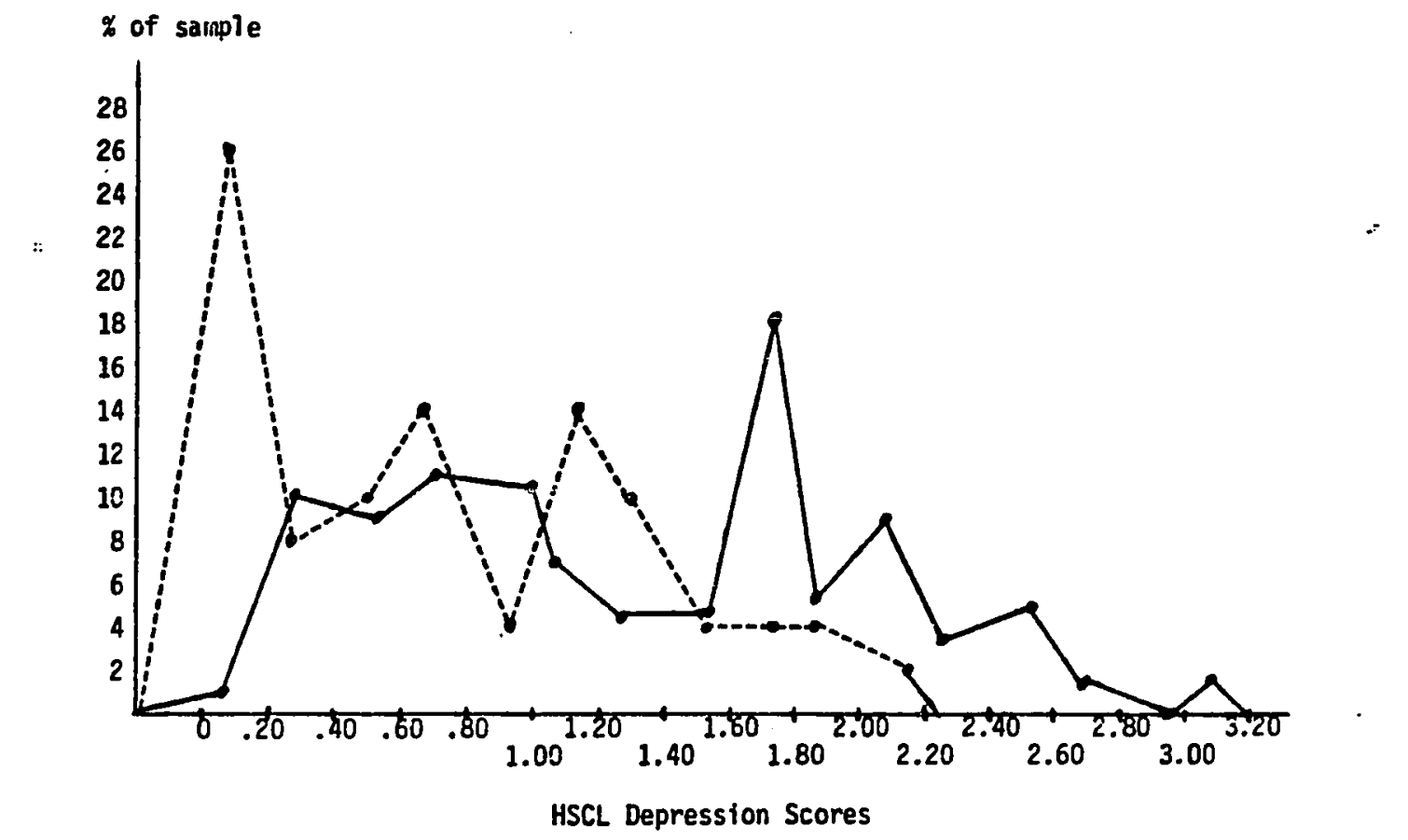

Figure 5. Percents of Combined Bereaved Group $(n=69),(-)$ and the Control Group ( $n=50)$, $(\cdot \cdots)$ samples compared on the HSCL Depression Measure.

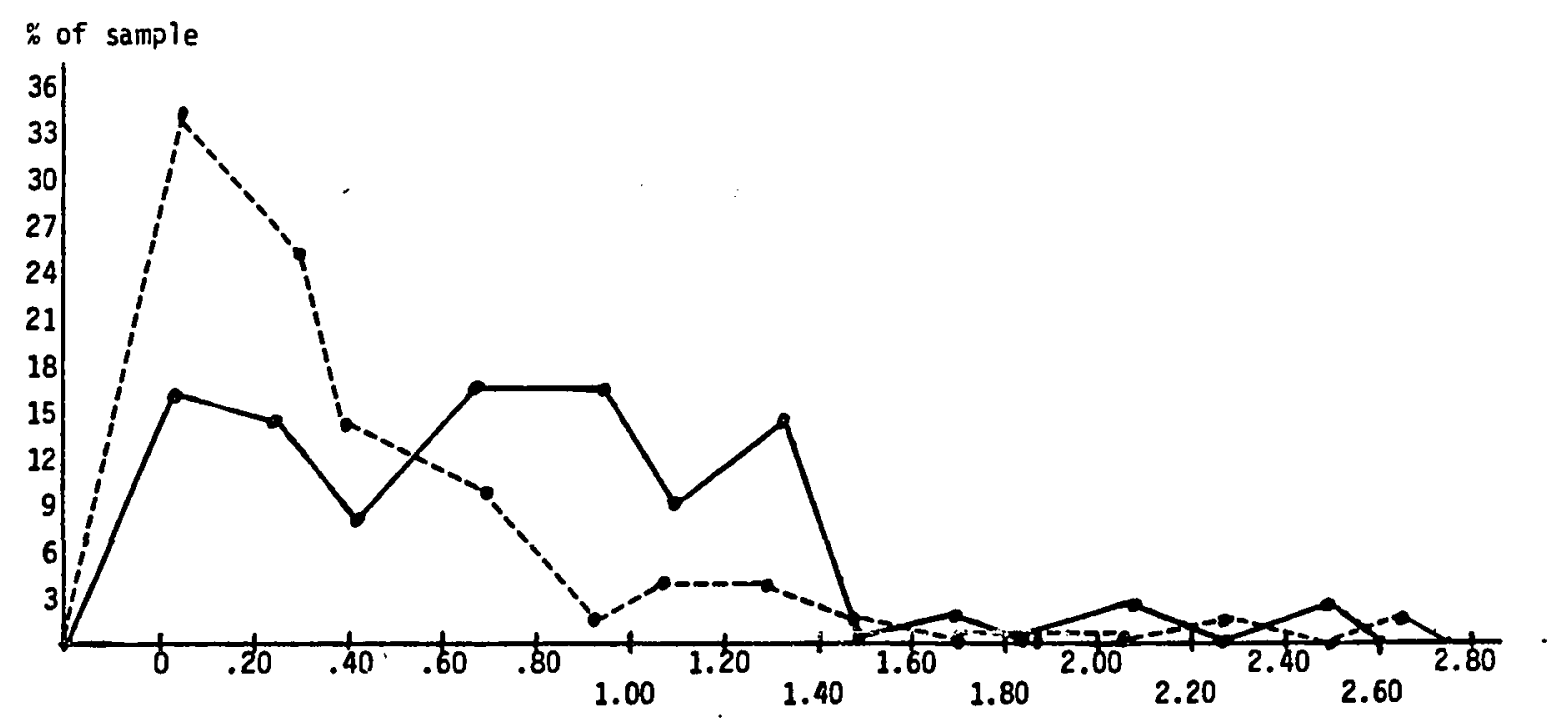

HSCL Somatization Scores

Figure 6. Percents of Combined Bereaved Group $(n=69),(-)$ and the Control Group $(n=50)$, (....) samples compared on the HSCL Somatization Measure. 


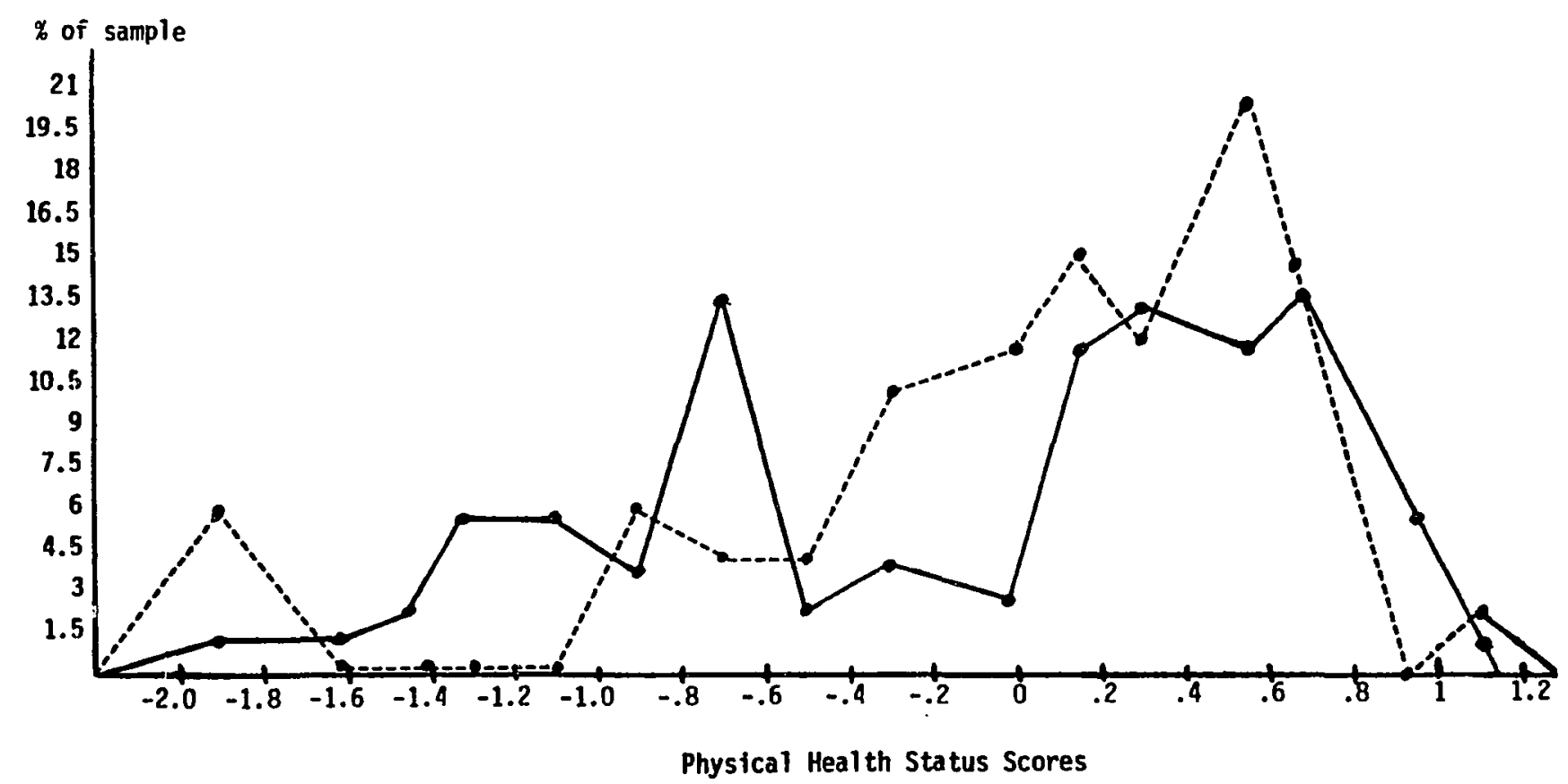

Figure 7. Percents of Combined Bereaved Group $(n=69),(-)$ and the Control Group $(n=50)$, (.-.) samples compared on the Physical Health Status Scores. 
the bereaved sample were more variable and platykurtic (flattened) in form.

\section{Findings Regarding the Second Study Question}

The second study question was: Do self-efficacy and social supports act as intervening variables to buffer the negative effects of stress on one's health when coping with loss? Two hypotheses were formulated to answer this research question.

\section{Hypothesis 1:}

It is hypothesized that among those who experience a loss due to volcanic eruption, higher levels of perceived negative and daily annoyances will be related to lower levels of health.

\section{Hypothesis 2:}

It is hypothesized that self-efficacy and social supports serve to mediate the negative effects of high levels of stress on health. Pearson correlations and regression analyses were conducted to test these hypotheses. Hypothesis 1 was tested using correlations between the stress and health measures for the combined bereaved groups and for each of the property loss groups. The same correlations were computed for the control groups for comparison purposes. (See Table VIII for these correlations). 
TABLE VIII

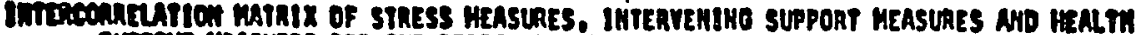

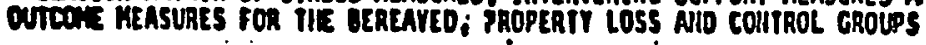

Stres Mearent

1. LEs Ropalfire

8. Massies

\section{Ppoore Marures}

3. Porealred Ovirall smom

A. S12e of Retworte

8. sented with Matwort

e. Seif errieney.

Mallh Quteone Neurian

8. Heter bepression

8. next somatization

9. musteal Health staters

\begin{tabular}{|c|c|c|c|c|c|c|c|c|}
\hline \multicolumn{2}{|c|}{ Seress Measures } & \multicolumn{4}{|c|}{ Suppore Verlables } & \multicolumn{3}{|c|}{ Healeh Quteome Brisures } \\
\hline 1 & 2 & $: 3$ & 4 & 3 & 6 & 1 & $8:$ & 9 \\
\hline 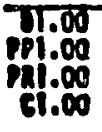 & $\begin{array}{l}71710 \\
.6000 \\
.520 \\
.59000\end{array}$ & $\begin{array}{l}-.09 \\
.012 \\
-112 \\
-.08\end{array}$ & 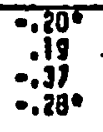 & $\begin{array}{l}-.07 \\
.07 \\
-.410 \\
.10\end{array}$ & $\begin{array}{l}\because 414 \\
\because 380 \\
\therefore 417 \\
\therefore, 220\end{array}$ & 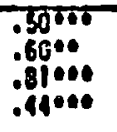 & 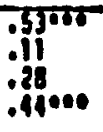 & 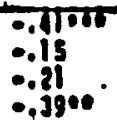 \\
\hline & $\begin{array}{l}.00 \\
.00 \\
.00 \\
. \infty\end{array}$. & $\begin{array}{l}.08 \\
.160 \\
\therefore .100 \\
\therefore .10\end{array}$ & $\begin{array}{l}-.11 \\
: .90 \\
: .650 \\
\because .290\end{array}$ & $\begin{array}{l}-.017 \\
\therefore .07 \\
\therefore .01\end{array}$ & $\begin{array}{l}-.16 \\
-.08 \\
-.50 \% \\
-.14 \cdots\end{array}$ & $\begin{array}{c}.580 \cdots 0 \\
.69010 \\
.650 \cdots \\
.720 .0\end{array}$ & $\begin{array}{l}.600010 \\
.59010 \\
.40 \\
.48000\end{array}$ & $\begin{array}{l}-18000 \\
\therefore .05 \\
\therefore .75 \\
\therefore .3000\end{array}$ \\
\hline
\end{tabular}

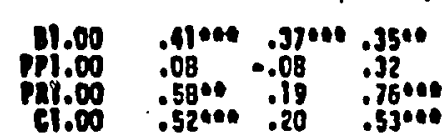

11.00 .59601 .2604

71.00 - .1900 .04

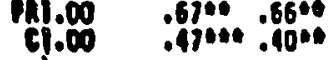

fi.j.

11.00

$m .00$

mi.j.

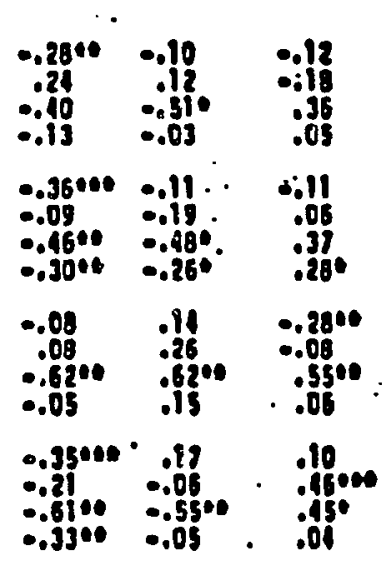

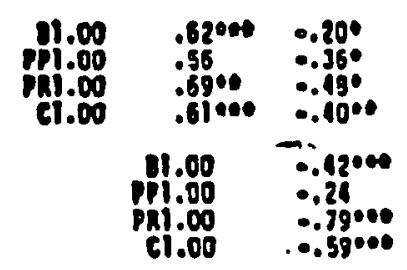

$11 . \infty$

Ppi.

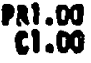

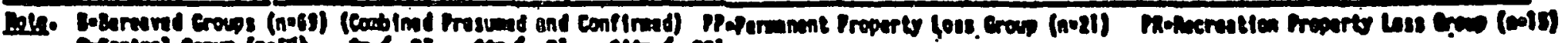

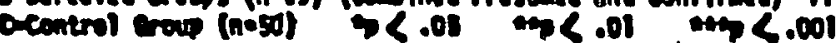


For the bereaved group, higher levels of stress (LES Negative and Hassles) are significantly related to lower levels of health on all three health outcome measures. LES Negative and Hassles are significantly correlated with HSCL Depression ( $r=0.50$ and 0.58 respectively, $p<0.001$ ), with HSCL Somatization ( $r=0.53$ and $0.60, p<0.001)$, and with Physical Health Status $(r=-0.41$ and $-0.46, p<0.001)$.

A somewhat different pattern of correlations emerges for the two property loss groups. For these two groups, while both LES Negative and Hassles are positively correlated with HSCL Depression $(r=0.60$ to $0.81, p<0.01$ to $\mathrm{p}<0.001)$, only Hassles is correlated with HSCL Somatization and only for the permanent-property loss group ( $r=$ $0.59, \mathrm{p}<0.011$. Neither stress measure is significantly correlated with Physical Health Status for either of the property loss groups.

The pattern of stress/health correlations for the control group, however, is similar to results for the bereaved group. For the control group, LES Negative and Hassles are significantly correlated with HSCL Depression ( $r=0.44$ and 0.72 respectively, $\mathrm{p}<0.001$ ), with HSCL Somatization ( $\mathrm{r}=$ 0.44 and $0.48, \mathrm{p}<0.001)$, and with Physical Health Status $(x=-0.39$ and $-0.30, p<0.01)$.

Hypothesis 2, which concerns the relative contribution of stress and the buffering effects of intrapersonal and interpersonal supports in predicting health outcomes, was 
assessed by multiple regression analysis. Prior to these analyses, decisions were made regarding which study groups should be included in the regression analysis and that predictors were to be employed.

It was decided to combine the two bereaved groups for the regression analyses. Findings from the first research question indicated that these groups were similar, and when combined the sample size is 69. In contrast, the two property loss groups were judged not similar enough to combine. Alone, their sample sizes are too small for appropriate use in multiple regression and thus were not included to test the second hypothesis. Again, the multiple regression analysis was carried out separately for the control group for comparison.

The initial plan for the multiple regression analysis involved using six predictors: The two stress measures, the three support measures, and the self-efficacy measure. However, examination of correlations for the bereaved and control groups in Table VIII indicate moderate to high intercorrelations between the two stress measures and among the three social support measures. These high intercorrelations result in problems of multicollinearity for the regression analysis. Therefore, the negative LES score and the Hassles score were transformed to $z$ scores and then averaged to form a single stress predictor. Likewise, the size and contact with one's network and perceived overall support scores were 
transformed to $z$ scores and then averaged to form a single social support predictor. Self-efificacy as a measure of intrapersonal support remained unchanged from the initial plan and thus became the third predictor for the regression analyses. Preparation of the data for testing hypotheses 2, then, included combining the bereaved groups, eliminating the property loss groups, using the control group for comparison, combining stress measures to form one predictor, and using self-efficacy as the final predictor. With these changes in place, the hierarchical stepwise option for the regression procedure was selected.

At the first step, the predictor of stress was entered. At the second step, the remaining two predictors, self-efficacy and support, were entered in order of their statistical significance. Six multiple regression analyses were completed, one for each of the three dependent measures (HSCL Depression, HSCL Somatization, Physical Health) for the bereaved and control groups separately. Results from the bereaved sample are reported first.

The significance of the overall $\mathrm{F}$ tests for the regression analyses ranged from $p<0.05$ to $p<0.001$. The stepwise contribution of each predictor of the total percentage of variance accounted for by each successive set of predictors are indicated in the percent of variance and adjusted $\mathrm{R}^{2}$ columns of Table IX. The F to enter each predictor, the multiple $R$, and beta weights at the final step are also presented. 
TABLE IX

PDEDICTING HEALTH OUTCOMES FROM STRESS, SUPPORT, AND SELF-EFFICACY: STEPUISE MULTIPLE REGRESSION RESULTS FOR THE BREAVED AND CONTROL GROUPS

\begin{tabular}{|c|c|c|c|c|c|c|c|c|}
\hline \multicolumn{9}{|c|}{ Outcome Measure: Depression } \\
\hline Group & $\begin{array}{l}\text { Predictor } \\
\text { Variable }\end{array}$ & $\begin{array}{l}\text { Percent of } \\
\text { Yariance Accounted } \\
\text { For at Each Entry Step }\end{array}$ & $\begin{array}{l}F \text { to Ente } \\
\text { Predictor }\end{array}$ & & $\begin{array}{c}\text { Puttiple } \\
R\end{array}$ & $\begin{array}{l}\text { Beta Wt. } \\
\text { at Final } \\
\text { Step }\end{array}$ & $\begin{array}{c}\text { hojusted } \\
R 2\end{array}$ & $\begin{array}{l}\text { Overall } \\
\text { Statistic }\end{array}$ \\
\hline $\begin{array}{l}\text { Bereaved } \\
(n=69)\end{array}$ & $\begin{array}{l}\text { Stress } \\
\text { Self-Efficacy } \\
\text { Support }\end{array}$ & $\begin{array}{r}32.8 \\
7.1 \\
2.6\end{array}$ & $\begin{array}{l}32.69 \hbar \omega t \\
7.76 \star \\
3.02\end{array}$ & $\begin{array}{l}\text { df }(1,67) \\
\text { df }(1,66) \\
\text { df }(1,65)\end{array}$ & $\begin{array}{l}.573 \\
.631 \\
.652\end{array}$ & $\begin{array}{r}.52 \\
-.21 \\
-.17\end{array}$ & $\begin{array}{l}.318 \\
.380 \\
.399\end{array}$ & $\begin{array}{l}32.69 \cdots \text { df }(1,67) \\
21.87 \cdots \cdots \text { df }(2,66) \\
16.04 \cdots \cdots \text { df }(3,65)\end{array}$ \\
\hline $\begin{array}{l}\text { Controls } \\
(n=50)\end{array}$ & $\begin{array}{l}\text { Stress } \\
\text { Self-Efficacy } \\
\text { Support }\end{array}$ & $\begin{array}{r}44.1 \\
.58 \\
.18\end{array}$ & $\begin{array}{l}37.98 \text { \# } \\
.50 \\
.15\end{array}$ & $\begin{array}{l}\operatorname{df}(1,48) \\
d f(1,47) \\
d f(1,46)\end{array}$ & $\begin{array}{l}.664 \\
.669 \\
.670\end{array}$ & $\begin{array}{r}.63 \\
.0 .06 \\
. .05\end{array}$ & $\begin{array}{l}.430 \\
.424 \\
.413\end{array}$ & 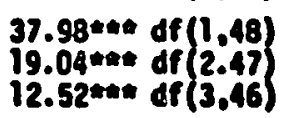 \\
\hline
\end{tabular}

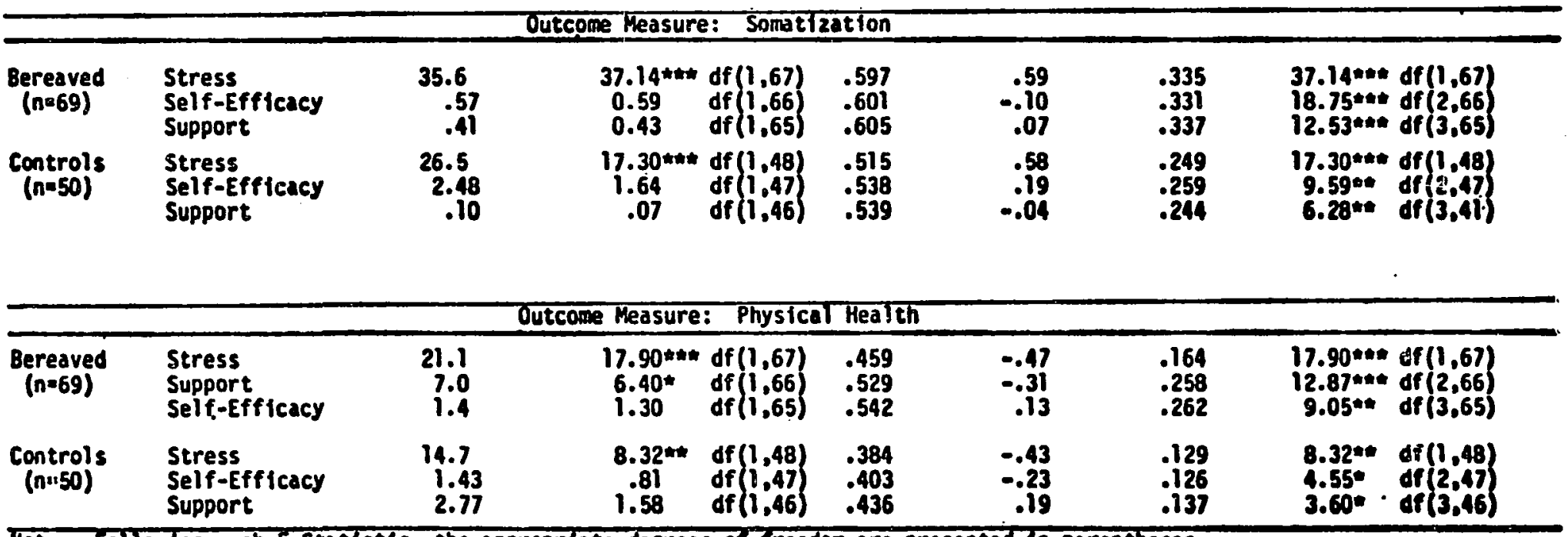

Wote. Following each F Statistic, the appropriate degrees of freedos are presented th parentheses. 
In all three regression analyses for the bereaved group, stress was a highly significant predictor of the health outcomes. Stress accounted for 35.68 of the variance in somatization, 32.88 of the variance in depression, and 21.28 of the variance in physical health.

Once stress was entered as a predictor for the dependent variable of HSCL depression, each of the remaining two predictors, self-efficacy and support, contributed significantly to the remaining variance in depression $(F(1,66)=$ 7.76 and 6.20 respectively, $p<0.05)$. After self-efficacy was entered as the second predictor, the independent contribution of support was no longer statistically significant $(F(1,65)=3.02, \mathrm{p}<0.10)$. For the dependent variable of somatization, neither self-efficacy nor support accounted for significant variance above and beyond stress. Once stress was entered as a predictor for the dependent variable of physical health, only support accounted for a significant increment in the variance. However, contrary to the hypothesis, higher levels of support occurred for those experiencing lower levels of health.

These same stepwise regression analyses were conducted with the control group $(n=50)$. Results of the regression analyses are presented in Table IX. Even though earliex results revealed that control subjects' mean stress and illness scores were much lower than those of the bereaved subjects, the stress-illness relationship is similar to that 
of the bereaved group. Results for the control group indicate that stress accounts for 44.18 of the variance in depression, $26 \%$ of the variance in somatization, and 14.78 of the variance in physical health. In contrast to the regression analyses for the bereaved group, the results of the regression analyses for the control group indicated that neither self-efficacy nor social support was a significant predictor for any of the three health outcome variables.

Summary of the Findings

Regarding the Second study Question

In general, both hypotheses were supported by the data. High stress measures correlate with lowered levels of health for all study groups. Self-efficacy and social support were significant predictors in mediating levels of depression in the bereaved disaster sample, although not to the extent reported in past studies (Coppel, 1980; Lin et al., 1979). Moreover, social support appeared to be greater for those experiencing lowered levels of physical health in those bereaved by the disaster. In contrast, if stress and illness are significantly lower, as in the control sample, the reactive role of social supports is less clear. 


\section{Findings Regarding the Third Study Question}

The third study question was: What are the perceived effects of the media on coping with loss following a disaster? No directional hypotheses were formulated to answer this question.

Twelve items were generated to assess whether the media was perceived to help, hinder, or not affect the recovery of the loss subjects. Four of these 12 items asked subjects to rate local news, local T.V., national news, and national T.V. on a 7-point likert-type scale regarding the media's hindrance, help, or no effect on their recovery from loss. Eight additional items gave respondents the opportunity to rate the media in general on a 9-point scale on such topics as invasion of privacy and delay in recovery. These 12 questions were part of the mailed questionnaire (Appendix B-7). Since the media questions were part of a series of questions written to assess the impact of the disastrous event, contre: "ubjects did not respond to these questions. It will be recalled that 12 items were subjected to preliminary correlations and factor analyses. Eleven items were selected to from a scale, 'Media' in order to use a single score in the analyses. When the term 'Media' is used in the reporting and discussion and results, the term refers to the loss subjects' perceptions of the positive or negative effects of various forms of news coverage had on their 
recovery. High media scores reflect a positive perception of the media's impact, whereas low media scores reflect a negative perception of the media's impact. No objective measures of media coverage were collected as part of the dissertation.

One area of interest was whether the media scale was related to other study variables. Pearson correlations were computed between the 11-item media scale and the five major outcome variables (LES negative, Hassles, HSCL Depression, HSCL Somatization, and Physical Health). Next, the media scale was correlated with four intervening variables (self-efficacy, overall perceived support, network size, and contacts with network members). Finally, the media scale was correlated with six secondary study variables (current life satisfaction, financial settlement satisfaction, rate of recovery, anger, importance of the deceased person, and rescue operations). These secondary variables were brought into the data analyses because of the media coverage devoted to some of the topics. The correlations comparing the combined bereaved group and the two property loss groups on these 15 measures are presented in Table $x$.

Significant correlations can be noted between the media scale and 11 out of 15 of the computed measures of the bereaved. The media scale was most significantly correlated $(p<0.001)$ with negative events $(r=-0.42)$, hassles 
TABLE $X$

PEARSON CORRELATION OF MEDIA SCOORES WITH FIFTEEN OTHER VARIABLES FOR THE FOUR LOSS GROUPS

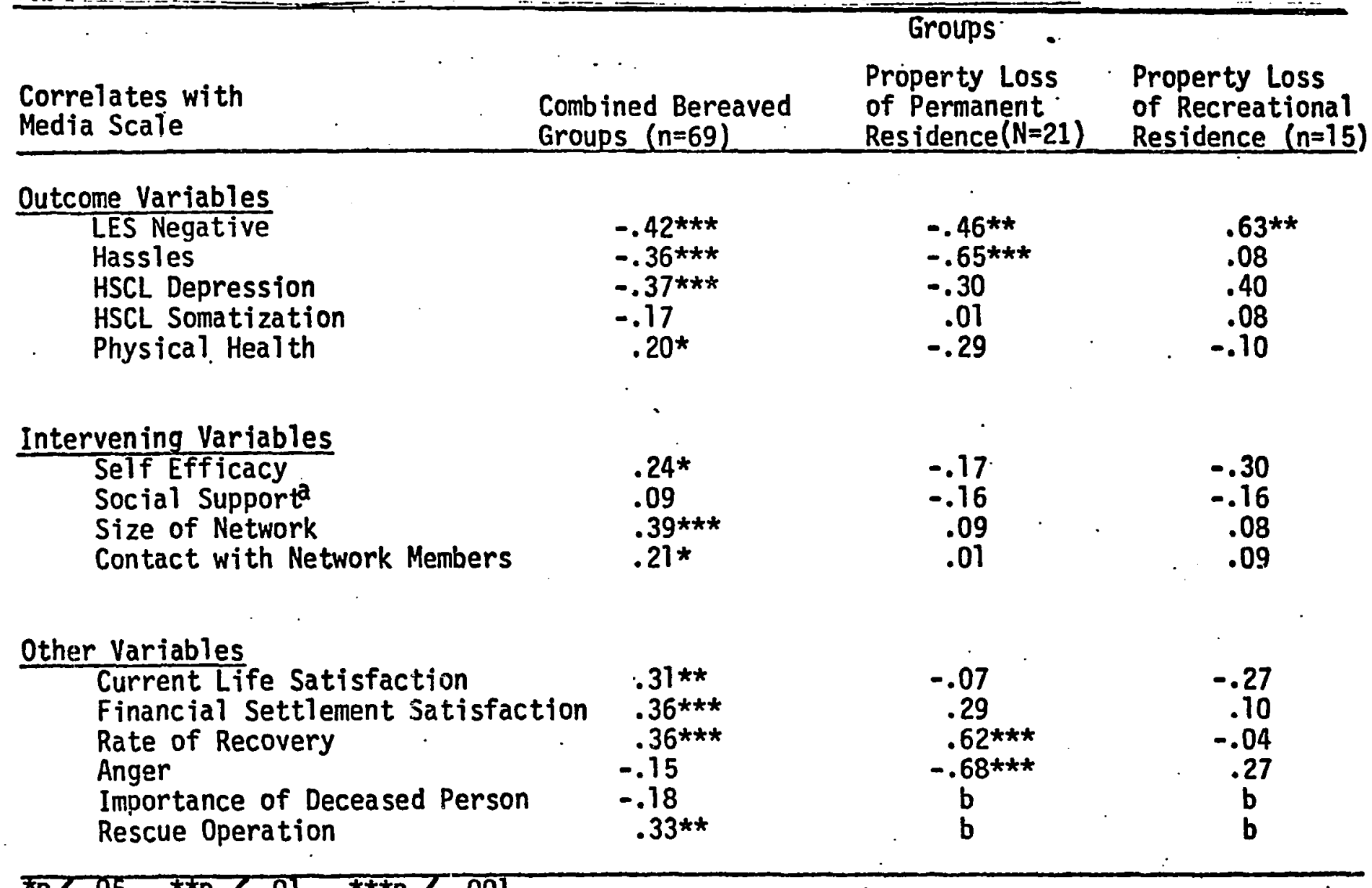

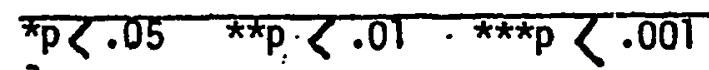

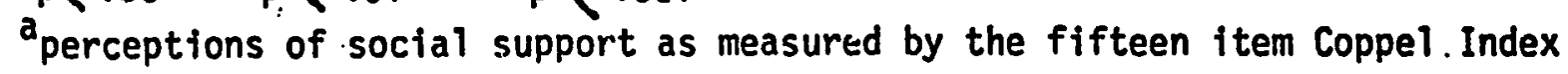

$b_{\text {questions not applicable to property groups }}$ 
$(r=-0.36)$, depression $(r=-0.37)$, size of social network $(r=0.39)$, financial settlement satisfaction $(r=0.36)$, and rate of recovery $(x=0.36)$.

A much different pattern of correlations emerged between comparisons on the same study variables for the property loss groups. Only four out of the 15 measures were significantly correlated with the media scale in the permanent-property loss group, and only one measure correlated with media in the recreational-property loss group. For permanent-property loss subjects, 'Media' was most significantly (p $<0.001$ ) correlated with Hassles $(r=$ $-0.65)$, anger $(r=-0.68)$, and rate of recovery $(r=0.62)$. At the 0.01 level of significance, negative events correlated with 'Media' $(x=-0.46)$. Only negative events was significantly correlated with Media in the recreationalproperty loss group $(\mathrm{r}=0.63, \mathrm{p}<0.01)$. It should be noted that while media and negative events were positively correlated for the recreational-property loss group, these two variables exhibited a negative relationship for the bereaved and permanent-property loss groups.

A second question regarding the media concerns differences in perceptions of help, hindrance, or no effect on recovery from loss. The four loss groups were compared on four different forms of the media llocal news, local T.V., national T.V., and national news magazines) and on the overall media scale. These data were analyzed by one-way 
analysis of variance. Mean scores, standard deviations, and $F$ values are presented in Table XI. Significant $F$ values ( $p<0.05$ ) between the groups can be noted for local news, local T.V., and the overall media scale. Results of Newman Keuls post hoc tests revealed no significant differences across groups on the four forms of media. However, regarding the overall effects of the media (invasion of privacy, delayed recovery, etc.) there were significant differences $(p<0.05)$ between the confirmed bereaved and permanent-property loss groups. The confirmed bereaved group viewed the media more negatively than did the permanent-property loss group.

\section{Findings Regarding Qualitative Data}

Open-Ended Questions

Four open-ended questions were written to provide an opportunity for participants to elaborate on their perceptions and experiences following the disaster. This opportunity for self-expression seemed particularly important because of the length and complexity of the series of questions and because of the limited opportunity for personal interaction with the investigator.

These questions can be found in Appendix B-7 (18, 20.2, 21.2, 31). Question 21.2 asks whether subjects can imagine the recurrence of the event and will not be reported in the dissertation. The remaining three questions were analyzed 
TABLE XI

SUMMARY OF THE ANALYSIS OF VARIANCE FOR THE LOSS GROUPS ${ }^{a}$

ON MEDIA SCALE AND TYPES OF MEDIA

\begin{tabular}{|c|c|c|c|c|c|}
\hline Media Variable & $\therefore$ Las & S: Group & & & $F(d f=3,100)$ \\
\hline Local New's .. & $\begin{array}{l}\text { Pres. } \\
\text { Conf. } \\
\text { Perm. } \\
\text { Rec. }\end{array}$ & $\begin{array}{l}\text { Bereaved } \\
\text { Bereaved } \\
\text { Property } \\
\text { Property }\end{array}$ & $\begin{array}{l}3.42 \\
3.67 \\
4.48 \\
4.57\end{array}$ & $\begin{array}{l}1.500 \\
1.936 \\
1.401 \\
1.505\end{array}$ & $2.98^{*}$ \\
\hline Local TV & $\begin{array}{l}\text { Pres. } \\
\text { Conf. } \\
\text { Perm. } \\
\text { Rec. }\end{array}$ & $\begin{array}{l}\text { Bereaved } \\
\text { Bereaved } \\
\text { Property } \\
\text { Property }\end{array}$ & $\begin{array}{l}3.47 \\
3.17 \\
4.14 \\
4.43\end{array}$ & $\begin{array}{l}1.590 \\
1.783 \\
1.493 \\
1.555\end{array}$ & $2.75^{\star}$ \\
\hline National TV & $\begin{array}{l}\text { Pres. } \\
\text { Conf. } \\
\text { Perm. } \\
\text { Rec. }\end{array}$ & $\begin{array}{l}\text { Bereaved } \\
\text { Bereaved } \\
\text { Property } \\
\text { Property }\end{array}$ & $\begin{array}{l}3.50 \\
3.00 \\
3.90 \\
4.07\end{array}$ & $\begin{array}{l}1.390 \\
1.640 \\
1.578 \\
1.207\end{array}$ & 2.34 \\
\hline National News & $\begin{array}{l}\text { Pres. } \\
\text { Conf. } \\
\text { Perm. } \\
\text { Rec. }\end{array}$ & $\begin{array}{l}\text { Bereaved } \\
\text { Bereaved } \\
\text { Property } \\
\text { Property }\end{array}$ & $\begin{array}{l}3.66 \\
4.00 \\
3.71 \\
4.21\end{array}$ & $\begin{array}{l}1.300 \\
1.600 \\
1.383 \\
1.377\end{array}$ & .72 \\
\hline $\begin{array}{r}\text { Media Scale } \\
\text { (11 items) }\end{array}$ & $\begin{array}{l}\text { Pres. } \\
\text { Conf. } \\
\text { Perm. } \\
\text { Rec. }\end{array}$ & $\begin{array}{l}\text { Bereaved } \\
\text { Bereaved } \\
\text { Property } \\
\text { Property }\end{array}$ & $\begin{array}{l}-.08 \\
-.21 \\
.26 \\
.31\end{array}$ & $\begin{array}{l}.652 \\
.664 \\
.633 \\
.188\end{array}$ & $3.65 * *$ \\
\hline
\end{tabular}

\footnotetext{
Note. ${ }^{a}$ based on 103 subjects. Presumed Bereaved $(n=38)$, Confirmed ${ }^{\star p} \mathrm{p}<.05$ Bereaved $(n=30)$, Perm. Property Loss $\star * p p<.01 . \quad(n=21)$, Rec. Prop. Loss $(n=14)$.
}

b Subjects rated the four forms of media on a $1-7$ scale with 1 being the most negative score and 7 the most positive score. The media scale items were standardized and then averaged. The possible range was -3.00 to +3.00 . 
by descriptive statistics and by the identification of significant themes. Tables XII and XIII present the most common response themes. Additional themes are reported in the text. Control subjects were excluded from all of these questions since these questions were specific to loss associated with the disaster.

Prior stressful experiences. Question 18 of Appendix B-7 asks: "What kinds of things have happened to you before that helped you get through, or prepared you for this event?" Group response rates by percent were: presumed bereaved - 798, confirmed bereaved - 77\%, permanent-property loss - 868, recreational-property loss - 738. This question attempted to assess past loss experiences and coping styles. Responses were indeed varied. Of those giving a response, the most common responses were "nothing", "death of a significant other", and "personal belief system". Group differences can be noted on Table XII. Less frequent themes were other losses such as career disappointments, personal illness, separation, financial setbacks, burglary, and accidents. Some subjects mentioned positive factors in coping, such as role models, supportive friends, and reading about death. The most informative theme from this question was that many loss subjects did not appear to "transfer" a similar past loss e perience to the current crisis. For example, only three subjects who had been through a divorce said that loss experience helped them cope with their current 
TABLE XII

SUBJECTS' RESPONSES TO QUESTION 18: WHAT KINDS OF THINGS

HAVE HAPPENED TO YOU BEFORE THAT HELPED YOU GET THROUGH, OR PREPARED YOU FOR THIS EVENT?

Group Responses by \%

\begin{tabular}{llccc}
\hline $\begin{array}{c}\text { Major } \\
\text { Response } \\
\text { Theme }\end{array}$ & $\begin{array}{c}\text { Presumed } \\
\text { Bereaved } \\
(\mathrm{n}=79 \%)\end{array}$ & $\begin{array}{c}\text { Confirmed } \\
\text { Bereaved } \\
(\mathrm{n}=77 \%)\end{array}$ & $\begin{array}{c}\text { Perm.-Prop. } \\
\text { Loss } \\
(\mathrm{n}=86 \%)\end{array}$ & $\begin{array}{c}\text { Rec. Prop. } \\
\text { Loss } \\
(\mathrm{n}=73 \%)\end{array}$ \\
\hline Nothing & 35.0 & 33.0 & 28.0 & 45.0 \\
$\begin{array}{l}\text { Prior } \\
\text { Death of a }\end{array}$ & & 58.0 & 17.0 & 45.0 \\
$\begin{array}{l}\text { Significant } \\
\text { Other }\end{array}$ & 29.0 & 17.0 & 28.0 & \\
$\begin{array}{l}\text { Personal } \\
\text { Belief } \\
\text { System }\end{array}$ & 23.0 & & & 0 \\
\hline
\end{tabular}

Note. Percentages in each column may not add up to the $100 \%$ since the table presents only Major themes and since subjects sometimes gave two or more responses. Additional, less frequently reported themes appear in the text. The n's listed for each group are the percent responding. 
loss experience. Yet, personal and telephone contacts with many of the study subjects by the investigator indicated that divorce was a prevalent occurrence among study participants. A similar past grieving process is thought to enhance coping with a current grief experience (Lazarus, 1966) .

Anger. The question, "Are you angry at anyone at the present time for your loss? If yes, please explain", (Appendix B-7, 20.2), provided respondents an additicnal opportunity to express the frustrations associated with the disaster experience. Response rates by group were: presumed bereaved - $13 \%$, confirmed bereaved - 27\%, permanentproperty loss - 528, recreational-property loss - 78 . Common response themes are reported in Table XIII. Adaitional themes are listed below. The permanent-property loss group who responded "yes", indicated that their anger was primarily directed toward government officials, insurance companies and scientists. These subjects also expressed anger toward major industries in the area, the economy, and local media coverage. The bereaved group, in contrast, expressed their anger initially at identification and rescue prodecures, government inefficiency, cowardice, and allowing business interests to take precedence over lives. Some of the bereaved were angry at the deceased victims themselves for being in the area. These same persons said they had resolved issues of blame and anger due to the magnitude of the 
eruption. Thus, nine months following the disaster, property-loss subjects reported a greater degree of anger than the bereaved.

TABLE XIII

SUBJECTS' RESPONSES TO QUESTION 20: ARE YOU ANGRY AT ANYONE AT THE PRESENT TIME FOR YOUR LOSS? IF YES, PLEASE EXPLAIN.

Group Responses by \%

\begin{tabular}{lcccc}
\hline $\begin{array}{l}\text { Major } \\
\text { Response } \\
\text { Theme }\end{array}$ & $\begin{array}{c}\text { Presumed } \\
\text { Bereaved } \\
(n=13 \%)\end{array}$ & $\begin{array}{c}\text { Confirmed } \\
\text { Bereaved } \\
(n=27 \%)\end{array}$ & $\begin{array}{c}\text { Perm.-Prop. } \\
\text { Loss } \\
(n=52 \%)\end{array}$ & $\begin{array}{c}\text { Rec.-Prop. } \\
\text { Loss } \\
(n=7 \%)\end{array}$ \\
\hline $\begin{array}{l}\text { State \& } \\
\text { Federa1 } \\
\text { Authorities }\end{array}$ & 50 & 75 & 55 & 100 \\
$\begin{array}{l}\text { Insurance } \\
\text { Companies }\end{array}$ & 0 & 0 & 33 & 100 \\
$\begin{array}{l}\text { Scientists } \\
\text { for lack } \\
\text { of warning }\end{array}$ & 38 & 40 & 18 & 0 \\
\hline
\end{tabular}

Note. Percentages may not add up to $100 \%$, since only major themes are presented in the table. Additional themes are reported in the text. Subjects sometimes gave more than one response. The n's listed for each group are the percent responding. 
The final question. The last open-ended question, "Is there anything else you would like to tell us to help us understand what you have been through?" (Appendix B-7, 31), was answered by 40 respondents (388 of all loss subjects), and primarily by the bereaved ( $\mathrm{n}=34)$. Property loss subjects were instructed not to answer the final six questions pertaining to the death of a significant other. Some of these subjects $(n=6)$, however, did answer the final, more general, loss question stated above. Seventeen of the 40 persons responding wrote up to three pages. The major themes that emerged were: extreme stress during the waiting period of identification of the dead, no bodies for burial, no norms for distributing property and valuables. Many middle-aged people died leaving both their parents and their children. Further, the large number of blended families (second and third marriages) made decisions regarding the deceased persons' belongings very sensitive issues among the bereaved. Other themes were the loss of extremely talented people, visions and nightmares experienced particularly by single young adults who lost both parents, sudden new responsibilities, financial ramifications, individual change, and urgency to reorder life priorities. Further analysis of these data are beyond the scope of the dissertation. 


\section{Interview Data}

Thirty-four personal and telephone interviews were conducted with a cross-section of bereaved widows; parents, adult children, sibling and friends of volcano victims and persons who experienced property 1oss. Interviews were designed to obtain in-depth information on the major research questions (Appendix B-12), and to provide an opportunity for personal contact between the investigator and some of the subjects. Responses varied as a result of the relationship to the deceased and age of the bereaved respondent. The following are the questions and answer themes drawn from the structured interviews.

Question 1. What were some of the daily changes you had to make as a result of your loss? Recurring themes from bereaved relatives were the need to take on new roles in the family such as caring for elderly parents, taking on the roles the deceased formerly carried out, coping with grief, loss and intense loneliness, and accepting change in social life. Bereaved friends expressed resistence toward the need to find new persons to share ideas and joint creative ventures, and resistance toward finding ways to spend leisure time. Property loss subjects stated they had to move one, two, or more times and accept the hassles associated with that, such as driving farther to work. They also said they had to accept uncertainty associated with living near an active volcano. 
Question 2. In what ways do you feel your health has been affected by your loss? Depression was the most common effect mentioned across all age and loss groups. Recurring minor illnesses such as colds and flu were mentioned frequently by the young bereaved. Most of those interviewed stated that their physical health had not been affected. These statements are consistant with quantitative data. However, in some cases, respondents indicated that other family members' health was severaly affected. For example, one elderly mother of a victim died a month following the eruption, one elderly father suffered a second stroke, two middle-aged mothers moved in with other family members due to poor physical health. These cases may or may not be related to the disaster. Some of the young adult bereaved frequently dreamed of their parents coming home, saw people in public places resembling one parent or the other and became upset when they saw cars like their parents owned. These same young people had difficulty sleeping, eating, and returning to normal activities.

Question 3. How have your relationships and interactions with others changed as a result of your loss? There were many positive expressions of support and closeness among family and friends in all four loss groups. There were minimal complaints of insensitivity. Two young adult children reported some family disputes with their grandparents over property that belonged to the deceased middle generation. 
Question 4. What has helped you get through this ordeal? Consistent themes were support, day-to-day involvement in activities, helping others, ability to problemsolve, experiences of past tragedy, personal philosophy that death is a part of life, reading books on death and coping, ability to change, and the belief that those who died were esteemed role models.

Question 5. What personal resources or inner strengths do you have that were helpful? Acceptance of what can't be changed, confidence in coping ability, and belief in a supreme being were themes from this question. None of the bereaved reported financial hardships.

Question 6. What kinds of social support did you receive? Was it enough? There were many positive accounts of support from family and friends, indicating a sense of "fit" between what was needed and what was received. There were only a few subjects who sought professional counseling following their losses. Two subjects asked the investigator to recommend resources in their areas. Others stated they were very disappointed in the professional help they received. Still others reported dissatisfaction with clergymen. The young adult bereaved found older brothers and sisters and friends of their deceased parents the best source of support. They reported increased quarrels with boyfriends and little understanding and support from peers. In contrast, elderly parents reported that their friends 
were very supportive.

Question 7. In your opinion, has the television coverage of the volcano been treated seriously or trivial? "Serious and informative, but insensitive to those who lost family and friends" was a consistent theme. In addition, respondents said coverage was "too much, too intense", and left them with feelings of no way to escape or forget an event whose outcome could not be changed.

Question 8. Have you experienced any positive, growthproducing effects? A sense of satisfaction that some deceased received recognition for talent and excellence, a reordering of personal priorities, and a sense of urgency to improve one's own work were frequently stated positive outcomes, mostly by brothers, sisters, and friends of deceased. Older parents and young adult children of deceased victims had difficulty expressing positive outcomes.

Question 9. How have you resolved the shortness of life? Young adult children consistently said they had not resolved their parents' untimely deaths. Friends said they had become much more present time-oriented. Others noted that many of the persons who died were committed to their reasons for being near Mt. St. Helens, and further believed they were willing to die for these commitments. Others, particularly friends, said they had made wills. 
Question 10. What are your impressions of the study materials? Several persons interviewed said they had no measure of how they were doing, and used the study questions as a gauge of their progress. Others said that even though several months had passed, that responding to questionnaires for this study was the first time "they really talked it out."

In conclusion, qualitative measures revealed a responsiveness that was consistent with other loss studies. People were in various phases along a continuum of resolution. Some unique aspects were the problems encountered by young adults' sudden death of both parents, by blended families, and by three-generation families. 


\section{Chapter V \\ DISCUSSION OF FINDINGS}

The concluding chapter of the dissertation discusses the results reported in the previous chapter. Relevant findings from the three study questions will be explored in view of pertinent theoretical concepts and methodological issues. Finally, implications for the findings and directions for future research are suggested.

The First Study Question: The Effects of Loss on Perceived Stress and Health

The first question differed from past studies in that it assessed the impact of various kinds of loss experienced as a result of the May 18, 1980 volcanic eruption of Mt. St. Helens. Briefly, it was expected that the bereaved of the presumed dead would experience the highest levels of stress and the lowest levels of health; that the confirmed dead bereaved group would experience similar, but less severe effects, and that subjects experiencing the loss of their permanent residence would report higher levels of stress and lower levels of health than the control subjects. The Adverse Effects of the Death of a Significant Other on the Bereaved

The findings from this study confirm the findings from past studies (Bal1, 1976-77; Clayton et al., 1972; Glick et al., 
1974; Harvey and Bahr, 1980; Titchener and Kapp, 1976). The death of a significant other has profound negative effects on the surviving bereaved. In this study, the bereaved of persons confirmed dead as the result of a natural disaster reported significantly higher $(p<0.01)$ scores on the impact of negative life events, hassles, depression, and somatization than did control subjects. The bereaved of presumed dead reported significantly $(p<0.05)$ higher scores on the LES measure and depression than did control subjects. Findings reported here are consistent with past research reporting that the death of a significant other produces an immediate crisis that is followed by episodes of depression and somatization. Furthermore, during the years following the event persons experience disruptions in roles, relationships, and responsibilities (Ball, 1976-77; Demi, 1978; Titchener and Kapp, 1976).

An interesting findings from this study that is also reported in past studies regarding the bereavement process is the high incidence of depressive symptoms and the low incidence of perceived recovery and help-seeking behavior associated with depression. In the current study, scores on the HSCL Depressioil Scale were significantly correlated $(p<0.001)$ with rate of recovery $(r=-0.69)$ for the combined bereaved group. However, depression scores and contacts with professional help were not significantly correlated $(x=0.18)$ for the bereaved, $(r=0.07)$ for the controls. Simarily, Ball 1976-77) reported that only four percent of her sample sought help for depressive symptoms, yet 548 of the sample 
reported that they were only "somewhat recovered", and $11 \%$ reported they were "not at all recovered" seven months postbereavement. Similar findings were reported following the Buffalo Creek disaster (Titchener and Kapp, 1976). These results are surprising because the majority of subjects in all three studies are women. Women reportedly are less reluctant to seek help than men (Parkes, 1972). A rival explanation to seeking help might be that supportive networks fulfill this need. No data on social supports were reported in either the Ball or the Titchener and Kapp studies. In the present study, depression and contact with one's social network for the combined bereaved group were not significantly correlated $(r=-.08)$. Another rival hypothesis might be that the bereaved expect to be depressed, and hence, do nothing about feeling badly. This explanation also seems unlikely since the literature generally supports the notion that friends and relatives in Western cultures are uncomfortable with death and encourage short bereavements (Blauner, 1966; Weisman, 1973). Thus, this phenomenon deserves additional study.

Another similarity between the current and past studies regarding bereaved individuals in general, and the disaster bereaved in particular, regards what Malinak, Hoyt, and Patterson (1979) term "prenatural experiences". Included in this category of disturbing experiences, for example, are premonitions that, frior to the actual event, something bad is about to happen. Following the calamitous event, there 
may be recall of a vague uneasiness that occurred when goodbyes were last exchanged, "lookalikes" of the deceased are thought to be seen in public places, and one might imagine the deceased person's car is about to park in one's driveway. A number of persons in the current study reported these experiences; particulary young single women who were living in their parents' homes at the time of the volcanic eruption. These experiences have been reported in past studies as well (Lifton, 1968; Lindemann, 1944; Malinak et al., 1979; Parkes, 1974).

Several past studies that have reported the negative impact of widowhood suggest that socio-economic status contributes more to the negative impact of bereavement than the widowhood status per se (Ball, 1976-77; Barrett and Becker, 1978; Glick et al., 1974; Harvey and Bahr, 1980) . Conversely, Sanders (1979-80) reported that the relationship between decpression and low income was more significant among controls than among the bereaved and concluded that pre-existing low income contributes negatively to any stressful situation. While the current study had only five widows as subjects, there were a number of young adults Iinancially dependent on their parents. Thus, the question of financial adequacy and satisfaction and financial settlement of the deceased' estates was addressed, although it was not a major research question. Briefly, among the bereaved, current life satisfaction and income adequacy were significantly correlated, $(x=0.46$, $p<0.001)$. Current life satisfaction and satisfaction 
with financial settlement of the deceased' estates were also significantly correlated $(x=0.20, p<0.04)$. Financial settlement satisfaction was also correlated with rate of recovery ( $r=0.19, p<0.05)$, but not with current health status. The Sunshine Mine disaster study concluded that both time and material advantages -- money, youth, health, education, employment, friends, and getting involved were all aids in the bereavement recovery process. Education was the most important predictor for morale, while age and income followed as important predictors (Harvey and Bahr, 1980). Thus, with the exception of the Sanders study, financial status has been found to be an important predictor of : well being associated with bereavement.

Finally, the therapeutic value of study participation, candor of response, and feelings of satisfaction toward research regarding grief and bereavement were reported by participants in this study as well as subjects participating in studies by Ball (1976-77) and Malinak et al., (1979). In the current study, even those individuals who were not contacted for a personal or telephone interview wrote positive comments about participation in response to the final question. Subjects of all ages reported they "thought long and hard" about their responses. Further, some reported feeling better as a result of finally sharing their bereavement experience. About $95 \%$ of the participants in this study have requested a report of the findings. These findings suggest that persons are willing to disclose 
sensitive information and apparently derived some therapeutic benefit from doing so.

The Effects of Permanent Property Loss on Stress and Health

One of the important objectives of this study was to compare the differential effects of personal and material loss on stress and health. Past disaster siudies have not made this differentiation (Singh and Raphael, 1981; Titchener and Kapp, 1976). One of the most interesting findings of this study is that the permanent-property loss group reported greater impacts of negative life events and lower levels of hassles than hypothesized. Three possible explanations for these findings are discussed below.

Self-report of negative events. Methodologically, the LES is an improvement over previous measures because respondents can 1) identify a stressful event or add one, 2) separate negative from positive effects of each event, and 3) individualize rating of the impact (Sarason, et al., 1979). However, it is possible that there were more events on the LES specific to the loss event to which the property loss subjects could respond. Sixteen items could be identified and rated as events associated with, or following, property loss on the LES, whereas only ten events were likely to be associated with, or occur as a result of bereavement. Thus, it may have been possible for this troup to report more events than bereaved subjects. 
Geographic location of subjects. With the exception of three subjects who moved away, the remainder of the subjects in the permanent residence loss group (86\%) reside close to or on the same property where their homes were destroyed by flooding of the Toutle and Cowlitz Rivers. These data are consistent with findings from other disasters. Victims apparently wish to remain living in the area despite potential recurrence of a disaster. In the event of another major eruption of the volcano, or even in the event of unseasonably heavy rainfall, the rivers could flood again. Thus, these persons live with unpredictable and uncontrollable threat of recurring loss of homes, employment, and even significant others. This disaster phenomenon is termed by Wilson (1972) as 'stress as enduring'. In contrast, only 48 of the bereaved subjects live in the immediate area of Mt. St. Helens. (Six additional bereaved families who also reside $i$ il the immediate area were invited to participate in the study, but declined). While the death of a significant other is conceptualized as more stressful, one major rare event may not be worse than several less stressful events that produce ongoing tension. Even though it is conceivable that another significant other could die; living away from the potentially dangerous area may cause individuals to perceive the event differently from those who reside in the immediate environment. Thus, since the majority of the property loss group live in a 
potentially dangerous area, they may have experienced and reported as much stress as the bereaved group who are likely to perceive less immediate threat of another loss. Dunn (1980) reported residents near the Three Mile Island nuclear disaster reported two times the rates of depression and anxiety when compared to controls. Proximity to the area was the highest stressor ( $\mathrm{s} \varangle 0.001$ ). Satisfaction with financial settlement. Both the bereaved of presumed dead and the permanent-property loss groups experienced financial effects opposite of those anticipated at the time the research was proposed. While the bereaved of presumed dead reported extreme stress immediately following the event, perhaps court testimony provided some movement toward resolution. All of the bereaved family members who testified did receive provisional death certificates. These provisional death dertificates were accepted by insurance companies and the federal government as verification of death. Conversely, property loss had not yet been resolved financially at the time of data collection. Property loss subjects who were interviewed, reported extreme dissatisfaction with the lack of progress associated with financial settlement. Pearson correlations indicate that current life satisfaction and level of income in 1981 compared with 1979 for the permanent-property loss group was highly significant $(r=-0.46, \mathrm{p} \varangle 0.01)$. This same correlation for the presumed bereaved was non-significant. On 
the other hand, Pearson correlations between current life satisfaction, income adequacy and financial settlement were non-significant for this property loss group, yet significant for the presumed bereaved group.

Some property loss subjects have become plaintiffs and defendants in lawsuits associated with property loss. Based on findings from past studies, it can be predicted that stress and dissatisfaction regarding financial losses will continue. Singh and Raphael (1981) reported that financial resolution for defendants in suits involving the commuter rail disaster in Sydney, Australia had not been reached three and one-half years following the deaths of 83 persons and injuries of about another 83 victims. Similarly, Titchener and Kapp (1976) report that it took two years to settle lawsuits resulting from the Buffalo Creek, West Virginia Flood.

According to Pearlin and Schooler (1978), stress associated with work and money can be decreased by disengagement from the stressful situation. Conversely, disengagement has not occurred as a result of personal property loss, nor is this a likely coping strategy, given what is at stake for these individuals. This group of subjects reported high rates of anger, dissatisfaction, stress, and depression. The qualitative data suggest much of their distress is associated with inequities. Thus, the protective coping theory proposed by Pearlin and Schooler (1978), appears 
inadequate in explaining property loss. Further, continuing high stress and perhaps low levels of health are reașonable expected outcomes for this study.group.

\section{The Absence of Significant Differences Between Bereaved of}

Presumed and Confirmed Dead

The presumed dead bereaved did not report higher levels of stress and lower levels of health than the other loss groups. There were no significant differences between the two bereaved groups on any of the five outcome measures. Rather, these two groups appeared to be more similar than different at the time of measurement. Factors that may account for these findings are characteristics of the event and sampling effects.

Characteristics of the event. According to Blauner (1966), Weisman (1973), and others, presumptive death and confirmed death are thought to be conceptually different. In cases of confirmed death, societal ritual associated with burial of a body provides appropriate rites of passage for the deceased, defines expectations of mourning behavior of the bereaved, and allows the search for meaning and resolution of the death. Alternatively, presumptive death provides no norms for the bereaved. Interviews and other data from some bereaved individuals of the presumed dead reported that information regarding the massive destruction of the area and conditions of the bodies of the confirmed dead were 
instructive and that hope for survival lessened as a result. Thus, the situation differs from some of the usual conditions of presumptive death. Further, data were collected ten and eleven months following the event, which would suggest that passage of time made the groups more similar than initially conceptualized.

Sampling effects. The bereaved of confirmed dead had a higher response rate than the bereaved of presumed dead. In some cases, the closest relative of a presumed dead victim could not be contacted due to serious personal chronic illness (four known cases). In contrast, only one serious illness and one death, both in elderly adults were known to occur in bereaved of confirmed dead. Parents of four young adult victims of presumptive death refused to participate, whereas this occurred only once in the confirmed bereaved group. Thus, it may be that the bereaved of those presumed dead did not participate because they were worse off. In addition, small sample sizes in both groups tend to lessen the predictive power of statistical analyses in a quasi-experimental research design. Contrary to statistical findings, interview data and data from openended questions suggest the presumptive death bereaved experienced the most devastating initial effects of the two groups. For instance, the bereaved of presumed dead reported dissatisfaction with the disaster rescue operation, the insensitivity of the media, family distress in planning 
and carrying out memorial services, and difficulty giving court testimony to verify death.

Discussion of Findings Related to the Second Study Question

While the first stidy question was uniquely designed to test the effects of a specific event, the second question provided an opportunity to examine the stress-illnesssupport theoretical model which is of current interest to many behavioral and health researchers.

\section{The Relationship Between Stress and Illness}

The second research question explored several conceptual issues regarding negative life stress, social support, psychological assets, and their relationship to emotional and physical health outcomes. The findings confirmed those of previous studies -- that stressful life events are positively correlated with iilness (Brown, 1974; Cassel, 1973; Rahe and Lind, 1971; Wyler et al., 1971). However, the majority of past studies have reported relatively low correlations between negative events and illness $(r=-0.20$ to 0.30 , Lin et al., 1979; $r=0.22$ to 0.36 , Rahe and Lind, 1971). Alternatively, the findings reported here are that, for the bereaved group, stress and illness are significantly correlated ( $p<0.001$ ) with $r$ 's for stress with depression and somatization ranging from 0.50 to 0.60 , and for stress with physical health equal to -0.41 and -0.46 . For the control sample in the current study, the correlation between 
the two stress measures, LES Negative and Hassles $(r=0.59$, $\mathrm{p}<0.001$ ), was higher than the corresponding correlation for Coppel's sample of normal college students ( $r=0.40$, $p<0.01)$. Coppel used the same stress measures employed in this study and similar health outcome measures. Finally, when LES Negative and Hassles were combined to form one stress measure this stress measure accounted for 338 of the variance in depression for the bereaved sample and 448 of the variance in depression for the control sample. Two explanations for the high correlations between stress and illness reported in this study are measurement of negative events and differences in sampling.

Measurement of negative events. Most past studies have focused on both positive and negative change as producing stress, rather than negative change alone, as suggested by Sarason et al., (1979). Further, only one other study (Coppel, 1980) could be found by the investigator that incorporated the Hassles Scale into the conceptualization and testing of life stress and its relationship to illness.

Sampling effects. Many past studies have used college students as control subjects or as comparison subjects serving as a sample for the normal population. Findings from this study suggest that control subjects matched with study subjects on such variables as age, sex, occupation, and place of residence, report higher correlations between 
stress and illness than do college students. The Buffering Effects of Social and Intrapersonal Supports

The most recent conceptual addition to the stress-illness research model has been to examine the buffering role of social supports on stress. Hypotheses that social support lessens the impact of stress have been supported in numerous past studies. However, Heller (1979) suggests that support for this hypothesis in past studies has methodological problems. While more and more studies confirm the mediating role of support on stress, Heller (1979) insists the same methodological weaknesses are repetitious.

The current study findings suggest only modest support for the intervening role of social support. The size of an individual's network was more important than the contact with members of one's network. This finding suggests that if individuals believe there is someone to whom one can turn, these perceptions of potential support affect the labeling of the stressful event, helping one to cope as a result of re-examination of the impact of the event. Since perceived social support and actual social competence may be confounded (Heller, 1979), the current study attempted to separate self-efficacy (the use of social competence) from social support. Self-efficacy was inversely related to depression in this study, while social support appeared to be reactive to physical illness. Multiple regression analysis indicated that, after controlling for stress, social 
support was higher for those experiencing illness and lower for those whose physical health was better. One possible explanation is that the level of social support increased due to needs for such support during illness, that is, doctor visits and hospitalizations which subjects were asked to report. Similar findings were reported by Andrews (1978) and Coppel (1980). It may be that depressive-prone individuals may be more likely to complain of illness or exhibit depressive symptoms and perceive the environment as less supportive. On the other hand, if physical illness is sanctioned whereas emotional illness is stigmatized, loss victims may believe their behavior is inappropriate and not seek help from the environment. Thus, depression is likely to influence both intraperson and interpersonal supports. Tolsdorf (1976) suggests that a combination of primary and secondary supports is more useful than support from only one kind of network. No attempt was made in this study to separate primary from secondary supports. Thus, the amounts of reciprocity (exchange) in a primary network may be useful to some, while burdensome for others. Secondary networks may make less demands on individuals than primary supports. As Miller et al. (1976) suggest, no one kind of support is helpful to all.

Iin et al. (1979), suggest that SEs may also interact with social support. Trose of lower SES status are said to have fewer resources, and fewer positive experiences asking 
for reeded support. The current study sample, for the most part, reported high rates of employment, satisfaction with income levels, and were fairly well educated. Thus, the lack of predictive power attributed to social supports, as reported, was not expected in the current study, and furthermore, contrary to interview data. Subjects interviewed, with few exceptions, indicated person/support "fit". If, as Kobasa (1979) suggests, stress is perceived by some individuals as challenge, commitment, and control, then findings from the current study are indeed puzzling. If this were the case, self-efficacy should have been a far better preaictor in this study than it was. Results from the stepwise regression analyses indicate that self-efficacy was a significant predictor only on the depression outcome measure for the bereaved. One-way analysis of variance and the Newman-Keuls post-hoc procedure revealed no significant differences among the five study groups on the self-efficacy measure. These findings suggest that perceptions of selfefficacy were not affected by the disastrous event. Kobasa's (1979) suggestion that stress can be perceived as an opportunity and challenge and that individuals will be "energized and exhilarated" by stressful events, raises the question, can these three C's (challenge, commitment and control) operate in situations of intense and prolonged stress? Bandura (1977) suggests that "the strength of people.'s convictions in their own effectiveness is likely to affect 
whether they will even try to cope with given situations" (p. 193). Results from this study seem to indicate that extreme amounts of stress do not increase one's efficacy expectations. If this is true, then appropriate interventions could be initiated to increase the sense of selfefficacy by modeling, verbal persuasion, and performance accomplishment (Bandura, 1977).

Andrews (1979) suggests that stimulation may interact with stress. There are no known optimal levels of stimulation. Perhaps those experiencing boredom, lack of novelty, and chronic role strain are affected by stress in unusual ways. Yet, the current measures of life stress all assume that it is change, not chronic stability that produces stress.

In summary, the most plausible explanation for results obtained as a result of testing the second hypothesis are: 1) the methodological confounding of the study variables stress, support, and self-efficacy, 2) lack of conceptual clarity of some concepts, and 3) measures for specific arrangement of support (primary and secondary) were not included in the current study.

The Final Question: The Effects of the Media on Loss

The third study question was an exploratory one. The research objectives were twofold. The first objective concerned the forms of the media and their potential differential effects on individuals experiencing 1oss. The second 
objective concerned the relationship between severity of loss and perceptions of media coverage. Specifically, would study subjects perceive the media as a help, hindrance, or as having no effect on their recovery?

As reported in the previous chapter, there were no statistically significant differences between pairs of study groups regarding differential effects of local news, local TV, national news, or national TV. However, the open-ended questionnaire items and interview data did reveal high levels of dissatisfaction with all forms of the media among bereaved individuals. For example, inaccurate identification of persons pictured both in newspapers and on television was reported. Furtrier, some television reports of finding dead victims, while accurate, were reported to the public prior to notification of immediate relatives. Findings from other stuaies are difficult to compare with the findings from this study because the published literature focuses primarily on effects of the media prior to a disaster. Abe (1979) investigated the extent to which the mass media spread rumors of an impending earthquake in Tokyo, Japan. According to Abe, anxiety was greatly aroused and 358 of those who heard the rumor took actions to deal with the potential earthquake. The Sunshine Mine disaster study reported very briefly that media personnel were perceived as intrusive and insensitive of victims whose bodies were recovered early in the week of the disaster /Harvey and 
Bahr, 1980).. Findings from the current study confirm these findings: The bereaved were the least likely to have neutral or favorable impressions of the press. One of the strengths of this study is that additional descriptive data have been collected on the effects of the media following a disaster.

These findings raise important legal and ethical issues. The rapidity with which events can be reported may contribute to both inaccuracies in stories and seemingly little sensitivity to those experiencing profound personal loss as a result of a natural disaster.

Theoretical and Methodological Implications

Several important theoretical and methodological issues were addressed in this study. Consideration was given to measurement of negative life change instead of total change, utilization of a stress instrument that provided an opportunity for respondents to rate the impact of change (Sarason et al., 1978), and the inclusion of both social supports and self-efficacy as buffers of stress on illness (Coppel, 1980). The sample size of 155 subjects includes a control group and is larger and more representative than samples in some past disaster studies (Singh and Raphael, 1981; Titchener and Kapp, 1976). Further, this study assessed differences between bereavement and property 1oss, which was not done in past studies. 


\section{Implications for Clinical Intervention}

According to Weisman's (1973) conceptualization of untimely death, those individuals bereaved by the volcanic eruption of Mt. St. Helens experienced all three kinds of untimely death. The first kind described by Weisman is premature death. The age range of deceased victims of the disaster was from nine to 85 years. However, only four of the deceased were over 58 years of age. Most were young and middle-aged adults. Age of both the deceased and bereaved have been shown to be important high risk and rate of recovery bereavement indicators (Ball, 1976-77; Barrett and Becker, 1978; Glick et al., 1974). The second kind of untimely death is unexpected death. Reports from abstracts of yet unpublished studies on the Mit. St. Helens disaster indicate that the risk level was perceived as low by those living in the area. According to Weisman, unexpected death is extremely upsetting because it "violaces our inner timetable of expectation" (p. 368). Third, "calamitous untimely death is not only unpredicted, but violent, destructive, demeaning, and even degrading" (p. 368). It is asserted here that the bereaved from this disaster have experienced the worse possible kind of death event. Unfortunately, there is no clear conceptualization of material 1oss. Additional data must be gathered on the unexpected and calamitous loss of one's home, property, and personal possessions. 
Results from this study indicate that the loss subjects suffered the effects of an immediate crisis and have demonstrated effects of acute stress syndrome consisting of sleep disturbances, anxiety, depression, grief, and preternatural disturbances. Further, it can be predicted that chronic stress syndrome effects are likely to occur due to lack of resolution of many problems. The gathering of longitudinal data to assess these outcomes is imperative. In terms, then, of clinical significance, responsibility for assessment and intervention for these loss individuals falls to the health care community in general, and the mental health care community in particular. Especially in terms of scarce resources, it becomes necessary to give primary consideration to those most seriously affected. Suggestions for intervention evolve from conceptual notions of sudden death as well as from a critique of this and other disaster study findings.

Specifically, Weisman (1973) suggests that interventions be directed toward transforming calamitous death into more acceptable forms. Thus "calamitous death must be changed into unexpected death, and unexpected death into premature death, and premature death into appropriate death" (p. 374). Similarly, Bugen (1977) suggests changing a central relationship at the time of death into a peripheral relationship as bereavement progresses. Along these same lines, the perception of preventable death must be 
changed to unpreventable death (Bugen, 1977). While these suggestions are very cognitively oriented, this study sample has demonstrated that the majority of subjects have been able to process information, draw conclusions from available information, and carry out a course of action. Thus, the proposed interventions would seem to be feasible and merit both trial interventions and research.

The problem-solving approaches suggested above are not intended to override affective considerations. According to Silver and Wortman (1980), helping professionals may under-estimate what victims have been through. In other words, outsiders may not appreciate the multitude and/or magnitude of events an individual is going through and fail to understand the situation well enough to be helpful. An example from the current study illustrates this point. An 18 year old bereaved participant lost two family members as a result of the disaster. A third member of the immediate family had died nine months prior to the eruption, leaving the study subject the only remaining family member. The young person proceeded with memoriai service arrangements for the two deceased disaster victims. During the service, the clergyperson referred to the deceased by the name of the bereaved, not once, but three times. In addition, the bereaved person was strongly urged by a crematorium attendant to open the box that contained the remains of the parent.: The bereaved was told the ashes were indeed beautiful. 
Much to the bereaved person's dismay, the box also contained several rocks, and an identifiable metal portion of the deceased victim's undergarment. The role of 'active listener' cannot be over emphasized in such sensitive situations.

Previous studies involving sudden death bereavement have reported the need for professional and personal support during the very early bereavement period (Lindy, 1971; Raphael, 1977). Ahearn (1981) reported long-term negative effects resulting from the 1972 Nicaragua earthquake. Lindy (1981) reported the effectiveness of brief intervention therapy for the bereaved following a fire in which 158 persons died.

Important clinical interventions should be directed toward: 1) identification of those loss victims at high risk, 2) better training for helping professionals, 3) backup consultation and support for mental health workers, 4) primary prevention teaching to local clergy, teachers, family practice physicians and nurse practitioners, and 5) use of the media to inform people about appropriate coping mechanisms and available services.

\section{Implications for Disaster Planning}

The findings from this study and those of past disasters delineate the short-term detrimental mental health outcomes associated with surviving a disaster or being a significant other of a disaster victim. Further, Engel's 
(1968) description of the giving-up/given-up syndrome associated with prolonged stress suggests deterioration of physical health may be affected by long term stress. Only recently have we begun to devote serious attention and funds to study both short and long-tem health outcomes following disasters.

The anger and blame directed toward the authorities responsible for the rescue operation and the media following the Mt. St. Helens disaster may be scapegoating phenomena. Further, the magnitude of the event was far greater than expected. This has been acknowledged by study victims as they have gradually reassigned their blame to the disaster itself. However, it could also be argued that disaster planning needs improvement.

The data from this and past studies are clear: Rapid identification and access to the deceased are very important personal and cultural considerations (Blauner, 1971). The anguish some of the bereaved reported for a full week while waiting for bodies to be released should be prevented from occurring again. Further, the availability of mental health professionals at temporary morgues has been shown to be useful (Lindy, 1971) and should be a service for those present.

The examples of insensitivity of the media reported in this study by a number of participants can certainly be a Learning experience and prevented in the future. While the 
media has an invaluable role both pre and post disaster, greater concern for suffering individuals is warranted. Perhaps no amount of planning could have lessened the damage and property loss. However, the inequitable treatment and lack of clear, consistent guidelines regarding financial settlement by both private and government agencies reported by the property loss group needs to be evaluated.

\section{Limitations of the study}

Questions of both a methodological and theoretical nature can be raised concerning present methods of assessing life change. Several of these questions such as conceptualizing life stress in terms of negative life change rather than total change, developing scales that allow subjects to rate impact of stressful life events, and establishing reliability and validity of measures have been addressed in the current study. However, three important limitations exist in the present study. These three limitations are problems in making causal inferences, difficulty in measuring the interactive effect of social supports and stressors on illness, and the sampling procedure employed. All are discussed below.

Numerous recent studies cited in the literature review have reported a relationship between life stress and illness (Brown, 1974; Casse1, 1973; Wyler et a1., 1971) . However, many of these studies, including the present one, have used 
instruments that include indentification of illness as a stressiul life event. Thus, there may be a confounding of the variable, illness, which can be identified as both a contribution to stress, and a consequence of the occurrence of major stressful life events that occur in one's life over time. Furthermore, both chronic and acute illness may have been present prior to the event under study, the volcanic eruption. Since it is not possible in a post-test research design to eliminate the confounding role of illness in the measures being used, correlations between perceived stress and reported health reported here must be interpreted with caution.

The second limitation regards measuring social support. While stressful life events are said to be positively related to illness, social supports are said to be negatively related to illness ( $\mathrm{Lin}$ et al., 1979). If these propositions are accurate, then, according to Iin et al. (1979), it could be hypothesized that the total variance of illness could be accounted for to a greater degree by both social support and stressful life events than by stressful life events alone. However, the role of social support can take more than one form. One perspective is that social support causally precedes stressors. A second possibility is that social supports are reactive to stressors. The theoretical perspective of Iin and his colleagues becomes very complex, then, because the direction of the relationship between 
stressors and social support becomes contingent upon differential reacting capabilities which are likely to be related to social class, social competence, and illness symptoms. Thus, for individuals enjoying high social class, stressors and social support might be positively related, whereas individuals of lower social standing with lesser reacting capabilities, stressors and social support might be negatively related (Iin et al., 1979). In order to test this theoretical formulation, longitudinal data are required. The present study does not provide longitudinal data of this kind; thus, conclusions regarding the complex relationship between life stress and social supports are 1 imited.

Finally, the third limitation of the current study regards the sampling procedure for the bereaved subjects. Due to a "fixed" number of subjects bereaved by the volcanic eruption, the sampling procedure called for a "linked pair" of bereaved subjects for each deceased volcano victim. In the event that some subjects could not be located or refused to participate in the study, a second priority "linked pair" for each victim was invited to participate in order to maintain optimal sample size. If replacement subjects did not experience the same magnitude and number of stressors, their scores on study measures could be lower than subjects initially contacted and thus significant differences among the bereaved, property 1oss, and control groups may not have 
been detected. This limitation is not, however, regarded as serious since replacement sampling occurred in only seven cases.

\section{Directions for Future Research}

The primary focus of this study was the coping response to sudden death bereavement as a result of a natural disaster. An attempt was made to clarify several conceptual and methodological issues regarding personal versus material loss, presumptive versus confirmed death, negative rather than total life change and its relationship to illness, identification of negative life events versus hassles, separation of intrapersonal and interpersonal supports, and assessment of the ameliorating role of support on illness. The unexpected finding of the impact of negative life events associated with property loss deserves additional attention.

While this study combined negative life events and hassles to form a single measure of stress in analysis, these scores were not combined when data were gathered. Combining measures of overall negative life stress and impact rating might be better conceptually than attempting to separate negacive life events and hassles since perception of a hassle to one individual may be perceived as a major stressor to another.

This study separated quantitative and qualitative measures of social support and social support from social 
competence. Many aspects of social support remain to be studied. For example, identifying the roles of primary and secondary supports has received limited attention. Self-expectations of the victims themselves appear to be aspects of coping that also need to be separated from social competence. Expectations can alter both initiation and continuation of adaptive coping processes. As Silver and Wortman (1980) report, victims are likely to experience more stress than they report. One reason for reluctance to report stressful experiences is the expectation held by some that one should not need to ask for outside help. Finally, in order to identify characteristics of high risk individuals in disasters from those who are likely to remain healthy when experiencing high or continued stress, several suggestions are offered. Longitudinal study designs are imperative. Analysis by age groups within conditions of loss and analysis controlling for prior health status may help clarify the impact of stress on health and illness. In summary, this study examined the effects of stress and health on both personal and property loss conditions. High levels of stress and depression were reported by both bereaved and permanent-property loss subjects. Stress was the most significant predictor of both depression and somatization. The role of the media following loss is deserving of further study. Finally, several theoretical and methodological suggestions from past research were incorporated in this study. 


\section{SELECTED REFERENCES}

Abe, $K$. Levels of trust and reactions to various sources of information in catastrophic situations. In Quarantell1, E. (Ed.) Disasters: theory and research. Beverly Hills: Sage Publications, 1978 .

Ahearn, F., Psychological consequences of the Managua, Nicaragua earthiuake. Paper presented at The American Orthopsychiatric Association annual meeting, New York, 1981.

Ainsworth, y. \& Bell, S. Attachment, exploration, and separation: Illustrated by the behavior of one-year olds in a strange situation. Child Development, 1970, 41, 49-67.

Andrews, G., Tennant, C., Hewson, D. \& Vaillant, G. Life event stress, social support, coping style and risk of psychological impairment. Journal of Nervous and Mental Disease, 1978, 166, 307-315.

Antonovsky, A. Health, stress, and coping. San Francisco: Jossey-Bass Publishers, 1979.

Averill, S. Grief: Its nature and significance. Psychological Bulletin, 1968, 70, 721-748.

Ball, J. Widow's grief: The impact of age and mode of death. Omega, 1976-77, $1,307-333$.

Bandura, A. Self-efficacy: Toward a unifying theory of behavioral change. Psychological Review, 1977, 84, 191-215.

Barret $\dot{t}$, c. Strategies for preventing the stresses of widowhood. Paper presented at the Southwestern psychological Association annual meeting. New Orleans, 1978.

Barrett, C. \& Becker, R. The prediction of adjustment to widowhood from social and demographic data. Paper presented at the Western Social Science Association annual meeting. Denver, Colorado, April 1978.

Blauner, G. Death and social structure. Psychiatry, Journal for the Study of Interpersonal processes, 1966, 29, 378-394.

Bolin, R. \& Trainer, P. Modes of family recovery following disaster: A cross-national study. In Quarantelli, E. (Ed.) Disasters: theory and research. Beverly Hills: Sage Pubiications, 1978 .

Bowlby, J. Attachment and loss. Attachment 1 . London: Hogarth, 1969. 
Brown, G. Life events and the onset of depressive and schizophrenic conditions. In Gunderson, E. \& Rahe, R. (Eds.), Iife Stress and Illness, Springfield: Charles C. Thomas, 1974.

Brown, G., Bhrolchain, M., \& Harris, T. Social class and psychiatric disturbances among women in an urban population. Sociology, 1975, $9,225-$.

Bugen, L. Death and dying: Theory/research/practice. Dubuque: Wm. Brown Co., Publishers, 1979.

Bugen, L. Human grief: A model for prediction and intervention. American Journal of Orthopsychiatry, 1977, 47, 196-206.

Burke, R., \& Weir, T. Marital helping relationships: Moderators between stress and well-being. The Journal of Psychology, $1977, \underline{95}, 121-130$.

Caplan, G. Support systems. H. Douglas Singer Zone Center, Rockford, Ilinois. Region Training Papers, 1973.

Caplan, G. Support systems and community mental health. Behavioral Publications, New York, 1974.

Cassel, J. Psychiatric epidemiology. In Caplan, C. (Ed.), American Handbook of Psychiatry, Volume II, Basic Books, New York, 1973.

Cassel, J:. Psychosocial processes and stress: Theoretical formulations. International Journal of Health Services, $1974, \underline{4}, 471-482$.

Clayton, P. The clinical morbidity of the first year of bereavement: A review. Comprehensive Psychiatry, 1973, 14, 151-157.

Clayton, P. \& Bornstein, P. Widows and widowers. Medical Aspects of Human Sexuality, 1976, 10, 22-53.

Clayton, P., Falikas, J, \& Maurice, $W$. The depression of widowhood. British Journal of Psychiatry, 1972, 120, 71-81.

Cobb, S. Social support as a moderator of life stress, Psychosomatic Medicine, 1976, 38, 300-314.

Cobb, S. and Lindemann, E. Neuropsychiatric observations after the Coconut Grove fire. Annals of Surgery. 1943, 117, 814-824. 
Coppel, D. The relationship of perceived social support and self-efficacy to major and minor stresses. Doctoral Dissertation (unpublished), 1980.

Dean, A. \& Lin, N. The stress-buffering role of social support: Problems and prospects for systematic investigation. Journal of Nervous and Mental Disease, 1977, $165,403-417$.

Defrain, J. \& Ernst, L. The psychological effects of sudden infant death syndrome on surviving family members. Journal of Family Practice, 1978, 6, 985-989.

Demi, A. Adjustment to widowhood after a sudden death: Suicide and nonsuicide survivors compared. Communicating Nursing Research, 1978, 11, 91-99.

Derogatis, I., Lipman, R., Rickels, K., Uhlenhuth, E., \& Covi, L. The Hopkins Symptoms Checklist (HSCL): A measure of primary symptoms dimensions. Psychological Measurements in Psychopharmacology. Modern Problems of Pharmacopsychiatry, 1974, ㄱ, 79-110.

DeVanzo, J. \& Morrison, P. Dynamics of return migration: Descriptive findings from a longitudinal study. Unpublished manuscript, The Rand Corporation, Santa Monica, Ca., 1977.

Dimsdale, J. Coping--Every man's war. American Journal of Psychotherapy, 1978, 32, 402-413.

Dohrenwend, B. \& Dohrenwend, B. Stressful life events: Their nature and effects. New York: John Wiley \& Sons, 1974 .

Dunn, I. Mental health of Three-Mile Island residents. Paper presented at The American Orthopsychiatric Association annual meeting, New York, 1981.

Engel, G. A life setting conducive to illness: The giving up-given up complex. Bulletin of the Menninger Clinic, $1968, \underline{32}, 355-365$.

Epstein, G., Weitz, I., Roback, H., \& McKee, E. Research on bereavement: A selective and critical review. In Bugen, I. Death and dying: Theory/research/practice. Dubuque: Wm. C. Brown Co.! 1979.

Feifel, H, The meaning of death. New York: McGraw-Hill, 1959.

Fried, M. Grieving for a lost.home. In Monat, A. \& Lazarus, R. (Eds.), Stress and coping, an anthology. New York: Columbia University, 1977. 
Friedman, S., Chodoff, P., Mason, J., \& Hamburg, D. Behavior observations.on parents anticipating the death of a child. Pediatrics, 1963, 32, 610-625.

Friedman, P. \& Iinn, I. Some psychological notes on the Andrea Doria disaster. American Journal of Psychiatry, 1957, 114, 426-432.

Fritz, C. \& Marks, E. The NORC studies of human behavior in disaster. Journal of Social Issues, 1954, 10, 2641 .

Fritz, C. \& Williams, H. The human being in disasters: A research perspective. Anrals of the American Academy Political and Social Sciences, 1957, 42-51.

Futterman, E., Hoffman, I. \& Sabshin, M. Parental anticipatory mourning. In Schoenberg, B., Carr, A., Kutscher, A., Peretz, D.\& Goldenberg, L. (Eds.), Anticipatory grief. New York: Columbia University Press, 1974.

Glick, I., Weiss, R. \& Parkes, C. The first year of bereavement. New York: John Wiley \& Sons, 1974.

Gordon, S. Memorandum, 15. Olympia: Attorney General's Office, 1980.

Gore, S. The influence of social support and related variables in ameliorating the consequences of job loss. Ann Arbor: University Microfilms International, 1973.

Gorer, G. Death, grief, and mourning. London: Cresset Press, 1965 .

Greenblatt, M. The grieving spouse. American Journal of Psychiatry, $1978, \underline{135}, 43-47$.

Hamburg, D. Coping and adaptation: Steps toward a synthesis of biological and social perspectives. In Hamburg, D. , Coelho, G. \& Adams, J., Coping and adaptation. New York: Basic Books, I974.

Harvey, C. \& Bahr, H. The sunshine widows: Adapting to sudden bereavement. Lexington: D.C. Health \& Co., 1980 .

Heller, K. The effects of social support: Prevention and treatment applications. In Goldstein, A. \& Kanfer, R. JEds.), Maximizing Treatment Gains. New York: Academic Press, 1979.

Henderson, S. A development in social psychiatry: The systemaric study of social bonds. Journal of Hervous and Mental Disease, $1980,168,63-69$. 
Henderson, S. \& Bostock, T. .Coping behavior after shipwreck. British Journal of Psychiatry, 1977, 131, 15-20.

Hinkie, L.E.- The effect of exposure to culture change, social change, and changes in interpersonal relationships on health. In B.S. Dohrenwend \& B.P. Dohrenwend (Eds.), Stressful life events: Their nature and effects, 1974.

Hirsch, B. Natural support systems and coping with major life changes. American Journal of Community Psychology, $1980,8,159-172$.

Hoff, L. People in crisis: Understanding and helping. Menlo Park: Addison-Wesley Publishing Co., 1978.

Holmes, T. \& Rahe, R. The Social Readjustment Rating Scale. Journal of Psychosomatic Research, 1967, 11, 213-218.

Jacobs, S. \& Douglas, L. Grief: A mediating process between a loss and 1llness. Comprehensive Psychiatry, 1979, 20, 165-176.

Jacobs, S. \& Ostfeld, A. An epidemiological review of mortality of bereavement. Psychosomatic Medicine, 1977, 39, 344-57.

Janis, I. Adaptive personality changes. In Monat, A. \& Lazarus, R. Stress and cuping. New York: Columbia University Press, 1977.

Kirk, R. Experimental design: Procedures for the behavioral Sciences. Belmont: Brooks-Cole Publishing Co., 1968.

Kitagawa, E. and Hauser, P. Differential mortality in the United States: A study of socioeconomic epidemiology. Cambridge: Harvard University Press, 1973.

Kobasa, S. Stressful life events, personality and health: An inquiry into hardiness. Journal of Personality and Social Psychology, 1979, 37, 1-11.

Kobasa, S., Hilker, R., \& Maddi, S. Who stays healthy under stress? Journal of Occupational Medicine, 1979, 2l, 595-598.

Korosec, M., Rigby, J., \& Stoffel, K. Information Circular \#71. Olympia: Washington State Department of Natural Resources, 1980.

Kraus, A., \& Lilienfeld, A. Some epidemiologic aspects of the high mortality rate in the young widowed group. Journal of Chronic Disease, 1959, 10, 207-217. 
- Kreps, G. The organization of disaster response: Some fundamental theoretical issues. In Quarantelli, E. (Ed.) Disasters: theory anu research. Beverly Hills: Sage Publications, 1978 .

Lancaster, J. Community mental health nursing. An ecological perspective. St. Louis: C.V. Kosby, 1.980.

Lazarus, R. Psychological stress and the coping process. New York: Mc-Graw-Hill Book Co., 1966.

Lazarus, R. \& Cohen, J. The hassles scale. Stress and coping project, University of California, 1977.

Lazarus, R. Little hass?.es can be hazardous to health. Psychology Today, $1981,58-62$.

Lieberman, S. Nineteen cases of morbid grief. British Journal of Psychiatry, 1978, 132, 159-163.

Lifton, R. Death in life. New York: Random House, 1968.

Lin, N., Simeone, R., Ensel, W., \& Kuo, W. Social support, stressful life events, and illness: A model and an empirical test. Journal of Health and Social Behavior, $1979,20,108-119$.

Lindemann, E. Symptomatology and management of acute grief. American Journal of Psychiatry, 1944, 101, 141-148.

Lindy, J., Affect defense and insight among rescue workers and bereaved families at a tempoxary morgue. Paper presented at The American Orthopsychiatric Association annual meeting, New York, 1981.

Lipman, R., Covi, L., \& Shapiro, A. The hopkins symptom checklist (HSCL). Factors derived from the HSCL-90. Journal of Affective Disorders, 1979, 1, 9-24.

Lopata, H. Widowhood in an American city. Cambridge: Schenkman, 1973.

McCubbin, H. Residuals of war. Families of prisoners of war and servicemen missing in action. Journal of Social Issues, 1975, 31, 95-109.

McCubbin, H. Coping repertoires of families adapting to prolonged war-induced separations. Journal of Marriage and the Family, 1976, 38, 461-471. 
McNeill, P. Mortality among the widowed in Connecticut. New Haven: Yale University Press, 1973.

MacElveen-Hoehn, P. \& Smith-DiJulio, K. Social network behavior in long-term illness: Preliminary analysis. Paper presented at Social Networks Conference, Portland State University, 1978.

Maddison, D. The relevance of conjugal bereavement for preventive psychiatry. British Journal of Medical Psychology, $1968,41,223-233$.

Malinak, D., Hoyt, M., \& Patterson, V. Adults' reactions to the death of a parent: A preliminary study. American Journal of Psychiatry, 1979, 136, 1152-1156.

Marris, P. Widows and their families. London: Routledge Press, 1958 .

Matthews, S. The social world of old women. Beverly Hills: Sage Publications, 1979.

Miller, J. A theoretical review of individual and group psychological reactions to stress. In Grosser, G., Wechsler, H., \& Greenblatt, M. (Eds.) Threat of impending disaster. Boston: MIT Press, 1964.

Miller, P. \& Ingram, J. Friends, confidants and symptoms. Social Psychiatry, 1976, 11, 51-58.

Miller, P., Ingram, J. \& Davidson, S. Life events, symptoms and social support. Journal of Psychosomatic Research,
$1976,20,515-522$.

Monat, A. \& Lazarus, R. Stress and coping, an anthology. New York: Columbia University Press, 1977.

Myers, J., Lindenthal, J., Pepper, M. , \& Ostrander, D. Life events and mental status: A longitudinal study. Journal of Health and Social Behavior, 1972, 13, 398-406.

Nie, N., Hull, C., Jenkins, J., Steinbrenner, K. \& Bent. Statistical Package for the Social Sciences. New York: McGraw Hill Book Co.: 1975.

Nighswonger, C. The vectors and vital signs in grief synchroniztion. In Schoenberg, B., Carr, A., Kutscher, A., Peretz, D., \& Goldberg, I. (Eds.), Anticipatory grief. New York: Columbia University Press, 1974.

Nuckolls, K., Cassel, J., \& Kaplan, B. Psychological assets, life crisis, and pregnancy. American Journal of Epidemiology. $1972,95,431-441$. 
Nuckolls, R. Widow study. Catalog of selected Documents in Psychology, 1973, 3,9.

Parkes, C. Bereavement: Studies of frief in adult life. New York: International Universities Press, 1972.

Parkes, C., Benjamin, B., \& Fitzgerald, R. Broken heart: A statistical study of increased mortality among widowers. British Journal of Medical, 1969, 1, 740-743.

Paykel, E. Life stress and psychiatric disorder. In Dohrenwend, B. \& Dohrenwend, B. (Eds.), Stressful life events: Their nature and effects. New York: John Wiley \& Sons, 1974 .

Pearlin, I. \& Schooler, C. The structure of coping. Journal of Health and Social Behavior, 1978, 19, 2-21.

Peretz, D. Reaction to loss. In Schoenberg, B., Carr, H., \& Peretz, D., Loss and grief: Psychological management in medical practice. New York: Columbia University Press, 1970 .

Pines, M. Psychological hardiness. The role of challenge in health. Psychology Today, 1980 (Dec.), 34-44.

Rabkin, J. \& Struening, E. Life events, stress and illness. Science, 1976, 194, 1013-1020.

Rahe, R. Life change events and mental illness: An overview. Journal of Human Stress, 1979, $\underline{5}, 2-10$.

Rahe, R. \& Lind, E. Psychosocial factors and sudden cardiac death. A pilot study. Journal of Psychosomatic Research, 1971, 15, 19-24.

Raphael, B. Preventive intervention with the recently bereaved. Archives of General Psychiatry, 1977, 34, 1450-1454.

Rees, D. \& Lutkins, S. Mortality of bereavement. British Medical Journal, 1967, 4, 13-16.

Rickels, K., Lipman, R.,. Garcia, C., \& Fisher, E. Evaluating clinical data improvement in anxious outpatients. A comparison of normal and treated neurotic patients. American Journal of Psychiatry, 1972, 128, 119-123.

Sanders, C. A comparison of adult bereavement in the death of a spouse, child, and parent. Omega, 1979-80, 10, $303-321$. 
Sarason, I., Johnson, J., \& Siegel, J. Assessing the impact of life changes: Development of the life experiences survey, Journal of Consulting and Clinical Psychology,

Schaar, K. News item, American Psychological Association Monitor, 11, No. $9 \& 10$ (Sept./Oct.) 1980.

Schulz, R. The psychology of death, dying, and bereavement. Redding: Addison-Wesley Publishing Co., 1978.

Shneidman, E. Postvention and the survivor-victim. In Schneidman, E. (Ed.) Death: Current pexspectives. Palo Alto: Mayfield Publishing Co., 1976.

Silver, R. \& Wortman, C. Coping with undesriable life events. In Garber, J. \& Seligman, M. (Eds.) Human Helplessness: Theory and Application. New York: Academic Press, 1980.

Silverman, P. Anticipatory grief from the perspective of widowhood. In Schoenberg, B., Carr, A., Kutscher, A., Peretz, D. \& Goldberg, I. (Eds.) Anticipatory grief. New York: Columbia University Press, 1974.

Sims, J. The next five years. Metropolitan Service District Planning Report. Portland, 1980.

Singh, B. \& Raphael, B. Post disaster morbidity of the rereaved. A possible role for preventive psychiatry? The Journal of Nervous and Mental Disease, 1981, 169, 203-212.

Stein, Z. \& Susser, M. Widowhood and mental illness. British Journal of Preventive and Social Medicine, 1969. 23, 106 .

Stroebe, M., Stroebe, W., Gergen, K. \& Gergen, M. The broken heart: Reality or myth?, unpublished manuscript, 1979.

The Oregonian: June 12, July 10, July 22, October 27, 1980.

Titchener, J. and Kapp, F. Family and character change at Buffalo Creek. American Journal of Psychiatry, 1976, 133, 295-299.

Tolsdorf, C. Social networks, support, and coping: An exploratory study. Family Process, 1976, 15, 407-417.

Toynbee, A. Man's concern with death. New York: McGraw-Hill Book Co., 1968 . 
Tyhurst, S. The role of transition states--including disasters-in mental illness. Walter Reed Symposium on Preventive and Social Psychiatry, Government Printing Office, 1958, 149-172.

United Nations. Guidelines for disaster prevention. Predisaster physical planning of human settlements, Vol. 1 , Geneva: The United Nations, 1976.

Vachon, M. Grief and bereavement following the death of a spouse. Canadian Psychiatric Association Journal, 1976, $21,35-44$.

Vinokur, A. \& Selzer, M. Desirable versus undesirable life events: Their relationship to stress and mental disease. Journal of Personality and Social Psychology, 1975, 32, 329-337.

Visotsky, H., Hamburg, D., Goss, M. \& Lebovits, B. Coping behavior under extreme stress. Archives of General Psychiatry, 1961, $5,423-448$.

Ward, A. Mortality of bereavement. British Medical Journal, $1976,1,700-702$.

Weinstein, S. Sudden infant death syadrome: Impact on families and a direction for change. American Journal of Psychiatry, 1978, 135, 831-834.

Weisman, A. Coping with untimely death. Psychiatry, 1973, 36, 366-379.

Weiss, R. The provisions of social relationships. In Rubin (Ed.), Doing unto others. Englewood Cliffs: Prentice-Hall, 1974 .

Wilson, R. Disaster and mental health. In Baker, G. \& Chapman, D., Man and Society in Disaster. New York: Basic Books, 1972 .

Wright, S., Rossi, P., Wright, S. \&-Weber-Burdin, E. After the cleanup: Long-range effects of natural disasters. Beverly Hills: Sage Publications, 1979.

Wyler, Â., Masuda, M., \& Holmes, T. Magnitude of life events and seriousness of illness. Psychosomatic Medicine, 1971, 33 , 115-122. 
APPENDIX A

An Outline of Disaster Plan Activities

Prepared by one Oregon County

Coordination Activities

I. Communications

A. Intragovernmental

1. declaration of disaster

2. personnel notification

B. Intergovernmental

1. human services coordination

2. shelter management

3. coordination of volunteers

II. Transportation
A. Personnel Assignment
B. Equipment Allocation

III. Health Care
A. Personnel Assignment
B. Assessing appropriate services
C. Screening and Triage

IV. Emergency Operations and Management Task Responsibilities

A. Development of Essential Personnel Notification Rosters

B. Development of Essential Equipment and Supply Resources

C. Development of Essential Emergency Alert Plans

Resource: Multnomah County, Oregon, Division of Public Safety, Office of Emergency Management, 1980 
APPENDIX - B

INSTRUMENTS

1 Hopkins Symptom Checklist - 90

2 Health Status Checklist

3 Life Experiences Survey (LES)

4 Hassles Scale (HS)

5 Perceived Self-Efficacy Scale

6 Coppel Index of Social Support

7 Demographic \& Other data

8 Personal Interview Guide

9 Agreement of Participation 


\section{PLEASE NOTE:}

Copyrighted materials in this document have not been filmed at the request of the author. They are available for consultation, however, in the author's university library.

These consist of pages:

$\begin{array}{r}216-217 \\ \hline 220-224 \\ \hline 225-233 \\ \hline\end{array}$

University

Microfilms International

300 N. ZEEB RD.. ANN ARBOR, MI 48106 (313) 761.4700 
APPENDIX B-2

\section{HEALTH STATUS CHECKLIST}

The SCL-90-R. you have just completed asked you to rate specific symptoms you have experienced in the past six months (since September 1 , 1980). Below :are some very general questions about your health. Directions: Circle one number under each question that best describes your health.

*1. As of right now, how do you rate your health? (Circle number)

$\begin{array}{ccccccccc}1 & 2 & 3 & 4 & 5 & 6 & 7 & 8 & 9 \\ \begin{array}{c}\text { Extremely } \\ \text { Poor }\end{array} & & \text { Poor } & & \text { Good } & & \begin{array}{l}\text { Very } \\ \text { Good }\end{array} & \text { Excellent }\end{array}$

2. Compared to six months ago (about September 1, 1980) is your health: (Circle number)

$\begin{array}{ccccccccc}1 & 2 & 3 & 4 & 5 & 6 & 7 & 8 & 9 \\ \begin{array}{c}\text { Much } \\ \text { Worse }\end{array} & & \text { Worse } & & \begin{array}{l}\text { The } \\ \text { Same }\end{array} & & \text { Better } & & \begin{array}{c}\text { Much } \\ \text { Better }\end{array} \\ \text {. } & & & & & & & & \end{array}$

3. Compared to one year ago (about March 1, 1980) is your health: (Circle number)

$\begin{array}{ccccccccc}1 & 2 & 3 & 4 & 5 & 6 & 7 & 8 & 9 \\ \begin{array}{c}\text { Much } \\ \text { Worse }\end{array} & & \text { Worse } & & \begin{array}{l}\text { The } \\ \text { Same }\end{array} & & \text { Better } & & \begin{array}{c}\text { Much } \\ \text { Better }\end{array}\end{array}$

*4. How many times have you called or seen a doctor or nurse practitioner about your health in the past six months (since September 1, 1980)? (Circle number)
$0 \quad 1 \quad 2$
34
56
$7 \quad 8 \quad 9$
10 or more

*5. How does the time period checked in \#4 compare to a typical sixmonths' period in your life as far as seeking assistance for your health is concerned? The time period check in number 4 is: (Circle)

\begin{tabular}{|c|c|c|c|c|}
\hline 2 & 3 & $5^{\circ}$ & 8 & 9 \\
\hline $\begin{array}{l}\text { Much More } \\
\text { Often Than } \\
\text { Usual }\end{array}$ & $\begin{array}{l}\text { More } \\
\text { Often Than } \\
\text { Usual }\end{array}$ & $\begin{array}{l}\text { About the } \\
\text { Same as } \\
\text { 'sual }\end{array}$ & $\begin{array}{l}\text { Less Often } \\
\text { Than Usual }\end{array}$ & $\begin{array}{c}\text { Much Less } \\
\text { Often Than } \\
\text { Usual }\end{array}$ \\
\hline
\end{tabular}


*6. How many times have you been hospitalized in the past six months (since September 1, 1980)? (Circle number)

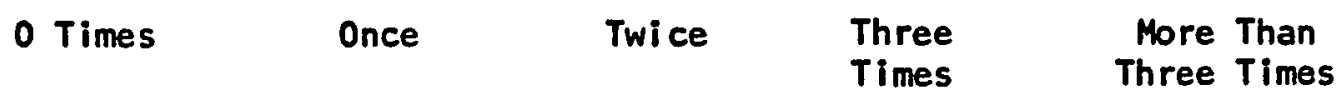

7. Do you have any chronic, on-going health conditions, such as diabetes, high blood pressure, or a heart condition? (Circle number)

1. No

2. Yes (Name of chronic health problem:

8. If Yes, compared to six months ago (September 1, 1980), is your health problem: (Circle number)

$\begin{array}{ccccccccc}1 & 2 & 3 & 4 & 5 & 6 & 7 & 8 & 9 \\ \begin{array}{c}\text { Much } \\ \text { Worse }\end{array} & \text { Worse } & & \text { Same } & & \text { Better } & \begin{array}{c}\text { Much } \\ \text { Better }\end{array}\end{array}$

Note. * indicates the item was used to form the scale, 'Current health'. Group mean scores were obtained for each item. These raw scores were converted to 2 scores and averaged to form the index. 


\section{APPENDIX B-7}

FOR ALL RESPONDENTS:

Finally, we would like to ask you some questions about yourself.

1. What is your major occupation? Are you a housewife, electrician, clerk, logger?

2. Last grade in school you completed.

3. Your birthdate:

Month Day Year

4. Compared with most people (the average American), how good is your current iife situation? (Circle answer)

$\begin{array}{cccccccc}1 & 2 & 3 & 4 & 5 & 6 & 7 & 8 \\ \begin{array}{l}\text { Worse } \\ \text { Than } \\ \text { Most }\end{array} & \begin{array}{l}\text { Worse } \\ \text { Than } \\ \text { Some }\end{array} & & \begin{array}{c}\text { Same } \\ \text { as Most }\end{array} & \begin{array}{c}\text { Better } \\ \text { Than Some }\end{array} & \begin{array}{c}\text { Better } \\ \text { Than Most }\end{array}\end{array}$

We would like you to rate the effect the media (television and newspapers, both local and national) has had on your recovery from your loss due to the volcano. Directions: Circle whatever number you feel applies to you.

\begin{tabular}{|c|c|c|c|c|c|}
\hline 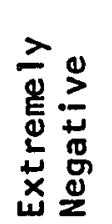 & 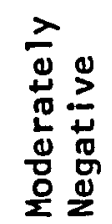 & 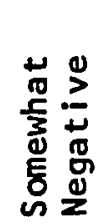 & $\begin{array}{l}0 \\
0 \\
4 \\
4 \\
4 \\
2\end{array}$ & 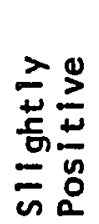 & 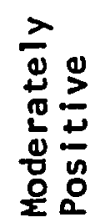 \\
\hline
\end{tabular}
$-3$
$-1$
0
$+1$
$+2$
$+3$

A Hindrance

No Effect

A Help

\begin{tabular}{|c|c|c|c|c|c|c|c|c|}
\hline$\div 5$. & Local newspaper & -3 & -2 & -1 & 0 & +1 & +2 & +3 \\
\hline$* 6$. & Local/state TV & -3 & -2 & -1 & 0 & +1 & +2 & +3 \\
\hline$* 7$. & National TV & -3 & -2 & -1 & 0 & +1 & +2 & +3 \\
\hline$* 8$. & $\begin{array}{l}\text { National news magazines } \\
\text { or periodicals }\end{array}$ & -3 & -2 & -1 & 0 & +1 & +2 & +3 \\
\hline
\end{tabular}


What effect has local and national news coverage had on your dealing with this tragedy? (circle number)

*9. Dealing with my loss is harder because the media makes it hard to forget about my loss.

*10. News coverage has been an invasion of my privacy.

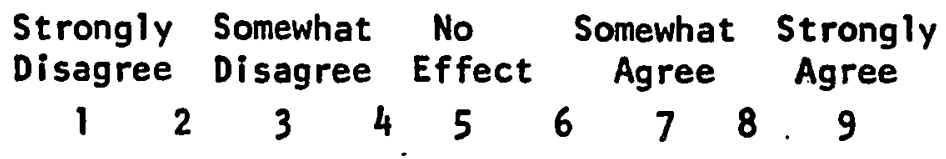

*11. Extensive news coverage has delayed my recovery from my loss.

$\begin{array}{lllllllll}1 & 2 & 3 & 4 & 5 & 6 & 7 & 8 & 9\end{array}$

12. The media has had no effect $\begin{array}{llllllllll}\text { on my dealing with my loss. } & 1 & 2 & 3 & 4 & 5 & 6 & 7 & 8 & 9\end{array}$

*13. Dealing with my loss is easier because I believe others sympathize with those of us who had a significant loss.

*14. News coverage has kept me from feeling so isolated.

*15. News coverage has helped me $\begin{array}{llllllllll}\text { recover from my loss sooner. } & 1 & 2 & 3 & 4 & 5 & 6 & 7 & 8 & 9\end{array}$

*16. Dealing with my loss is easier because 1 believe
others are sympthetic and
would help if they could. easier because 1 believe
others are sympthetic and
would help if they could. easier because 1 believe
others are sympthetic and
would help if they could.

$\begin{array}{lllllllll}1 & 2 & 3 & 4 & 5 & 6 & 7 & 8 & 9\end{array}$

$\begin{array}{lllllllll}1 & 2 & 3 & 4 & 5 & 6 & 7 & 8 & 9\end{array}$

17. How well do you feel you have recovered from your loss? (Circle number)

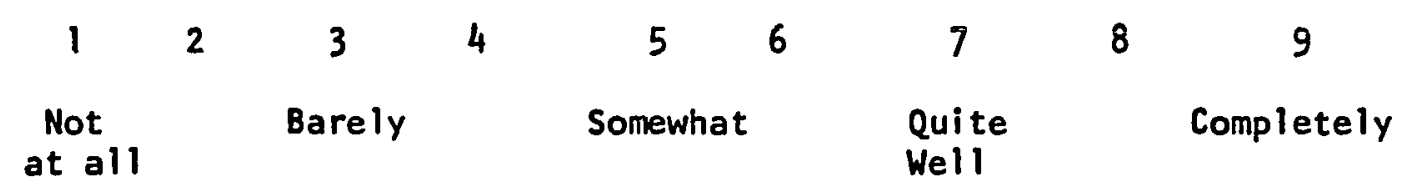

18. What kinds of things have happened to you before that helped you get through, or prepared you for, this event?

Note. * indicates item was used to form the 11-item scale 'Media'. 
19. Considering the best and worst things that could happen to you in your lifetime, where does this loss fit into the scale (circle number)
1
2
3
4
5

Worst that

could happen

Best that could happen

20. Are you angry with anyone at the present time fir your loss? (Circle number)

1. No

2. Yes (If Yes, please explain)

21. Can you imagine that such a devastating loss might happen to you again? (Circle number)

1. No

2. Yes (if Yes, please explain)

22. How is the amount of your income now compared to 1979? (Circle number)
1
2
3
4
5

Much Less

Less

No Change

Greater

Much Greater

23. How adequate is your current income? (Circle number)
12
34
5
$6 \quad 7$
8
9

Not at All

Adequate

Much More Than Adequate

Adequate

24. How satisfied are you right now with the progress of settling financial matters assoclated with your loss? (circle number)

$\begin{array}{cccccc}1 & 2 & 3 & 4 & 5 & 6 \\ \text { Very } & \text { Moderate- } & \text { Slightly } & \text { Silghtly } & \text { Moderate- } & \text { Very } \\ \text { Dissat- } & \begin{array}{l}\text { ly Dissat- } \\ \text { isfied }\end{array} & \begin{array}{c}\text { Dissatis- } \\ \text { isfied }\end{array} & \begin{array}{l}\text { Satisfied } \\ \text { ly Satis- Satisfied }\end{array}\end{array}$

IF YOU HAD A PROPERTY LOSS, STOP HERE! IF YOU SUFFERED THE LOSS OF A PERSON, PLEASE ANSWER THE FINAL SIX QUESTIONS. 
25. What was the relationship and age of the person(s) who died? (circle all numbers that apply to your situation.)
1. Husband
2. Wife
3. Intimate Friend
4. Mother
5. Father
6. Son
7. Daughter
8. Other (Specify)
Age
Age
Age
Age
Age
Age
Age
(Colleague, grandparent, grandchild)
Age

26. If husband or wife, how long were you married to your spouse? If intimate friend, approximately how long did you know the person who died? years

27. Describe your relationship with the person who died as the result of the volcanic eruption. For each of the following statements, circle the number which best describes your relationship.
a. Not a very important person in my life.
67
78
89 Very important person in my
life.
b. Very un- $\begin{array}{lllllllllll}\text { happy } & 1 & 2 & 3 & 4 & 5 & 6 & 7 & 8 & 9 & \text { Very happy }\end{array}$

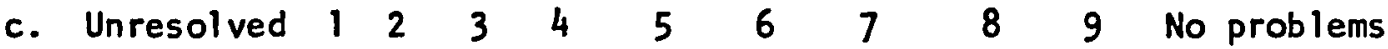 problems at in relation- time of ship at time death. of death.

28. Compared to other deaths of close friends and relatives you have experienced, this one was:

1. Much more difficult

2. More difficult

3. About the same

4. Less difficult

5. Much less difficult

6. No previous experience with loss of a significant other. 
29. How satisfied are you with the rescue operations undertaken for people not found within the first 72 hours following the eruption? (Circle number)

1. Not at all satisfied

2. Slightly satisfied

3. Moderately satisfied

4. Very satisfied

30. Whom do you blame for the death of your loved one(s)? (Circle number)

1. God

2. Myself

3. The person(s) who went to area

4. Those responsible for rescue

5. Other (Specify)

6. No one

31. Finally, is there anything else you would like to tell us which might help us understand what you have gone through? Write on the other side of this sheet of paper if you wish. 


\section{Appendix B-8}

Open-Ended Items for Optional Personal Interview

1. What were some of the daily changes you had to make as a result of your loss?

(Some suggested probes for interviewer: seek employment, take on activities to keep from getting lonely, fight off invasion of privacy, fill out numerous forms, change roles, borrow money, worry more)

2. In what ways do you feel your health has been affected by your loss? (Probes: illness, depression, dealing with angry and hostile feelings toward others).

3. How have your relationships and interactions with others changed as a result of your loss?

4. What has helped you get through this ordeal?

5. What personal resources or inner strength to you have that were helpful?

6. What kinds of social support did you receive? Was it enough? Too much?

7. In your opinion, has the television coverage of the volcano been treated seriously or trivial?

8. Have you experienced any positive, growth-producing effects?

9. How have you resolved the shortness of life?

10. Your impression of the study materials? 
APPENDIX B-9

Agreement of Participation

I agree to serve as a consultant and subject in the research project entitled, "Coping with Stress Following a Natural Disaster", to be conducted by Shirley A. Murphy.

It has been explained to me that the purpose of the study is to learn more about the relationship of major life stresses and illness and factors that may lessen stress. Although I may not receive any direct benefit from participation in this study, sharing my experiences may help to increase knowledge which may benefit others in the future.

I understand the study involves a mail questionnaire and an optional personal interview. I understand tisat I will be asked to respond to a series of questionnaires to determine how I have coped with a substantial property loss and /or the sudden death of a significant person. I have been told that this may take forty-five to sixty minutes of my time. No risks to me are expected to occur.

Shirley A. Murphy has offered to answer any questions I may have about the study and I have been assured that all. information I give will be kept confidential and that the identity of all subjects will remain anonymous.

I understand that I am free to withdraw from participation in this study at any time.

I have read and understand the foregoing information.

Name (printed)

Date

Signáture

Address

Telephone Tro. 